\title{
Snow physics as relevant to snow photochemistry
}

\author{
F. Domine ${ }^{1}$, M. Albert ${ }^{2}$, T. Huthwelker ${ }^{3}$, H.-W. Jacobi ${ }^{4,}{ }^{*}$, A. A. Kokhanovsky ${ }^{5}$, M. Lehning ${ }^{6}$, G. Picard ${ }^{1}$, and \\ W. R. Simpson ${ }^{7}$ \\ ${ }^{1}$ Laboratoire de Glaciologie et Géophysique de l'Environnement, CNRS et Université Joseph Fourier, BP96, 54 rue Molière, \\ 38402 Saint Martin d'Hères cedex, France \\ ${ }^{2}$ Army Cold Regions Research and Engineering Lab, 72 Lyme Road, Hanover, NH 03755-1290, USA \\ ${ }^{3}$ Paul Scherer Institute, Laboratory for Radiochemistry and Environmental Chemistry, 5232 Villigen, Switzerland \\ ${ }^{4}$ Alfred Wegener Institute for Polar and Marine Research, Am Handelshafen 12, 27570 Bremerhaven, Germany \\ ${ }^{5}$ Institute of Environmental Physics, Bremen University, O. Hahn Allee 1, 28334 Bremen, Germany \\ ${ }^{6}$ WSL, Eidg. Swiss Federal Institute for Snow and Avalanche Research, SLF Davos, Flüelastrasse 11, 7260 Davos Dorf, \\ Switzerland \\ ${ }^{7}$ Department of Chemistry and Geophysical Institute, University of Alaska Fairbanks, Fairbanks, AK 99775-6160, USA \\ * now at: Laboratoire de Glaciologie et Géophysique de l'Environnement, CNRS et Université Joseph Fourier, BP96, 54 rue \\ Molière, 38402 Saint Martin d'Hères cedex, France
}

Received: 12 April 2007 - Published in Atmos. Chem. Phys. Discuss.: 8 May 2007

Revised: 22 November 2007 - Accepted: 5 December 2007 - Published: 16 January 2008

\begin{abstract}
Snow on the ground is a complex multiphase photochemical reactor that dramatically modifies the chemical composition of the overlying atmosphere. A quantitative description of the emissions of reactive gases by snow requires knowledge of snow physical properties. This overview details our current understanding of how those physical properties relevant to snow photochemistry vary during snow metamorphism. Properties discussed are density, specific surface area, thermal conductivity, permeability, gas diffusivity and optical properties. Inasmuch as possible, equations to parameterize these properties as functions of climatic variables are proposed, based on field measurements, laboratory experiments and theory. The potential of remote sensing methods to obtain information on some snow physical variables such as grain size, liquid water content and snow depth are discussed. The possibilities for and difficulties of building a snow photochemistry model by adapting current snow physics models are explored. Elaborate snow physics models already exist, and including variables of particular interest to snow photochemistry such as light fluxes and specific surface area appears possible. On the other hand, understanding the nature and location of reactive molecules in snow seems to be the greatest difficulty modelers will have to face for lack of experimental data, and progress on this aspect will require the detailed study of natural snow samples.
\end{abstract}

Correspondence to: F. Domine

(florent@lgge.obs.ujf-grenoble.fr)

\section{Introduction}

\subsection{Context and general objectives}

During the boreal winter, snow coverage includes most land masses north of $50^{\circ} \mathrm{N}$, a significant fraction of land masses between 40 and $50^{\circ} \mathrm{N}$, the whole Arctic ocean and Antarctica (e.g. Pielke et al., 2004), representing about $14 \%$ of the Earth's surface. Snow on the ground is a porous medium with a high surface area, it is fairly permeable and transmits light, and snow can for these reasons be suspected of being an efficient multi-phase photochemical reactor whose products, after release to the atmosphere, could dramatically affect atmospheric composition. Physical properties of the snow that will determine its efficiency as a photochemical reactor include its surface area, its ability to transmit light and its permeability to facilitate the release of reaction products. It is interesting to compare the physical properties of the snow cover to those of other surface covers, such as soils and vegetation, in particular forest. The Snow Area Index (SAI), defined by Taillandier et al. (2006) as the vertically integrated surface area of snow crystals (in $\mathrm{m}^{2}$ of snow surface area per $\mathrm{m}^{2}$ of land surface area), is about 1000 for the subarctic snowpack in Alaska (Taillandier et al. 2006, and 2000 for the Arctic snowpack (Domine et al., 2002). In contrast, the Leaf Area Index (LAI) is usually below 10 (e.g. Bremond et al., 2005) and the soil area index is around 80000 (Petersen et al., 1996), using a depth of interaction with the atmosphere of $5 \mathrm{~mm}$. However, soils have a permeability to air that is

Published by Copernicus Publications on behalf of the European Geosciences Union. 


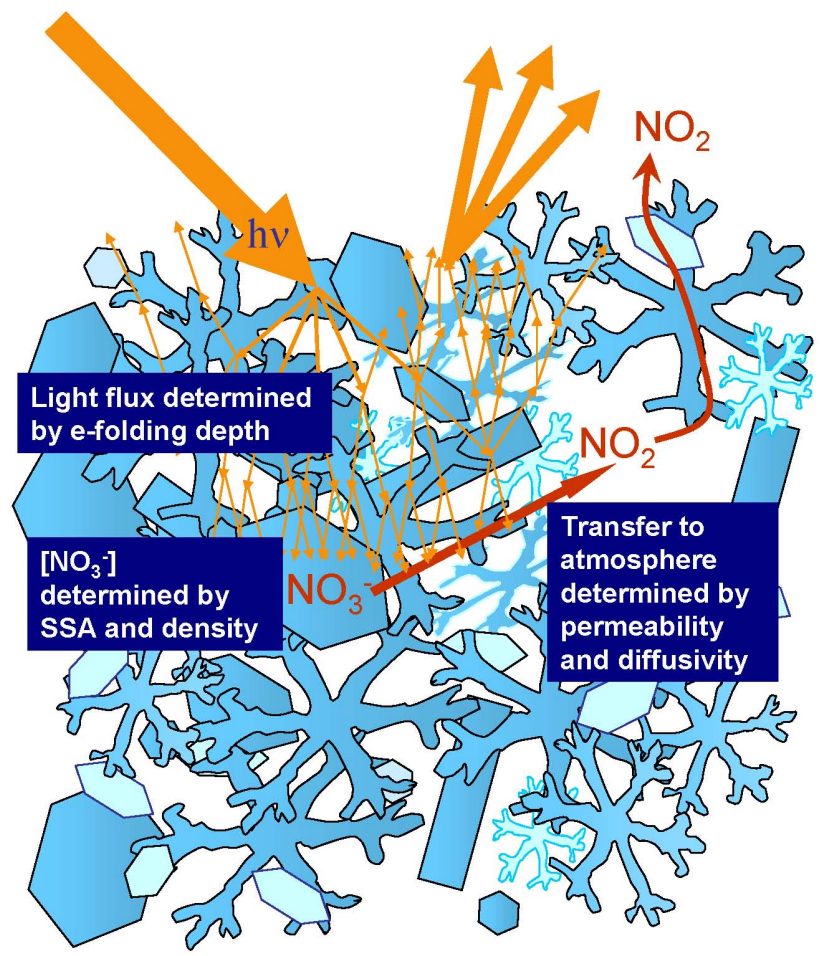

Fig. 1. Schematic illustrating the physical variables that determine the snow-to-atmosphere flux of $\mathrm{NO}_{2}$ due to the photolysis of adsorbed $\mathrm{NO}_{3}^{-}$. These variables include light $e$-folding depth, snow specific surface area, density, permeability and diffusivity (see text). Figure in part taken from Domine and Shepson (2002).

very low, of the order of $10^{-12} \mathrm{~m}^{2}$ (Iversen et al, 2003) while snow permeabilities are around $10^{-9} \mathrm{~m}^{2}$ (Albert and Schultz, 2002) while forest permeability is clearly much higher. Light penetration can be quantified by the $e$-folding depth (the distance over which the actinic flux is divided by $e$ ). Forest have $e$-folding depth values of at least several meters, even in dense tropical forests (Koop and Sterck, 1994), snowpacks have values around $20 \mathrm{~cm}$ (Simpson et al., 2002a) while soils have values below $1 \mathrm{~mm}$.

It therefore appears likely that the multi-phase photochemical activity of soils will be severely limited by their $e$ folding depth, while that of forests will be limited by the low LAI values, except perhaps when snow is present on trees (Pomeroy et al., 1999). Snowpacks have intermediate permeability, SAI and $e$-folding depth values and therefore appear good candidates to be efficient multi-phase photochemical reactors. This suggestion is consistent with observations that atmospheric chemistry over snow surfaces is strongly affected by contributions from snow emissions, as discussed by Domine and Shepson (2002) and detailed in the recent review of Grannas et al. (2007) in this special issue. For example, the presence of a snow cover can result in a 10-fold increase in OH concentrations (Mauldin et al., 2001; Domine and Shepson, 2002). Snow is also the source of reactive gases such as $\mathrm{NO}_{\mathrm{x}}$ (Jones et al., 2001; Honrath et al., 2002; Beine et al., 2002), HONO (Zhou et al., 2001; Beine et al., 2006), $\mathrm{H}_{2} \mathrm{O}_{2}$ (Hutterli et al., 1999; Jacobi et al., 2002), HCHO and other carbonyl compounds (Sumner and Shepson, 1999; Hutterli et al., 1999, 2002; Grannas et al., 2002; Jacobi et al., 2002), hydrocarbons and chloro-hydrocarbons (Swanson et al., 2002), organic acids (Dibb and Arsenault, 2002), and halogens (Spicer el al., 2002). Moreover, the complete destruction of ozone (Bottenheim et al., 1990) and the deposition of elemental mercury by the action of halogens (Steffen et al., 2002) in the lower polar troposphere have been traced back to processes that originate at least in part in the snow (Simpson et al., $2008^{1}$ ), so that snow plays an important role in the composition of the planetary boundary layer over snow-covered areas.

However, elucidating the processes responsible for the quantitative understanding of these emissions remains a challenge. For example, HONO is thought to be formed from the photolysis of the $\mathrm{NO}_{3}^{-}$ions contained in snow, but $\mathrm{HONO}$ emissions have been observed above some snow-covered areas (Zhou et al., 2001), and not detected over others where conditions for emissions were thought to have been met (Beine et al., 2006). Part of the problem is that snow is a complex multiphase system whose chemistry cannot be treated as in a homogeneous gas phase. Two reactants that are found to be present in snow by analytical techniques such as ion or liquid chromatography may be in two distinct phases and are thus not in contact. Another difficulty concerns the wide variation in physical properties such as grain size and air permeability that is found in deposited snow. If some stages of a reaction scheme requires solid phase diffusion of a species to the ice crystal surfaces, as suggested in the production of $\mathrm{NO}_{\mathrm{x}}$ from $\mathrm{NO}_{3}^{-}$photolysis (Beine et al., 2003 and 2006), areas with large-grained snow on the ground will be less productive than those with small-grains. Reactive gases produced in snow need to diffuse or be advected out of the snow. In areas with less permeable snow, the residence time may be sufficiently large to allow those gases to react with other reactants contained in snow, resulting in no observed emissions, even though production did take place.

These examples illustrate that emissions of reactive gases from snow on the ground depend on its chemical composition, on the distribution of chemical species between the different phases that form the snow, on the mobility of reactants, and on the physical properties of the snow. Figure 1 uses a very simplified scheme of $\mathrm{NO}_{2}$ production from $\mathrm{NO}_{3}^{-}$photolysis to illustrate the necessity to include snow physics in the description of its chemical emissions. One of the proposed channels for $\mathrm{NO}_{3}^{-}$photolysis in snow is (Honrath et al., 1999; Jacobi and Hilker, 2007):

$\mathrm{NO}_{3}^{-}+h v \rightarrow \mathrm{NO}_{2}+\mathrm{O}^{-}$

\footnotetext{
${ }^{1}$ Simpson, W. R., Phillips, G. J., Taillandier, A.-S., and Domine, F.: Testing the relationship between snow optical properties and specific surface area, in preparation, 2008.
} 
The rate of $\mathrm{NO}_{2}$ production in snow interstitial air per unit

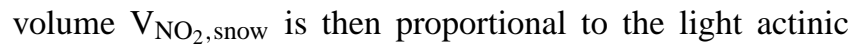
flux (i.e. the spherically-integrated light intensity) $\Phi_{\text {light }}$ and to the concentration of $\mathrm{NO}_{3}^{-}$adsorbed onto the surface of snow crystals $\left[\mathrm{NO}_{3}^{-}\right]_{\text {ads }}$, expressed in moles per $\mathrm{cm}^{3}$ of snow. $\Phi_{\text {light }}$ is proportional to the light flux incident upon the snow surface $\Phi_{\text {incident }}$ and will depend on light attenuation by snow. When the light flux is isotropic, and this happens a few $\mathrm{cm}$ below the surface (e.g. Simpson et al., 2002a), $\Phi_{\text {light }}$ decreases with depth $\mathrm{z}$ as $\exp (-\mathrm{z} / \varepsilon)$ where $\varepsilon$ is the snow $e$ folding depth. If we make the simplification that adsorbed $\mathrm{NO}_{3}^{-}$comes from the adsorption of gas phase $\mathrm{HNO}_{3}$, then $\left[\mathrm{NO}_{3}^{-}\right]_{\mathrm{ads}}$ is proportional to the specific surface area of snow ( $S S A$, in $\mathrm{cm}^{2} \mathrm{~g}^{-1}$ ), to the snow density $\left(\rho \mathrm{g} \mathrm{cm}^{-3}\right)$ and to the partial pressure of $\mathrm{HNO}_{3}, P_{\mathrm{HNO}}$. We then have:

$V_{\mathrm{NO} 2 \text {, snow }} \propto P_{\mathrm{HNO} 3} \times \Phi_{\text {incident }} \times S S A \times \rho \times e^{-z / \varepsilon}$

A subject of great importance to atmospheric chemistry is

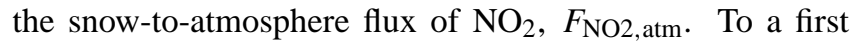
approximation, this will be proportional to $V_{\mathrm{NO} 2 \text {, snow }}$, and will depend on the way $\mathrm{NO}_{2}$ produced in the snow will be transported out of the snow. A priori, this will depend on the diffusivity of the snow, $D_{\text {snow }}$, if diffusive transport predominates, and on the snow permeability $K_{p}$ if advective transport is more important. Overall, we have:

$F_{\mathrm{NO} 2, \mathrm{~atm}} \propto P_{\mathrm{HNO} 3} \times \Phi_{\text {incident }}$

$\times S S A \times \rho \times e^{-z / \varepsilon} \times f\left(K_{p}, D_{\text {snow }}\right)$

Equation (3) shows that the oversimplified description of snow-to-atmosphere $\mathrm{NO}_{2}$ fluxes from $\mathrm{NO}_{3}^{-}$photolysis requires the knowledge of five physical properties of snow : specific surface area, density, $e$-folding depth, permeability and diffusivity. A more complete treatment would also mention that the absorption cross section and quantum yield of reaction (1) may be temperature-dependent, so that the snow temperature also comes into play. This variable is determined by the surface energy balance and albedo, the density, the permeability, and the thermal conductivity of snow. The purpose of this paper is to present an overview of current knowledge on the physical properties of deposited snow, in order to assist modelers in their inclusion of snow physics in coupled air-snow chemical models.

Below we define the snow properties more precisely, we give a brief description of the dynamic character of snow, and we briefly list the physical properties relevant to this overview. The main section of the paper then details our knowledge of the selected physical properties, as studied in the field. Field studied are irreplaceable, but their drawback is that such measurements may lack spatial representativity. Upscaling field data can in principle be done by remote sensing methods and we therefore show in a subsequent section how remote sensing may complement field studies in the determination of snow physical properties. The final section discusses current snow physical models, and how these may be used and modified to contribute to a coupled air-snow chemical model.

\subsection{Brief definition and description of surface snow layers}

In the common vocabulary, the snow on the ground is usually called "snow", a term that also applies to snow crystals in the atmosphere. This paper discusses seasonal snow on the ground where the terms "snowpack" and "snow cover" are commonly used, but also refers to snow on the surface of ice sheets and glaciers, where such terms are less meaningful, because of the slow and continuous transition to ice. We therefore refer to snow that has been deposited on the earth surface simply as "snow". Our discussions do not specifically address snow falling through the atmosphere.

Because we are interested in snow-atmosphere interactions, our main focus will be surface layers, which most readily interact with the atmosphere. Defining the snow depth of interest is necessarily arbitrary. The photic zone is the depth down to which light penetrates, and this is often described as the $e$-folding depth of total shortwave energy extinction, which is of the order of 10 to $20 \mathrm{~cm}$ (Simpson et al., 2002a; Perovich, 2007). Snowpack ventilation by wind may under certain topographic conditions take place down to 50 to $100 \mathrm{~cm}$ (Albert and Schultz, 2002; Albert et al., 2002); although it is mostly restricted to the depth of surface roughness (Clifton et al., 2007). Therefore, our interest will in general be focused on the top $50 \mathrm{~cm}$ of the snow, hereafter called "surface snow". When only the most superficial layers will be of interest, we will refer to "the photic zone".

Deposited snow most often originates from the discontinuous precipitation of snow on the surface, resulting in a layered structure (Colbeck, 1991). Other processes contribute to the development of layering in snow, such as rain that subsequently freezes inside the snow, and the condensation of atmospheric water vapor on the snow surface, that forms ice crystals known as surface hoar (Colbeck et al, 1990; Cabanes et al., 2002). Dry snow is therefore a layered medium that is composed mostly of ice crystals and air. A property commonly used to describe the proportion of these two phases is the snow density, which varies between $0.01 \mathrm{~g} \mathrm{~cm}^{-3}$ or even lower for fresh dendritic snow to $0.61 \mathrm{~g} \mathrm{~cm}^{-3}$ for hard windpacked snow (e.g. Gray and Male, 1981; Sturm and Benson, 1997; Judson and Doesken, 2000; Domine et al., 2002 and unpublished results). The most common density values for snow are between 0.2 and $0.4 \mathrm{~g} \mathrm{~cm}^{-3}$ so that on a volume basis, snow is mostly formed of air. Snow also contains aerosol particles that have been either scavenged from the atmosphere by snow crystals during precipitation (Franz and Eisenreich, 1998; Lei and Wania, 2004), or deposited into snow on the ground by the circulation of air driven by surface wind (Cunningham and Waddington, 1993; Harder et al, 2000; Domine et al., 2004). Depending on the environment, the total concentration of particulate species in snow can show large variations, from less than $0.1 \mathrm{ppmw}$ in 
central Antarctica (Proposito et al., 2002) to $100 \mathrm{ppmw}$ for coastal snow subjected to sea spray (Beine et al., 2006) to values as high as $0.037 \%$ by weight when dust storms deposit huge amounts of mineral dust aerosol into the snow (Painter et al., 2007). Ice crystals within the snow also contain dissolved gases such as $\mathrm{H}_{2} \mathrm{O}_{2}, \mathrm{HCHO}, \mathrm{HCl}$ and $\mathrm{HNO}_{3}$ (Domine et al., 1995; Legrand et al., 1996; Hutterli et al., 2002 and 2004) that are incorporated within their crystalline lattice. Dry snow is thus a complex porous multiphase system formed of air, ice with dissolved gases, and any of the types of aerosols present in the lower troposphere. Snow on the ground is in contact with the atmosphere through the network of open pores. Even ice layers that are seen as thick and continuous to the naked eye have some degree of permeability (Albert et al., 2000).

On glaciers and ice sheets, where snow accumulates over many years, the open network of pore space continues down for many tens of meters as the snow evolves into firn (a term for snow older than one year) and finally becomes compressed into solid ice with only bubbles of air remaining. The depth at which there ceases to be connected pathways of interstitial air is called the depth of pore close-off, which is typically found in the range 60 to $105 \mathrm{~m}$ depth depending on the local climate (Barnola et al., 1991). In polar regions with low accumulation there are large areas (such as East Antarctica) where the top $50 \mathrm{~cm}$ is firn that can be 10 years old, possibly more (Albert et al., 2004). Since here we are concerned primarily with the top half-meter, we refer to this medium as "snow", whether it is seasonal snow or is in fact firn.

Snow at $0^{\circ} \mathrm{C}$ contains another phase: liquid water. At low liquid water content, water forms isolated patches in concave areas such as grain boundaries. Above about $10 \%$ water, continuous water paths appear and at yet higher liquid water contents, no more ice surfaces are in contact with interstitial air (Colbeck, 1982; Raymond and Tusima, 1979) so that the photochemistry of very wet snow can be expected to be very different from that of dry snow. Although we will mention several aspects of wet snow, this overview focuses on dry snowpacks.

\subsection{The dynamic character of snow: snow metamorphism}

The transformation of snow to firn to ice illustrates the fact that snow is a dynamic medium whose physical properties need to be described as a function of time. The crystal structure of near-surface snow evolves over time in response to changing weather. The processes responsible for physical evolution of snow are called "snow metamorphism". When metamorphism takes place at $0^{\circ} \mathrm{C}$, liquid water appears and the term "wet snow metamorphism" is used, while at temperatures below freezing, the term "dry snow metamorphism" applies (Colbeck, 1982).

In dry snow, a vertical temperature gradient almost always exists due to temperature changes at the surface. In temperate areas without permafrost, the base of the snowpack is often near $0^{\circ} \mathrm{C}$, while its surface can be much colder, resulting in typical values of the temperature gradient of 10 to $30^{\circ} \mathrm{C} \mathrm{m}^{-1}$. These temperature gradients produce gradients in water vapor in the snowpack interstitial air. For example, a $1 \mathrm{~m}$ thick seasonal snowpack with a basal temperature of $0^{\circ} \mathrm{C}$ and a surface temperature of $-15^{\circ} \mathrm{C}$ will have a water vapor pressure gradient of $444 \mathrm{~Pa} \mathrm{~m}^{-1}$ that will generate upward water vapor fluxes, maintained by a net sublimation of lower layers and a net condensation in upper layers (Colbeck, 1983), with a possible loss of water vapor to the atmosphere. Overall, it is observed that snow crystals grow during metamorphism, resulting in a decrease in their specific surface area and in the modification of other snow physical properties. These variations are complex and are also affected by other factors, such as wind that transports and compacts snow crystals and atmospheric relative humidity that affects the snow mass balance.

Dry snow metamorphism is often devided into two types, depending on the value of the temperature gradient (Sommerfeld and LaChapelle, 1970). When the temperature gradient is low, differences in curvature between adjacent snow grains have a role in vapor transport, and the term "equitemperature" (ET) metamorphism is used. When most of the water vapor transport is caused by the temperature gradient in the snowpack, the term "temperature-gradient" (TG) metamorphism is used. Sommerfeld and LaChapelle do not specify at what value of the temperature gradient is the limit between both metamorphic regimes, but we shall see below when we discuss changes in specific surface area that this limit is probably somewhere in the range 9 to $20^{\circ} \mathrm{C} \mathrm{m}^{-1}$.

When snow contains more than approximately $0.1 \%$ of water by volume, wet snow metamorphism occurs. Melting of the convex surfaces occurs first, with moisture movement to the concave (or less convex) surfaces, where it may refreeze. This process, towards an equilibrium rounded form, tends to minimize the specific surface area. When there is high liquid water content, the liquid can move easily, metamorphism proceeds rapidly, and intergranular bonds are weak. Under conditions of very low liquid water content, the liquid water is in disconnected menisces between crystals and may be immobile, slowing the metamorphism. If the bulk temperature of the snow cools and the water begins to freeze, the liquid water becomes part of the adjacent ice grains, causing rapid grain growth during melt-freeze cycling (Colbeck, 1982; Brun, 1989). Cold refrozen snow typically has strong intergranular bonds.

\subsection{Snow physical properties relevant to photochemistry} and to exchanges with the atmosphere

Many physical properties are needed to fully describe snow physics, such as mechanical resistance, which is required in avalanche research but is of little interest to this overview. The properties important for atmospheric chemistry discussed here are the following: 
- The density is the mass of ice/water per unit volume of snow. The associated property, snow porosity $\phi$, is the fraction of the snow occupied by air. With $\rho_{i}$ the density of ice $\left(0.917 \mathrm{~g} \mathrm{~cm}^{-3}\right.$ at $\left.0^{\circ} \mathrm{C}\right)$, porosity is given by:

$\phi=1-\frac{\rho}{\rho_{i}}$

- The specific surface area (SSA) is the surface area of snow crystals accessible to gases per unit mass. It is often expressed in $\mathrm{cm}^{2} \mathrm{~g}^{-1}$ and is in fact a measure of the area of the snow-air interface.

- The effective thermal conductivity of snow $k_{\text {eff }}$ is the proportionality factor between the temperature gradient $d T / d z$ and the heat flux $q$ :

$q=-k_{\mathrm{eff}} \frac{d T}{d z}$

- The air permeability of snow $K_{p}$ is the proportionality factor between the pressure gradient $d P / d z$ and the interstitial air flow velocity $v_{\text {air }}$ :

$v_{\text {air }}=-\frac{K_{P}}{\eta} \frac{d P}{d z}$

where $\eta$ is the air viscosity. Equation (6) is known as Darcy's law and under this formulation $K_{p}$ is called the "intrinsic permeability", but will be simply referred to as "permeability" hereafter.

- The gas diffusion coefficient in snow, $D_{g s}$, for nonflow situations pertains to gas transport according to Fick's law of diffusion in a system composed of one gas species in air. The gas diffusivity is the proportionality factor between the gradient in gas concentration in the interstitial air of the snow and the gas flux $F_{\text {gas }}$ :

$F_{\text {gas }}=-D_{g s} \frac{d C}{d z}$

$D_{g s}$ is related to the diffusion coefficient of the gas in air, $D_{g}$, by (Mason and Malinauskas, 1983; Fabre et al., 2000):

$D_{g s}=\frac{D_{g} \phi}{\tau}$

where $\tau$ is the tortuosity of the medium, i.e. the ratio of the path length in a porous medium over the direct path length, so that $\tau>1$ and $D_{g s}>D_{g}$.

- The diffusion of gases in the snowpack can be complicated and considerably slowed down by the adsorption of gases onto snow crystal surfaces. This process will be referred to as "adsorptive diffusion" and will be briefly discussed below.
- Light intensity in snow is relevant to the calculation of photochemical reactions. It dependson snow albedo and on the ability of snow to transmit visible and UV light, this latter property being often described by its $e$-folding depth $\varepsilon$, defined above. We stress that here $\varepsilon$ is an actual snow depth, not an equivalent water height. The variable $\varepsilon$ depends on snow scattering properties, which is affected by grain size and shape, and on snow absorption, which is determined mostly by the snow content in absorbing impurities such as carbonaceous and mineral aerosols.

\section{Physical properties of snow, as determined from field studies}

2.1 Preamble: variety of snow crystal shapes and of snowpacks

Snow crystals show a wide variety of sizes and shapes, caused by their conditions of formation in the atmosphere or by their metamorphic history (e.g. Colbeck et al., 1990; Wergin et al., 1996; Legagneux et al., 2002; Domine et al., 2003; Libbrecht, 2005) and we present here a brief overview of crystal characteristics relevant to this paper. The reader is referred to Colbeck et al. (1990) for a detailed classification.

The definition of the size of a snow crystal has been ambiguous (Colbeck et al., 1990; Aoki et al., 2000), especially in the case of precipitating crystals. For example, sixbranched dendritic crystals have a largest dimension of a few $\mathrm{mm}$, but a thickness of only a few tens of microns. The problem is less complex for metamorphic crystals whose shapes are simpler. The size is often taken as either the longest dimension (adopted here), or an average characteristic dimension, and the definition varies from publication to publication. Since $S S A$ is now routinely measured with a fairly good accuracy (Legagneux et al., 2002; Domine et al., 2007a) it is also possible to define the average size of crystals in a snow sample, $d_{\text {eff }}$, by the diameter of ice spheres of the same $S S A$ so that $d_{\mathrm{eff}}=6 / \rho_{i} S S A$.

The most frequent crystals types observed on the ground are described below, with some illustrated in Fig. 2.

- Fresh snow crystals have varied shapes depending mostly on the temperature and supersaturation in the cloud where they formed (Nakaya, 1954). Common shapes include plates, dendritic crystals, graupel, columns and needles, as abundantly illustrated by Wergin et al. (1995 and 1996) and Domine et al. (2003).

- Decomposing crystals are fresh crystals in early stages of transformation, so that the initial shapes of the precipitating crystals are recognizable. Relevant pictures are reported in the above three references.

- Faceted crystals (Fig. 2b) have flat faces with sharp angles, and are usually 0.5 to $2 \mathrm{~mm}$ in size. They are 

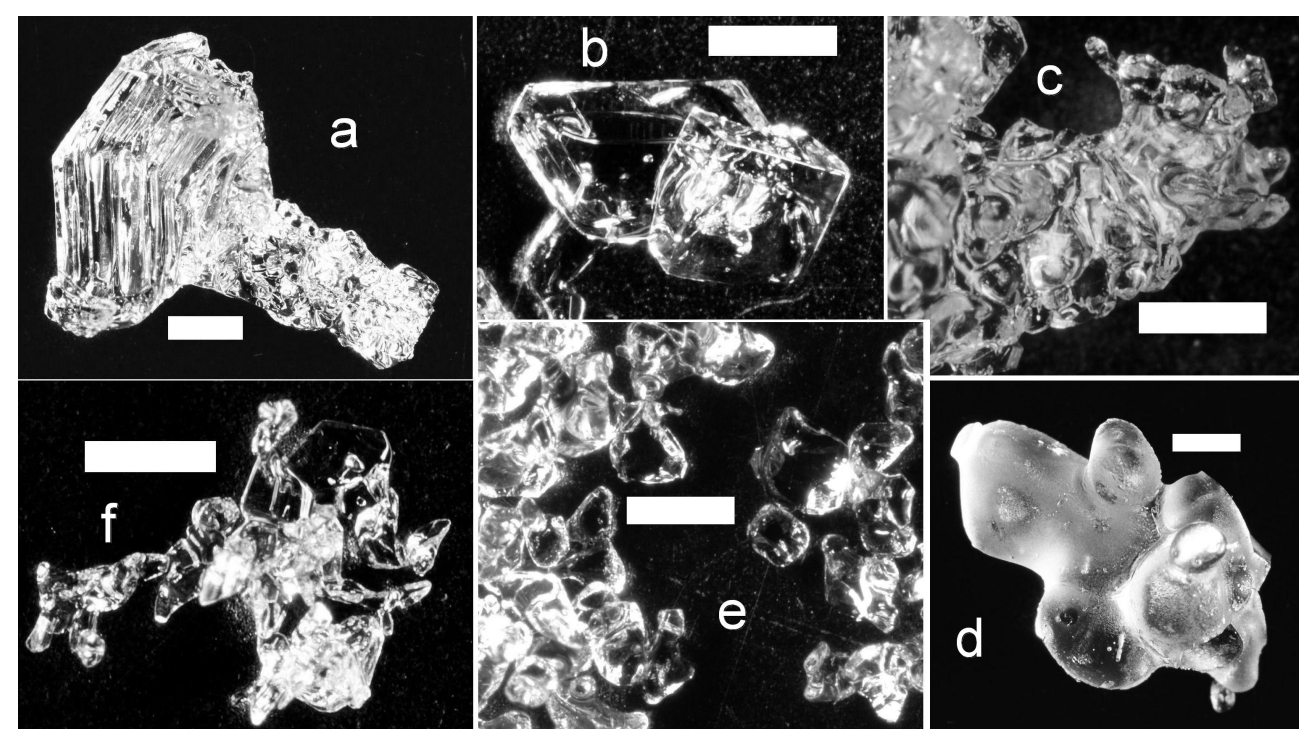

Fig. 2. Photomacrographs of metamorphic crystals frequently observed in snowpacks. (a) Depth hoar crystal; (b) faceted crystals; (c) dense melt-freeze crust; (d) melt-freeze polycrystal in low density $\left(0.11 \mathrm{~g} \mathrm{~cm}^{-3}\right)$ melt-freeze layer; (e) medium-size rounded grains in a near-basal layer subjected to near-isothermal metamorphism, of density $0.35 \mathrm{~g} \mathrm{~cm}^{-3}$; (f) crystals with mixed forms, showing facets and rounded shapes. All scale bars are $1 \mathrm{~mm}$.

Table 1. Typical ranges of values of selected physical variables for the most frequent snow crystal types in surface snow (top $50 \mathrm{~cm}$ ). Data from Sturm et al. (1997); Domine et al. (2002); Albert et al. (2002); Simpson et al. (2002a); Legagneux et al. (2002).

\begin{tabular}{|c|c|c|c|c|c|c|c|}
\hline $\begin{array}{l}\text { Physical } \\
\text { variable }\end{array}$ & $\begin{array}{l}\text { Fresh } \\
\text { snow }\end{array}$ & $\begin{array}{l}\text { Decomposing } \\
\text { particles }\end{array}$ & $\begin{array}{l}\text { Rounded } \\
\text { grains, ET } \\
\text { metamorphism }\end{array}$ & $\begin{array}{l}\text { Rounded } \\
\text { grains, } \\
\text { windpack }\end{array}$ & $\begin{array}{l}\text { Faceted } \\
\text { crystals }\end{array}$ & $\begin{array}{l}\text { Depth } \\
\text { hoar }\end{array}$ & $\begin{array}{l}\text { Melt- } \\
\text { freeze } \\
\text { crusts }\end{array}$ \\
\hline Density, $\mathrm{g} \mathrm{cm}^{-3}$ & $0.01-0.2$ & $0.06-0.25$ & $0.15-0.35$ & $0.3-0.6$ & $0.13-0.3$ & $0.15-0.28$ & $0.15-0.4$ \\
\hline $\begin{array}{l}\text { Specific surface area, } \\
\mathrm{cm}^{2} \mathrm{~g}^{-1}\end{array}$ & $350-1600$ & $150-900$ & $110-300$ & $150-380$ & $80-450$ & $70-220$ & $20-50$ \\
\hline$e$-folding depth, cm & $3-10$ & $2-10$ & $5-15$ & $3-10$ & $10-25$ & $15-30$ & $20-40$ \\
\hline $\begin{array}{l}\text { Permeability, } \\
10^{-10} \mathrm{~m}^{2}\end{array}$ & $30-80$ & $10-90$ & $10-80$ & $5-30$ & $50-200$ & $100-600$ & $1-20$ \\
\hline $\begin{array}{l}\text { Heat conductivity, } \\
\mathrm{W} \mathrm{m}^{-1} \mathrm{~K}^{-1}\end{array}$ & $0.03-0.12$ & $0.06-0.2$ & $0.08-0.3$ & $0.2-0.6$ & 0.08 & $0.03-0.15$ & $0.1-0.6$ \\
\hline
\end{tabular}

produced in the early stages of depth hoar formation (Sturm and Benson, 1997; Taillandier et al., 2006), or under conditions of moderate temperature gradient (10 to $20^{\circ} \mathrm{C} \mathrm{m}^{-1}$, Domine et al., 2002 and 2003). They are poorly interconnected and layers of such crystals are as uncohesive as depth hoar layers.

- Depth hoar crystals in seasonal snow (Fig. 2a) usually result from the metamorphism of snow with low to moderate density $\left(<0.35 \mathrm{~g} \mathrm{~m}^{-3}\right)$ under high temperature gradient $\left(>20^{\circ} \mathrm{C} \mathrm{m}^{-1}\right.$, Marbouty, 1980) that generate strong water vapor fluxes and rapid growth, resulting in hollow faceted crystals with sharp angles. Their sizes range from 2 to $20 \mathrm{~mm}$. The connectivity between crystals is usually very weak, producing very uncohesive snow.

- Rounded grains (Fig. 2e) are produced by low temperature gradient $\left(<10^{\circ} \mathrm{C} \mathrm{m}^{-1}\right)$ metamorphism of precipitating snow, and layers of such crystals have densities between 200 and $350 \mathrm{~kg} / \mathrm{m}^{3}$ (Albert and Shultz, 2002; Domine et al., 2003). Crystal size range from $0.1 \mathrm{~mm}$ to almost $1 \mathrm{~mm}$ at the end of the season. Rounded grains can also be produced by hard-packed wind-blown snow crystals, in which case their density can reach 0.5 (Domine et al., 2002), or exceptionally $0.61 \mathrm{~g} \mathrm{~cm}^{-3}$, as observed near the Antarctic coast, in areas subjected to strong katabatic winds (Domine, unpublished results). Crystals in hard windpacks seldom exceed $0.4 \mathrm{~mm}$ in 
size. The interconnectivity between rounded grains is strong: these layers are cohesive and their cohesiveness increases with density.

- Mixed forms refer to sets of crystals displaying both flat faces and rounded shapes (Fig. 2f). Their size is often in the range 0.3 to $1 \mathrm{~mm}$. They can be formed under low to moderate temperature gradients, or by the rounding of small faceted crystals following a decrease in the temperature gradient.

- Melt-freeze crusts and layers are formed by the thermal cycling of snow layers, usually with diurnal melting and nocturnal freezing (Colbeck, 1982). Grains grow with each cycle, and are often observed to have a size in the range 0.5 to $2 \mathrm{~mm}$ (Raymond and Tusima, 1979). Thick melt-freeze layers made up of large rounded grains formed by repeated thermal cycling in the spring are often referred to as corn snow. The melting of low density snow allows facile percolation. This can form meltfreeze layers of low density, down to $0.1 \mathrm{~g} \mathrm{~cm}^{-3}$, and of moderate cohesiveness when frozen (Fig. 2d). Melting in denser layers results in dense melt-freeze crusts that have a strong cohesiveness when frozen (Fig. 2c).

Table 1 reports typical values of physical properties of snow layers formed by seven types of snow crystals. The snow on the ground usually consists in layers of several of the above snow crystal types, and the formation of each metamorphic type is governed by climatic variables that include the amount of precipitation, air temperature, wind speed and insolation. There is therefore a strong correlation between climate and the structure of the snow, which has motivated several classifications. Below is a brief summary of typical forms of seasonal snowpacks as described by Sturm et al. (1995). We illustrate in Fig. 3 the snowpack types that are the subject of most current photochemistry investigations. The tundra snowpack (Fig. 3) is found in polar treeless areas with low precipitation ( $<250 \mathrm{~mm}$ water equivalent per year) that can be episodically swept by strong winds. It is typically $40 \mathrm{~cm}$ thick, and formed of a basal depth hoar layer 10 to $20 \mathrm{~cm}$ thick covered by a hard windpacked layer formed of small rounded grains. Variations include several windpacks, sometimes separated by layers of faceted crystals or by ice layers (Domine et al., 2002; Sturm and Benson, 2004). The taiga snowpack (Fig. 3) forms mostly in wind-sheltered subarctic regions with trees and low to moderate precipitation and is about $50 \mathrm{~cm}$ thick. This snowpack, extensively described by Sturm and Benson (1997) and Taillandier et al. (2006), is subjected to strong temperature gradients and is eventually almost fully transformed into depth hoar, except perhaps top layers deposited in late winter or spring. In the middle of winter, it is typically formed of a thick $(20 \mathrm{~cm})$ basal depth hoar layer surmounted by a layer of faceted crystals and episodically by a fresh snow layer.

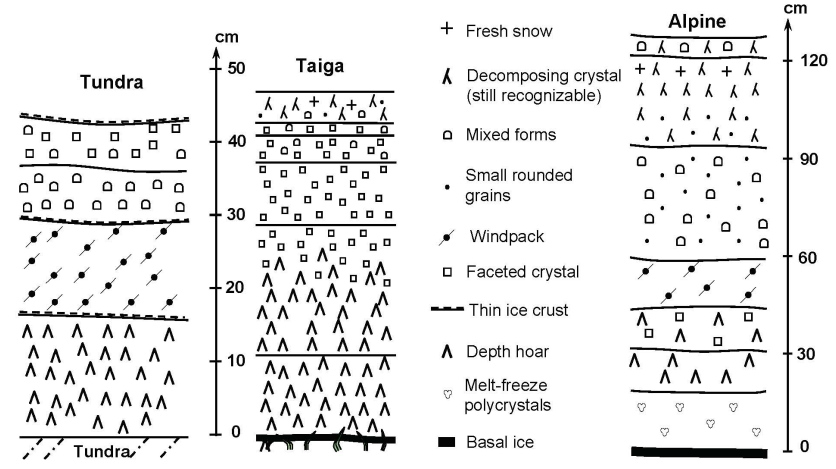

Fig. 3. Simplified stratigraphies illustrating the main seasonal snowpack types: the tundra snowpack near Barrow, Alaska, on 4 April 2004 (Domine, Taillandier and Simpson, unpublished results); the taiga snowpack near Fairbanks, Alaska, on 12 February 2004 (after Taillandier et al., 2006); the Alpine snowpack in the ablation zone of the Argentières glacier, near Chamonix, French Alps, on 31 January 2002 (Domine and Lauzier, unpublished results).

The Alpine snowpack (Fig. 3) forms in fairly cold areas with abundant precipitation. The snowpack thickness prevents the establishment of the high temperature gradient necessary for depth hoar formation, except at the beginning of the season. Frequent precipitation of thick layers result in many layers of fine-grained snow not compacted by wind, separated by occasional windpacks and sometimes melt-freeze crusts and ice layers.

The maritime snowpack forms in temperate areas with abundant precipitation. The temperature gradients within this snowpack are often low. However strong gradients early in the season can induce kinetic crystal growth leading to depth hoar in shallow snow, and steep near-surface gradients at night can impose kinetic growth in surface snow in deep snowpacks. In maritime snow, melting events can be frequent, resulting in ice layers with grains that grew during melt-freeze cycles interspersed with layers of snow that have not experienced melt (e.g. Albert and Shultz, 2002). Ice layers are common, and so are vertical percolation channels (e.g. Marsh and Woo, 1984; Albert et al., 1999).

The crystal structure of snow and firn on the polar ice sheets is significantly different in form than that found in temperate snowpacks described above. In the cold, high altitude regions, snow typically falls as small plates or prisms. Cold strong winds create thick layers of windpack, which are composed of small solid rounded crystals. At high-accumulation (greater than approximately $20 \mathrm{~cm}$ water equivalent per year) polar sites, near-surface temperature gradients and solar radiation during warmer summer conditions create surface hoar at the snow-air interface or near-surface depth hoar. If additional snowfall occurs before strong winds develop, these persist as low-density buried layers that can be used as markers of summer, even decades after deposition in regions where the snow does not melt (Alley et al., 
Table 2. Typical values of selected physical variables encountered in the top $20 \mathrm{~cm}$ (photic zone) of three seasonal snowpacks in late winter. Data from Sturm and Benson (1997); Sturm et al. (1997); Simpson et al. (2002a and unpublished results); Albert et al. (2002); Taillandier et al. (2006); Domine et al. (unpublished results).

\begin{tabular}{llll}
\hline $\begin{array}{l}\text { Physical } \\
\text { variable }\end{array}$ & $\begin{array}{l}\text { Tundra } \\
\text { snowpack }\end{array}$ & $\begin{array}{l}\text { Taiga } \\
\text { snowpack }\end{array}$ & $\begin{array}{l}\text { Alpine } \\
\text { snowpack }\end{array}$ \\
\hline $\begin{array}{l}\text { Density, } \mathrm{g} \mathrm{cm}^{-3} \\
\text { Specific surface area, cm } \mathrm{c} \mathrm{g}^{-1}\end{array}$ & 0.4 & 0.18 & 0.2 \\
$e$-folding depth, cm & 5 & 190 & 380 \\
Permeability, $10^{-10} \mathrm{~m}^{2}$ & 8 & 15 & 8 \\
Heat conductivity, $\mathrm{W} \mathrm{m}^{-1} \mathrm{~K}^{-1}$ & 0.4 & 200 & 50 \\
\hline
\end{tabular}

1990). In addition to layering created by changing seasons, the properties of snow and firn change over time due to postdepositional metamorphism. This results in property changes that combine influences of original form with influences of grain growth, sintering, and pressure sintering over time. At high accumulation cold sites, this results in grain size that generally increases with depth, while permeability and thermal conductivity profiles take on more complicated forms (Albert and Shultz, 2002; Albert et al, 2000; Rick and Albert, 2004). In very low accumulation areas such as East Antarctica, layering exists but may reflect topographically-driven precipitation patterns rather than snowfall patterns, and large, well-sintered, faceted crystals are grown in the near surface from decades of vapor transport under very cold conditions (Albert et al., 2004).

Thus snow on the ground takes on a variety of layering and crystal properties that relate to the local climate, and the contrasting physical properties should be readily apparent to the non-specialist who is a careful observer. With regards to snow photochemistry, what is of interest includes the ability of the snowpack to store reactants, as influenced for example by its SSA, to transmit light, as dictated by its $e$-folding depth, and to release products to the atmosphere, as determined in part by its permeability. Typical values of relevant physical variables encountered in the photic zone of selected seasonal snowpacks in late winter are reported in Table 2 to illustrate the relationship between snowpack type and physical properties. The actual ranges of values encountered are fairly wide. For example the SSA of surface snow often exceeds $800 \mathrm{~cm}^{2} \mathrm{~g}^{-1}$ in the Alpine snowpack, due to the frequent presence of thick layers of fresh snow, whose density can remain below $0.1 \mathrm{~g} \mathrm{~cm}^{-3}$ for several days under windless conditions at sub-freezing temperatures. The heat conductivity of such layers can then be very low, down to $0.03 \mathrm{~W} \mathrm{~m}^{-1} \mathrm{~K}^{-1}$. Details on the range of values of several physical variables encountered in major snowpack types, and on the physical processes that determine them, are given in the following sections.

\subsection{Density}

Density is defined as the mass per unit volume, and it is usually measured in the field or the laboratory by weighing a sample of known volume. Because weighing always takes place in air, the density of snow measures the amount of ice in a unit volume of snow. Since density is intuitive and does not require complex equipment to be measured, it has traditionally been the parameter used to describe the nature of snow. However, it is now widely recognized that density alone cannot be used as a descriptor of other snow properties. The porosity is then defined from the snow density according to Eq. (4) above.

The density of natural snow can change enormously over time: from less than $0.01 \mathrm{~g} \mathrm{~cm}^{-3}$ for fresh cold dendritic snow to more than $0.6 \mathrm{~g} \mathrm{~cm}^{-3}$ for very hard windpacks and snow subjected to numerous melt freeze cycles. Physical processes involved in density changes include compaction, drifting, and dry and wet metamorphism. Deposited snow, with densities usually in the range 0.01 to $0.2 \mathrm{~g} \mathrm{~cm}^{-3}$ (Judson and Doesken, 2000) is subject to settling and compaction especially within the first week after deposition. Wind-drifted snow often forms thick layers of small rounded grains that sinter well and produce hard windpacks, with the windpacks density in the range 0.3 to $0.6 \mathrm{~g} \mathrm{~cm}^{-3}$ increasing with the speed of the wind that formed them. High temperature gradient metamorphism can produce intense upward water vapor fluxes that can fully compensate the effects of compaction, so that for example the density in the taiga snowpack is vertically fairly constant around $0.2 \mathrm{~g} \mathrm{~cm}^{-3}$ (Sturm and Benson, 1997; Taillandier et al., 2006). This intense dry metamorphism can lead to large mass losses in Arctic windpacks in the fall (Domine et al., 2002) and transform them into depth hoar, showing that significant density decreases can take place in snow layers. The appearance of liquid water usually leads to crystal rounding, compaction and density increase. Snow density ranges for a variety of snow types are reported in Table 1.

Density values are required for almost all applications. Density parameterizations are therefore proposed in most 
snow physical models. Snow densification involves several processes and the rate of snow settling depends on density itself, temperature, liquid water content and on the evolving snow microstructure, whose description remains a challenge. In contrast to this complexity, snow densification is often described by simple empirical relationships (Verseghy, 1991). Even advanced models usually assume that snow behaves like a viscous material and propose parameterizations for snow viscosity, which try to incorporate some of the settling processes. Using this approach, snow viscosity, $\eta_{s}$, then relates the stress $\sigma$ to the strain rate $(d h / h) / d t$, where $h$ is the thickness of the layer under consideration:

$\frac{d h}{h}=-\frac{\sigma_{s}+\sigma_{0}}{\eta_{s}} d t$

Here $\sigma_{s}$ is the applied snow stress i.e. in general the selfweight of the snow pack and the initial stress, $\sigma_{0}$, is a possibility to include the effect of the rapid initial settling associated with destructive metamorphism of dendritic snow. The complex snow processes during settling are then expressed by mostly empirical relationships for viscosity and the initial stress. Simple models typically use $\sigma_{0}=0$ and parameterize the viscosity as a non-linear function of density and temperature only (e.g. Kojima, 1975). More advanced models have complicated parameterizations for both. We report here the formulations in SNTHERM (Jordan, 1991), CROCUS (Brun et al., 1989) and SNOWPACK (Lehning et al., 1999).

In SNTHERM, the initial settling is described independently of viscosity, which can be written as a function of temperature, $T$, ice volumetric fraction, $\theta_{i}$, and water volumetric fraction, $\theta_{w}$ :

$$
\begin{aligned}
& \sigma_{0} / \eta_{s}=2.77810^{-6} c_{3} c_{4} e^{0.04 T}, \\
& c_{3}=c_{4}=1, \theta_{i} \leq 0.15 \text { and } \theta_{w}=0 \\
& c_{3}=e^{-42\left(\theta_{i}-0.15\right)}, \theta_{i}>0.15 \\
& c_{4}=2, \theta_{w}>0
\end{aligned}
$$

The snow viscosity is then parameterized as function of temperature and snow density, $\rho$ :

$$
\begin{aligned}
& \eta_{s}=\eta_{0} e^{-c 5 T_{c}} e^{c 6} \rho, \\
& \eta_{0}=3.610^{6} \mathrm{~N} \mathrm{~s} \mathrm{~m}^{-2} \\
& c_{5}=0.08 \mathrm{~K}^{-1} \\
& c_{6}=0.021 \mathrm{~m}^{3} \mathrm{~kg}^{-1}
\end{aligned}
$$

Both above equations use SI units, with $T$ in ${ }^{\circ} \mathrm{C}$. The critical volumetric ice fraction of 0.15 used above has been found to be rather high in several applications. Subsequent studies have set the value to 0.1 , while also modifying the value of $\eta_{0}$, from $1.010^{6} \mathrm{~N} \mathrm{~s} \mathrm{~m}^{-2}$ to values as high as 9.0 $10^{7} \mathrm{~N} \mathrm{~s} \mathrm{~m}^{-2}$ (e.g. Coléou et al., 2005). In CROCUS, a similar yet somewhat simpler formulation based on the settling law of Navarre (1975) is implemented. In the original implementation (Brun et al., 1989), snow viscosity is described as a function of temperature and snow density alone. That formulation suggested a factor for a microstructure correction, which has been implemented since (Coléou et al., 2005).

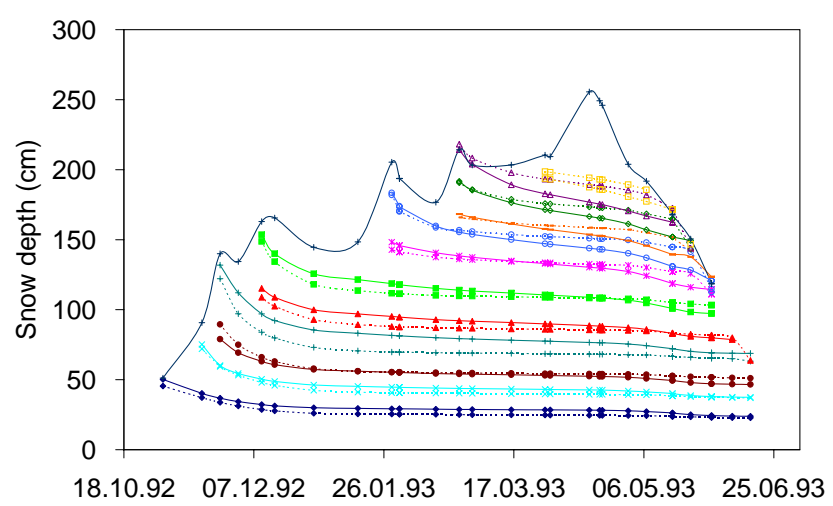

Fig. 4. Snow stratification at Weissfluhjoch, Davos, during the winter 1992/1993: comparison between measured values and calculations using the SNOWPACK model. The upper envelope represents the measured, total snow height. The solid lines show the heights above ground of 12 markers placed on the snow surface at different times of the winter and subsequently buried by precipitation. The dotted lines show the computed heights of the corresponding layers.

The original implementation of SNOWPACK used a visco-elastic, natural strain settling law (Bartelt and Lehning, 2002) with different viscosity laws for fresh and old snow (Lehning et al., 2002a). The viscosity formulation made use of a grain-bond description of snow microstructure and reduced snow settling to the deformation of ice bonds between the grains distinguishing between linear and non-linear yields of the ice matrix. Additional experiments and sensitivity studies have shown, however, that in natural settling elasticity and non-linear yield can be neglected and Eq. (9) is a good description of the settling behaviour. The current version of SNOWPACK therefore retains the microstructure-based development of a linear snow viscosity as described by Eqs. (33)-(35) in Lehning et al. (2002a). However, the empirical adjustment factor, $F_{\eta}$, is reformulated to include the liquid water content $\theta_{w}$, the age of the snow layer, $t_{d}$ (days), and variables representing crystal shapes and taking values between 0 and 1, namely dendricity, $d d$, and sphericity, $s p$, as defined in Brun et al. (1992):

$$
\begin{aligned}
& F_{\eta}=\frac{0.4+9.5 \theta_{w}}{\theta_{i}}+c_{t}\left(1-\frac{t_{d}}{90}\right), \\
& t_{d} \leq 90 ; \\
& c_{t}=2.1 \sqrt{d d}+0.7 \mathrm{sp}
\end{aligned}
$$

Here the time coefficient, $c_{t}$, is a function of the additional grain shape parameters $d d$ and $s p$ for all snow types except for melt-freeze crusts, where it is set constant to 1.7. The initial stress is formulated as a function of the ice surface tension, $\sigma_{i}\left(0.11 \mathrm{~N} \mathrm{~m}^{-2}\right)$, the grain size, $r_{g}$ and the dendricity, $d d$ with the constants 1.5 and 2 having units of $\mathrm{m}$ :

$\sigma_{0}=\frac{\sigma_{i}}{r_{g}}(1.5+2 \sqrt{d d})$.

The new SNOWPACK formulation calculates reliable settling curves for an Alpine seasonal snow cover. As shown 
in Fig. 4, the settling of individual snow layers tracked in the Alps at the Weissfluhjoch Versuchsfeld (Fierz and Lehning, 2001) can be described with good accuracy for the full seasonal development. It has also been investigated that errors in the settling curves such as in the 4th layer from the bottom arise from errors in the density estimation for fresh snow (Lehning et al., 2002b). Both a good density estimation and a good settling description are mandatory to allow a reliable snow mass balance at a point (Lehning et al, 1999) or for a full catchment (Lehning et al., 2006) based on snow depth measurements.

\subsection{The specific surface area of snow}

The specific surface area (SSA) of snow is a measure of the area of the air-snow interface. Its usual definition is the surface area of snow crystals accessible to gases per unit mass (Legagneux et al., 2002), often expressed in $\mathrm{cm}^{2} \mathrm{~g}^{-1}$. Values measured in surface snow range from $19 \mathrm{~cm}^{2} \mathrm{~g}^{-1}$ for meltfreeze crusts to $1558 \mathrm{~cm}^{2} \mathrm{~g}$ for fresh dendritic snow (Domine et al., 2007a).

Three methods are reported in the literature to measure reliably snow $S S A$ : $\mathrm{CH}_{4}$ adsorption at $77 \mathrm{~K}$, stereology, and $\mathrm{X}$-ray tomography. The first one, detailed in Legagneux et al. (2002) and Domine et al. (2007a) has produced the largest number of measurements (345) for surface snow. Its principle is to measure the adsorption isotherm of $\mathrm{CH}_{4}$ on snow using a volumetric method. The SSA is then derived using the method (called BET) of Brunauer et al. (1938). Obtaining reliable $S S A$ values using gas adsorption is not simple for snow because this solid has a much lower SSA than other porous solids for which the method was intended, such as catalysts. Using $\mathrm{CH}_{4}$ rather than $\mathrm{N}_{2}$ considerably improved measurement accuracy by lowering the vapor pressure of the adsorbate at $77 \mathrm{~K}$ (Chaix et al., 1996). The detection limit for this method is about $10 \mathrm{~cm}^{2} \mathrm{~g}^{-1}$. One of its advantages is that it requires no sample preparation: snow is just sampled into a vacuum container which is immersed in liquid nitrogen. This has the added advantage of stopping metamorphism. However, the liquid nitrogen requirement can be a difficulty in polar campaigns. One SSA measurement with this method takes about $3 \mathrm{~h}$.

Stereology is the study of 2-dimensional images to obtain information on 3-dimensional objects (Underwood, 1970) and is often used to study porous media such as snow (Narita, 1971; Perla et al., 1986). One method to obtain 2dimensional images of snow is to harden a snow sample by filling it with a water-insoluble liquid that freezes at $\mathrm{T}<0^{\circ} \mathrm{C}$, such as dimethy-phthalate (Perla et al., 1986). The sample is then polished and micrographs are analyzed using appropriate methods (Davis et al., 1987) to derive SSA. The succession of all these preparation stages takes about $4 \mathrm{~h}$ for one SSA measurement.

The most extensive set of SSA measurements of surface snow using stereology is that of Narita (1971). This paper is in Japanese with only an English abstract, so that details are not readily accessible. Narita studied snow and firn samples, and it appears that a few tens of samples were surface snow, the highest $S S A$ value being about $750 \mathrm{~cm}^{2} \mathrm{~g}^{-1}$.

$S S A$ values of surface snow obtained by both methods are in the same range, but no comparative studies have been made. The former method is probably more suited for surface snow, while the latter appears more suitable for firn and ice cores because of a lower limit of detection. From the data of Alley and Koci (1988), SSA values for ice cores of about $2 \mathrm{~cm}^{2} \mathrm{~g}^{-1}$ are calculated, and this is below the detection limit of $\mathrm{CH}_{4}$ adsorption. On the other hand, fresh snow crystals have microstructure with radii of curvature of only a few $\mu \mathrm{m}$, such as thin dendrites, that can be destroyed while warmer liquid is poured or the sample is polished for stereological studies. Moreover, structures a few $\mu \mathrm{m}$ in size may not be detected in automated processing of optical micrographs, and SSA of fresh snow may be underestimated. Stereology, however, does not require liquid nitrogen.

Recently, X-ray tomography has been used to obtain 3-D images of snow samples (Flin et al., 2003; Schneebeli and Sokratov, 2004; Kerbrat et al., 2007), from which the SSA can be computed. This method requires a synchrotron (Flin et al., 2003) with the benefit of good spatial resolution and fast data acquisition, or a microtomograph (Schneebeli and Sokratov, 2004; Kerbrat et al., 2007). Kerbrat et al. recently performed a comparison between X-ray tomography and $\mathrm{CH}_{4}$ adsorption, and the methods agreed with $3 \%$ for snows with $\mathrm{SSA}<700 \mathrm{~cm}^{2} \mathrm{~g}^{-1}$. However, for fresh snow, the resolution of X-ray tomography was insufficient to detect small structures, resulting in an underestimation of SSA.

At present, it appears that $\mathrm{CH}_{4}$ adsorption at $77 \mathrm{~K}$ is best suited to the measurement of the SSA of snow in the photic zone. However, this is time consuming and the need for liquid nitrogen limits its use, so that a faster method readily useable in the field is desirable.

Recently, Domine et al. (2006) have observed an excellent correlation between snow SSA measured by $\mathrm{CH}_{4}$ adsorption and snow reflectance in the near and short-wave infrared (NIR and SWIR). Wavelengths tested were 1310, 1629,1740 and $2260 \mathrm{~nm}$. The relationship was linear for the last 3 wavelengths. This is based on only 9 snow samples and further work is needed before the potential of using NIR or SWIR reflectance to measure snow SSA can be established. In particular, the effect of grain shapes (Neshyba et al., 2003; Kokhanovsky and Zege, 2004) needs further detailed studies. Matzl and Schneebeli (2006) also used NIR reflectance around $900 \mathrm{~nm}$ to measure snow SSA with a camera. The signal was calibrated with stereological measurements. This method is very rapid and quite promising. Its accuracy and in particular the dependence of the NIR signal on crystal shape needs to be studied further, however. In any case, both these IR studies suggest that the accurate and rapid measurement of snow SSA in the field may soon be at hand. 
SSA parameterization in models is necessary. The simplest method would be to correlate SSA with the snow variable that is the most easily and most commonly measured: density. Such an approach has been attempted for other variables. For example, Sturm et al. (1997) tested a correlation between heat conductivity and density. In the case of $S S A$, Fig. 5 shows a poor correlation. A significant improvement is obtained if the snow type is considered, and further improvement is observed if both the snow type and the snowpack type are considered. For example, Domine et al. (2007a) show that for depth hoar in the taiga snowpack, the following relationship is found, with $R^{2}=0.66$ :

$S S A=-23.97 \ln (\rho)-241.9$

with $S S A$ in $\mathrm{cm}^{2} \mathrm{~g}^{-1}$ and $\rho$ in $\mathrm{g} \mathrm{cm}^{-3}$. Domine et al. (2007a) also show that depth hoar in the tundra and Alpine snowpacks follow a similar relationship with different coefficients, yielding higher $S S A$ values than in the taiga snowpack, for a given density.

Rather than attempt to link SSA to density, one can attempt to predict its rate of decrease after precipitation. Cabanes et al. (2002 and 2003) monitored the rate of decrease of dry snow SSA in the Arctic and in the Alps and proposed an empirical equation of the form:

$S S A=S S A_{0} \exp (-\alpha t)$ with $\alpha\left(d a y^{-1}\right)$

$=76.6 \exp (-1708 / \mathrm{T}(\mathrm{K}))$

This formulation is based on a limited data set, and predicts $S S A$ only as a function of temperature, time, and initial $S S A$ of the snow, $S S A_{0}$ (i.e. the $S S A$ of the freshly fallen snow). Legagneux et al. (2003 and 2004) and Taillandier et al. (2007) have studied the rate of decrease of dry snow SSA in the field and during cold room experiments. In all cases, an equation of the form:

$S S A(t)=B-A \ln (t+\Delta t)$

could adequately fit the data. Taillandier et al. (2007) found that two sets of values of $B, A$ and $\Delta t$ could be used for two different types of conditions and expressed as a function of $S S A_{0}$ and the time-averaged temperature of the snow $T_{m}$ : one set was valid when the temperature gradient in the snowpack was low $\left(<9^{\circ} \mathrm{C} \mathrm{m}^{-1}\right.$, this probably corresponds to the ET conditions defined by Sommerfeld and LaChapelle, 1970) and the other set was valid under high temperature gradient $\left(>20^{\circ} \mathrm{C} \mathrm{m}^{-1}\right.$, probably the TG conditions of Sommerfeld and LaChappelle, 1970). Under ET conditions, the coefficients are:

$$
\begin{aligned}
& A_{E T}=0.0760 S S A_{0}-1.76\left(T_{m}-2.96\right) \\
& B_{E T}=0.629 S S A_{0}-15.0\left(T_{m}-11.2\right) \\
& \Delta t_{E T}=\exp \left(\frac{-0.371 S S A_{0}-15.0\left(T_{m}-11.2\right)}{0.0760 S S A_{0}-1.76\left(T_{m}-2.96\right)}\right)
\end{aligned}
$$

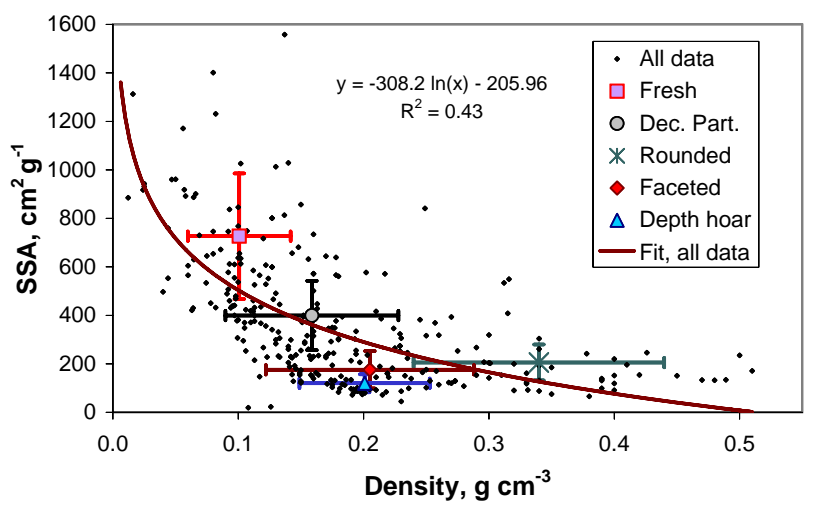

Fig. 5. SSA-density correlation, using the 297 coupled SSA-density measurements of Domine et al. (2007a). SSA was measured using $\mathrm{CH}_{4}$ adsorption at $77 \mathrm{~K}$. The graph also shows average values and standard deviations of some of the snow types mentioned in Table 1: Fresh snow, decomposing particles, rounded grains (encompassing both ET metamorphism grains and windpacked grains), faceted crystals and depth hoar (after Domine et al., 2007a).

Under TG conditions, the coefficients are

$$
\begin{aligned}
& A_{T G}=0.0961 S S A_{0}-3.44\left(T_{m}+1.90\right) \\
& B_{T G}=0.659 S S A_{0}-27.2\left(T_{m}-2.03\right) \\
& \Delta t_{T G}=\exp \left(\frac{-0.341 S S A_{0}-27.2\left(T_{m}-2.03\right)}{0.0961 S S A_{0}-3.44\left(T_{m}+1.90\right)}\right)
\end{aligned}
$$

In the above equations, $S S A$ is in $\mathrm{cm}^{2} \mathrm{~g}^{-1}, T_{m}$ is in ${ }^{\circ} \mathrm{C}$ and $\Delta t$ is in hours. Figure 6 shows plots of $S S A$ decay under both ET and TG regimes, when $S S A_{0}=800 \mathrm{~cm}^{2} \mathrm{~g}^{-1}$. Depending on the temperature and the metamorphic regime, $S S A$ is reduced to half its initial value in 1.5 to 18 days. The above equations reproduce well the experimental data of Taillandier et al. (2007), but the authors note a number of limitations, such as the lack of data for dense snow $\left(\rho>0.3 \mathrm{~g} \mathrm{~cm}^{-3}\right)$ so that predicting the SSA decay of for example Arctic windpacks is not possible. Another crucial lack of data is for wet snow, as Domine et al. (2007a) report only a handful of measurements.

Flanner and Zender (2006) modeled SSA decay during metamorphism as a function of temperature, temperature gradient, snow density, particle size distribution and irregularity of particles spacing in the snow. They assumed that snow crystals were spheres. Their model reproduced very well the isothermal experiments of Legagneux et al. (2004), after adjusting parameters describing the particle size distribution. Taillandier et al. (2007) compared their model results under temperature gradient conditions with their new experimental data. The agreement was in general good, but could possibly be improved using another value of the irregularity in particle spacing, as Flanner and Zender (2006) had no data to constrain that variable at the time. This modeling approach is promising but requires significant calculation time. 


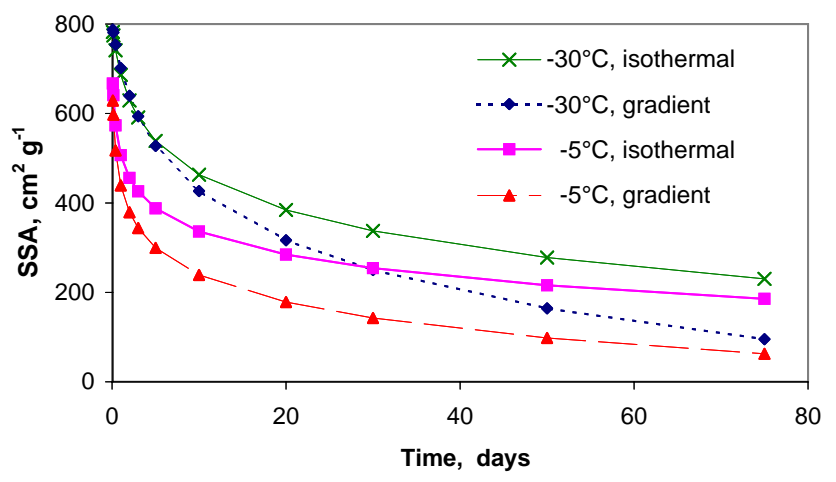

Fig. 6. Evolution of the specific surface area $(S S A)$ of snow at -5 and $-30^{\circ} \mathrm{C}$, for the cases where the snowpack is isothermal and where it is subjected to a temperature gradient $>20^{\circ} \mathrm{C} \mathrm{m}^{-1}$. Equations (17) and (18) were used, with a value for the initial SSA of $800 \mathrm{~cm}^{2} \mathrm{~g}^{-1}$.

A significant difference with Eqs. (14) and (15), which are empirical and based on experiments, is that it predicts continuous transitions between metamorphic regimes.

Despite these recent experimental and modeling studies, data on snow SSA is still limited, despite its importance in snow chemistry and physics. Studies on for example the effect of melting or surface hoar deposition are lacking. Understanding snow SSA would definitely benefit from a new rapid measurement method based on IR reflectance (Domine et al., 2006; Matzl and Schneebeli, 2006).

\subsection{Thermal conductivity}

Because of snow metamorphism, the thermal properties of snow are highly variable and can change dramatically in time. Traditionally, estimates of snow thermal properties are based on readily-measurable characteristics such as density and grain size, though it is well known that the geometric forms of the microstructure are a first-order effect. Adams and Sato (1993) were the first to try to derive a physical model for snow conductivity considering snow microstructure (packed spheres) and distinguishing between ice conduction, conduction in the pore space and vapor transport. This microstructure-based conductivity model has been successfully implemented in SNOWPACK (Lehning et al., 2002a). Recent use of micro-tomography for imaging snow metamorphism (Coléou et al., 2001) offers promise for forthcoming formulations of the thermal properties to be based on microstructure characteristics (Kaempfer et al., 2005).

The thermal conductivity of snow controls the net heat transfer in the snow when there is no interstitial air flow. In one dimension, the heat flux $q$ at a point is given by the Fourier Eq. (5) where $k_{\text {eff }}$ is the effective thermal conductivity. Heat flow through snow results from the combined effect of several physical processes, as shown in Fig. 7.

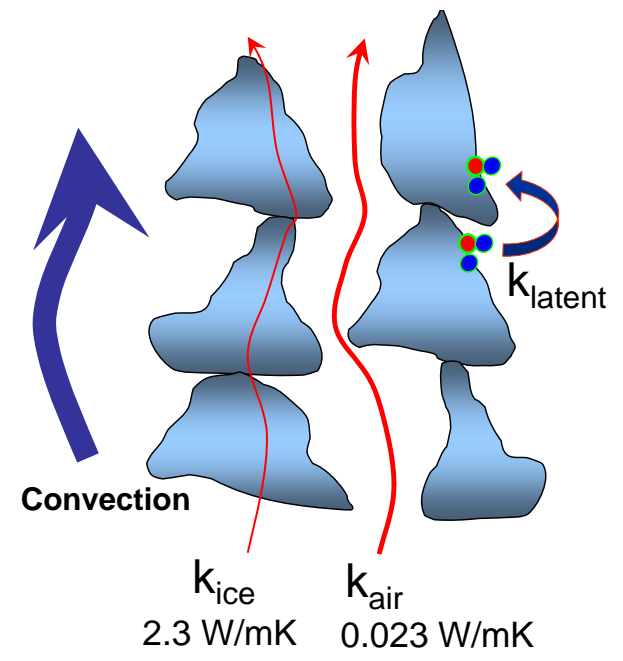

Fig. 7. The main processes responsible for heat transport through snow. The snow structure represented is columnar depth hoar. Processes shown are conduction through interconnected snow crystals (the heat conductivity of ice is $k_{\text {ice }}=2.3 \mathrm{~W} \mathrm{~m}^{-1} \mathrm{~K}^{-1}$ ), conduction by air in the pore space (the heat conductivity of air is $k_{\text {air }}=0.023 \mathrm{~W} \mathrm{~m}^{-1} \mathrm{~K}^{-1}$ ), latent heat transport by sublimation/condensation cycles induced by the temperature gradient. These three processes are measured as $k_{\mathrm{eff}}$, for example using a heated needle probe. Additionally, air flow through snow can be induced by surface wind or air convection and this represents an extra process which, when present, can transport heat much faster than either conduction through the ice or void space.

Heat conduction takes place through the network of interconnected snow crystals and through air in the pore space. In addition, there almost always exist a temperature gradient in dry snow, which generates water vapor sublimation from warmer grains, diffusion through the pore space and condensation on colder grains (Colbeck, 1983) leading to heat transport through latent heat exchanges. The effects of these processes can be measured using a heated needle probe (e.g. Sturm and Johnson 1992; Sturm et al., 1997; Mellor, 1977; Lange, 1985) where the rate of dissipation of a given heat pulse is analyzed to derive the "effective" thermal conductivity $k_{\text {eff. }}$. For this type of measurement, the snow sample is maintained enclosed in a fairly air-tight container to avoid heat transport due to air flow.

Air flow in snow can be caused by wind-driven variations in surface pressure over a rough snow surface (Colbeck, 1983; Cunningham and Waddington, 1993; Albert et al., 2002) or by thermal convection caused by a high temperature gradient in very permeable snow such as depth hoar (Sturm and Johnson, 1991), but this heat transport process is discussed in a subsequent section.

The variable $k_{\text {eff }}$ has contributions from several physical processes, and the relative contributions of each one of these processes are expected to depend on the geometric aspects of the crystal structure and on the snow temperature. We therefore expect to observe a large scatter in values reported 
for direct measurement of $k_{\mathrm{eff}}$. For dry snow, values between 0.025 and $0.65 \mathrm{~W} \mathrm{~m}^{-1} \mathrm{~K}^{-1}$ have indeed been measured (Sturm et al., 1997, and references therein). To attempt to predict $k_{\text {eff }}$ values, correlations with snow density have been explored. Sturm et al. (1997) and Jordan et al. (2007) report density- $k_{\text {eff }}$ correlations. A significant scatter exists, which could be reduced if the snow type were taken into account. Reported correlations show $k_{\text {eff }}$ values ranging from approximately $0.07 \mathrm{~W} \mathrm{~m}^{-1} \mathrm{~K}^{-1}$ for a density of $0.1 \mathrm{~g} \mathrm{~cm}^{-3}$ to $0.7 \mathrm{~W} \mathrm{~m}^{-1} \mathrm{~K}^{-1}$ for a density of $0.5 \mathrm{~g} \mathrm{~cm}^{-3}$ (Jordan et al.,

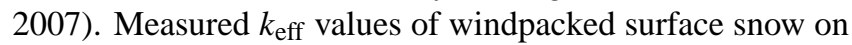
polar ice sheets are between $0.15-0.20 \mathrm{~W} \mathrm{~m}^{-1} \mathrm{~K}^{-1}$ for a density near $0.35 \mathrm{~g} \mathrm{~cm}^{-3}$, while aged near-surface firn that has not experienced melt on the East Antarctic ice sheet shows

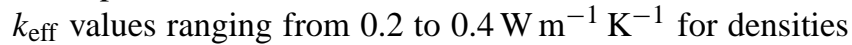
between 0.35 to $0.45 \mathrm{~g} \mathrm{~cm}^{-3}$ (Courville et al., 2007). Despite the large scatter in the density correlation, Sturm et al. (1997) proposed the following equations for seasonal snow:

$k_{\text {eff }}=0.138+1.01 \rho+3.2233 \rho^{2} \quad\{0.156 \leq \rho \leq=0.6\}$

$k_{\text {eff }}=0.023+0.234 \rho \quad\{\rho<0.156\}$

that have been extensively used in various calculations and model parameterizations for seasonal snow, but they are not applicable to polar firn.

\subsection{Permeability of snow and firn}

The air permeability of snow is the property of snow that controls the ease with which a fluid, typically air or water, can move through the snow. Permeability $K_{p}$ is the proportionality factor between the pressure gradient $d P / d z$ and the interstitial air flow velocity $v_{\text {air }}$ as defined by Eq. (6) above, known as Darcy's law. The permeability is sensitive to the nature of the interconnected pore space, and it depends both upon the crystal structure and the snow layering. As in all physical properties of snow, permeability will change as the snow undergoes metamorphism. The permeability of snow is typically measured by drawing air through a snow sample and measuring the pressure drop and air flow rate through the sample, then calculating the permeability using Darcy's law (e.g. Albert et al., 2000). For seasonal snow, permeability ranges over two orders of magnitude depending on the snow type, density, grain size, and degree of metamorphism. The most permeable snow is depth hoar in seasonal snow, with permeability in the range from 100$600 \times 10^{-10} \mathrm{~m}^{2}$ (Sturm, 1991; Jordan et al., 1999). Freshly fallen snow in the mid latitudes typically has permeability in the range from 30 to $80 \times 10^{-10} \mathrm{~m}^{2}$, while old coarse seasonal snow typically exists in the range from 8 to $50 \times 10^{-10} \mathrm{~m}^{2}$ (Jordan et al., 2007, and references therein). Ice layers in seasonal snowpacks and crusts formed by melt in seasonal snow, and subsequently buried by later snowfalls, have permeability ranging from 1 to $20 \times 10^{-10} \mathrm{~m}^{2}$ depending on the degree of refreezing (Albert et al., 2000; Albert and Perron, 2000). Wind-packed snow on polar ice sheets typically falls in the

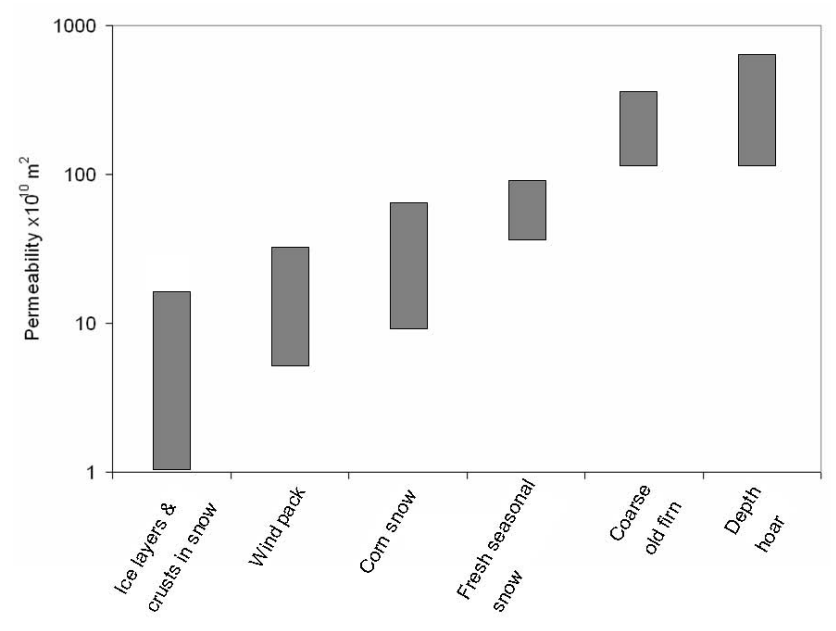

Fig. 8. Range of permeability values for different snow types. Corn snow refers to thick melt-freeze layers made up of large rounded grains formed by repeated thermal cycling in the spring.

range 5 to $30 \times 10^{-10} \mathrm{~m}^{2}$ (Conway and Abrahamson, 1984; Buser and Good, 1986; Albert and Shultz, 2004). Coarsegrained, aged firn in very cold low accumulation sites like the East Antarctic plateau has high permeability in the range of $100-300 \times 10^{-10} \mathrm{~m}^{2}$ (Albert et al., 2004; Courville et al., 2007). The natural stratification of snow that occurs due to different depositional events can yield buried layers that are more permeable than surface layers, causing flow channelling through the buried high-permeability layers (Albert, 2000). Luciano and Albert (2002) reported measurements of anisotropy in snow permeability and concluded that differences in permeability between layers from different storms caused larger variation than directionality differences in a single layer. A graph showing the permeability spread for various types of snow is given in Fig. 8. Since snow density and grain size are the most commonly measured snow variables, several attempts have been made to relate snow permeability to density and grain size. One widely used equation is that of Shimizu (1970):

$K_{P}=0.077 e^{(-0.0078 \rho)} D^{2}$

with $D$ the grain diameter in $\mathrm{m}$ and $\rho$ the snow density in $\mathrm{kg} \mathrm{m}^{-3}$. As noted by Jordan et al. (1999), Shimizu's formula was obtained for small rounded grains, and can be in error by an order of magnitude for calculations based on grain size and density for other snow types. Jordan et al. (1999) also note that progress in predicting snow permeability may come from the use of the snow specific surface area rather than grain size, as SSA is a clearly defined variable, even though it is still rarely measured in the field. Sommerfeld and Rocchio (1993) did attempt to correlate SSA and permeability, but did not find a conclusive correlation. However, their SSA range was very narrow (less than a factor of 2) and their SSA values were surprisingly low, so their conclusion should be tested by further work. 


\subsection{Gas diffusivity of snow}

The gas diffusivity is a property of snow that indicates the ease with which gases can move through the interstitial pore space by diffusive processes. The ratio $\phi D_{g} / \tau$ where $D_{g}$ is the diffusivity of the gas in air, $\phi$ the porosity and $\tau$ is tortuosity, is the proportionality factor between the gas concentration gradient $d C / d z$ and the interstitial gas flux $F_{\text {gas }}$ as shown in Eqs. (7) and (8). Gas diffusivity will vary according to chemical species, as it depends on the size of the molecules relative to the size of an interstitial pathway. For reactive chemical species, sometimes the diffusivity is posed as an "effective" parameter that includes not only the obstruction aspects of diffusion in the pore space around snow grains, but also adsorption/desorption processes that occur on the grain surface. Thus, when using published values of gas diffusivity in snow, one must be careful to note whether or not the values are based on only the obstruction effect or whether they also include the adsorption/desorption reactive impacts. For this discussion, we define the diffusivity to be the behavior of the gas as though it were inert. Adsorption and desorption are then separate source-sink type processes.

Pioneering investigations of gas diffusivity of firn were done by Schwander et al. (1988) and more recently by Favre et al. (2000), whose experiments based on elution peaks of an advected tracer gas in a moving carrier gas led to the conjecture that snow microstructure and layering are inconsequential to gas diffusion. Recently, experiments on firn cores by Courville et al. (2007) have shown that the gas diffusivity of snow does depend on the structure of snow and firn. The measurement technique for in-situ measurements is described in Albert and Shultz (2002), which was adapted from a technique described by McIntyre and Philip (1964) for soils. Measurements of the diffusion of $\mathrm{SF}_{6}$, an inert gas, through partially decomposed fresh dendritic seasonal snow has typical values close to $0.025 \mathrm{~cm}^{2} \mathrm{~s}^{-1}$ (Albert, unpublished data), while the $\mathrm{SF}_{6}$ gas diffusivity of wind-packed snow typically ranges between 0.02 to $0.06 \mathrm{~cm}^{2} \mathrm{~s}^{-1}$ (Albert and Shultz, 2002). The $\mathrm{SF}_{6}$ gas diffusivity of aged, coarse, near-surface polar snow in cold low accumulation sites in East Antarctica depends on the accumulation rate and ranges from 0.04 to $0.08 \mathrm{~cm}^{2} \mathrm{~s}^{-1}$ (Courville et al., 2007). For comparison, the diffusivity of $\mathrm{SF}_{6}$ in air between 0 to $-10^{\circ} \mathrm{C}$ is $0.08 \mathrm{~cm}^{2} \mathrm{~s}^{-1}$. Thus, depending on the nature of the snow, surface snow can either be little barrier to the transport of gas, or else slow down gas transport by as much as a factor of four compared to diffusion through air alone.

2.7 Effect of air advection in snow on the transport of heat and gases

Heat and chemical species can move through the snow by diffusion, a relatively slow, gradient-driven process, or by advection, a faster process by which heat and mass are transported by interstitial air flow ("ventilation") in the pore space between the snow grains. In natural snow, diffusion is ubiquitous because the snow is almost never in perfect thermal or chemical equilibrium. Thus diffusion must always be considered. Advection can occur both naturally and when interstitial air in the snow is sampled for chemical analysis (Albert et al., 2002). Wind-driven interstitial air flow within snow occurs mostly from pressure disturbances of the wind flowing over surface roughness (Colbeck, 1983; Cunningham and Waddington, 1993). Thermal convection due to buoyancy effects under high temperature gradients in extremely permeable snow has been observed by Sturm and Johnson (1991) and resulted in easily detectable heat transport. Albert et al. (2004) found that extensively recrystallized firn formed under extremely cold conditions on the East Antarctic plateau has characteristics that would make it prone to thermal convection. However, buoyancy-induced convection is rarely found in other types of snow. Experimental studies performed under different conditions failed to detect convection (Brun and Touvier, 1987), and we therefore subsequently treat only wind-driven and sampling-induced advection.

Wind-driven ventilation can advect chemical species, and it has been shown to impact the concentrations of species contained in aerosols (Cunningham and Waddingon, 1993; Harder et al., 2000; Domine et al., 2004), of species soluble in snow crystals (McConnell et al., 1998; Waddington et al., 1996), water vapor transport (Albert, 2002), and isotopic composition (Neumann and Waddington, 2004). In addition to advection caused naturally by the wind, advection also occurs when firn air is sampled for analysis. Because the technology of measuring trace gases currently uses through-flow chemical sampling devices, the sampling procedure itself induces ventilation and mixing of the air sampled. In the top meter or so of snow, this introduces ambient air dilution to the natural firn air composition (Albert et al., 2004). There have been no field experiments reported to date where the firn air gas sample concentrations reported are due purely to diffusion alone. Firn air sampling procedures for $\mathrm{CO}_{2}$, methane, and other climate indicators that are sampled very deep in the firn typically call for withdrawal of discrete samples of gas in order to minimize the disturbance of the natural firn air concentration profile.

\subsection{Transport of species that interact with the snow surface}

Diffusion and advection are not the only processes that affect trace gas transport through porous snow, because molecules hit ice surfaces while travelling through porous snow and those with sufficient affinity with these surfaces may become accommodated on the ice for various lengths of time. This "sticking" will therefore slow down gas transport through snow. The residence time of the molecule on snow crystal surfaces affects the partitioning of molecules between interstitial air and ice surfaces, and this can be characterized by an adsorption equilibrium, either a surface Henry's law 
coefficient, $H$ (in $\mathrm{Pa} \mathrm{m}^{2} \mathrm{~mol}^{-1}$ ) or an interfacial partitioning coefficient $K_{i a}$ (in m) (Roth et al., 2004). Models that couple transport, adsorption and reaction in porous media have been derived from the study of reactions in porous catalysts. Such models are used for example to study transport processes in soil, and have also been applied to analyze reactions and uptake processes of trace gases on porous ice films in laboratory experiments, which lead to some controversy (Hanson and Ravishankara, 1993; Keyser et al., 1993; Keyser et al., 1991; Leu et al., 1997).

What needs to be modeled is simply the fact that the diffusion of trace gases through the snow is hampered by resistance of the porosity and the finite residence time of the trace gases when adsorbed on the ice surface, and this requires the knowledge of the pore size and of SSA. Modeling can be achieved by numerical solution of the one-dimensional diffusion equation, with appropriate terms for the flux matching on the ice surface, as done by Hutterli et al. (1999) who modeled the seasonal transport of formaldehyde in snow by assuming one-dimensional diffusion for the gas phase transport.

A semi-empirical approach was suggested by Herbert et al. (2006), which allows to assess the impact of the adsorption on the diffusion. In a first step, the theoretical diffusion coefficient $D_{\text {theo }}$ in a porous medium was calculated from the tortuosity $\tau$, the snow porosity $\phi$ and the diffusivity in the undisturbed gas phase $D_{\text {air }}$ by $D_{\text {theo }}=D_{\text {air }} \phi \mathrm{v} \tau \mathrm{s}$ in Eq. (8). The additional resistance to the diffusive transport by the adsorption of the molecules is described by an effective diffusion constant $D_{\text {eff }}=f D_{\text {theo }}$ with

$f=\frac{1}{1+r_{s p} K_{i a} S S A}$

Parameters are the specific surface area (SSA), the solid ice to air volume ratio $r_{s p}$ and the gas-solid partitioning coefficient $K_{i a}$ (Roth et al., 2004). Figure 9 plots $f$ as function of $K_{i a}$, illustrating the impact of the value of $K_{i a}$ on diffusion. For $K_{i a}$ smaller than $10^{-4} \mathrm{~m}$ (for example aliphatic hydrocarbons lighter than decane at $\mathrm{T}=-6.8^{\circ} \mathrm{C}$, Roth et al., 2004), there is almost no influence of the adsorption on the diffusion. For more strongly adsorbing species, with $K_{i a}>10^{-3}$ m (e.g. phenanthrene, Domine et al., 2007b), the impact of the adsorption can be critical.

\subsection{Optical properties of snow}

\subsubsection{Light transmission}

The transmission of light in snow plays important roles in atmospheric and snow chemistry as well as climate. The relationship to climate occurs largely through the albedo of snow, which is an important factor in the radiation balance (Grenfell et al., 1994). Recent work also shows that photochemistry in snowpacks plays an important role in the atmospheric chemistry in snow-covered regions (Honrath et al.,

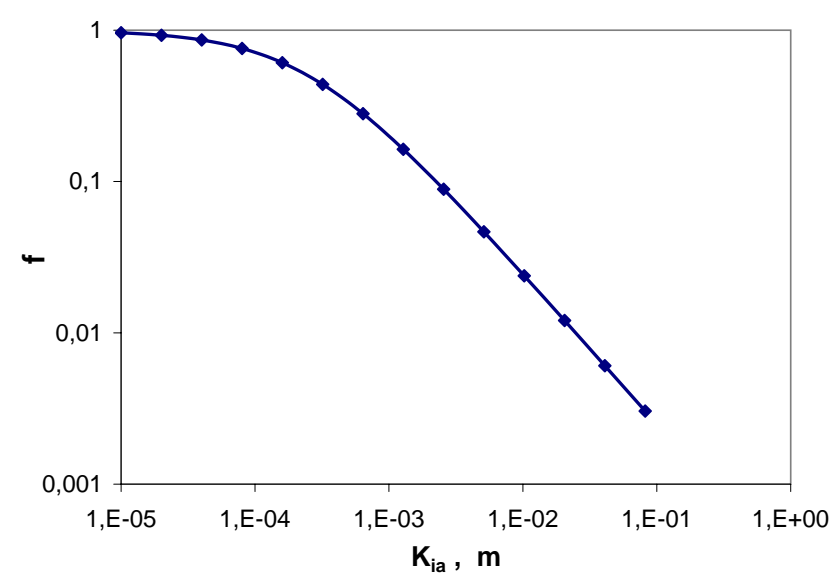

Fig. 9. Impact of the value of $K_{\text {ia }}$ on the trace gas diffusion in snow, calculated after Herbert et al. (2006), for a snow density of $0.34 \mathrm{~g} \mathrm{~cm}^{-3}\left(r_{s p}=0.2 \mathrm{~g} \mathrm{~cm}^{-3}\right)$ and a $S S A$ of $200 \mathrm{~cm}^{2} \mathrm{~g}^{-1}$. The factor $f$ is the ratio of the effective diffusion coefficient of an adsorbing trace gas in snow over the diffusion coefficient in snow in the absence of adsorption.

1999; Sumner and Shepson, 1999; Jones et al., 2000; Beine et al., 2002; Dibb et al., 2002). Light transmission in snow is also an important variable for biological activity in the subnivean environment, e.g. Kappen (1993) and Cockell et al. (2002).

When light interacts with snow grains, there are two important physical processes: scattering and absorption. We can consider the probability of either scattering or absorption per unit length traversed by a photon in the snowpack. We will refer to these scattering and absorption coefficients (rates per length) as $K_{\text {sca }}$ and $K_{\text {abs }}$, and each has units of inverse length, typically $\mathrm{cm}^{-1}$. The sum of scattering plus absorption is the extinction coefficient, $K_{\text {ext }}=K_{\text {sca }}+K_{\text {abs }}$. The ratio of scattering to total extinction, $\omega_{0}=K_{\text {sca }} / K_{\text {ext }}$, is called the single scattering albedo. Typically, for visible wavelengths, the scattering coefficient is much larger than the absorption coefficient, leading to a single scattering albedo very close to unity. This dominance of scattering makes reflection the most probable occurrence for a photon that hits the snow and makes snow white in appearance. The simplest optical models of snow use two-stream radiative transfer theory (Ishimaru, 1978; Bohren and Barkstrom, 1974; Beaglehole et al., 1998; Thomas and Stamnes, 2002) to solve the transmission of light in snow. If simple two-stream theory is used for snow, the scattering and absorption parameters have little physical meaning and are similar to fitting parameters. More advanced treatments take into account the angular asymmetry of light scattering by snow (Wiscombe and Warren, 1980; Warren, 1982). Because snow grains are much larger than the wavelength of light, they typically forward scatter the light. This angular asymmetry can be included into advanced 2- 


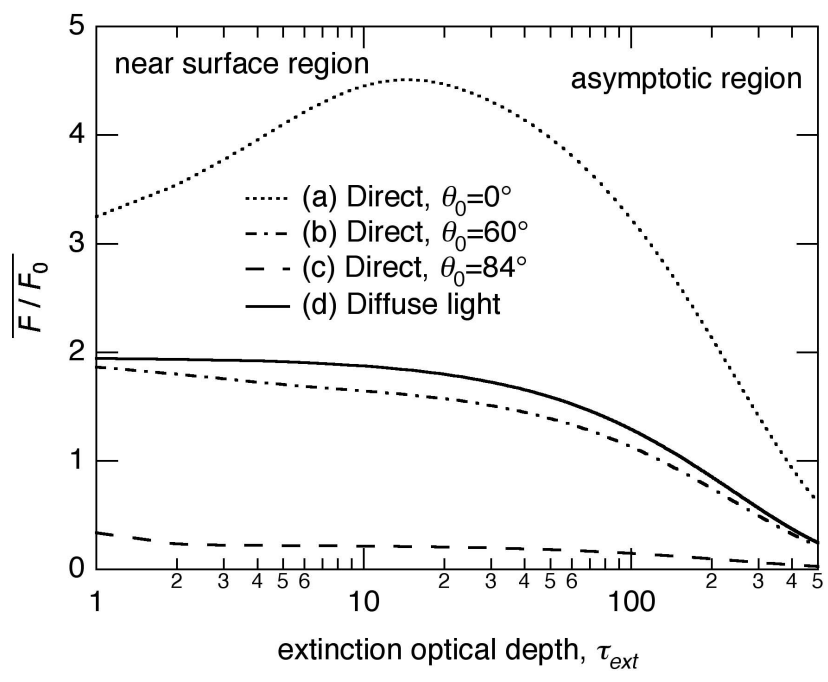

Fig. 10. A simulation of optical transmission in snow (after Simpson et al., 2002a). In this simulation, the ratio of the actinic flux in snow, $F$, to the downwelling incident flux, $F_{0}$, is shown as a function of depth in the snow. The depth in the snow is listed as the optical depth, $\tau_{\text {ext }}$, which is proportional to the physical depth in the snowpack. The relationship to physical depth depends upon the equivalent spherical radius of the snow grains (related to SSA) and density, as described in the text. For this example (aged snow, density $=0.3 \mathrm{~g} \mathrm{~cm}^{-3}$ ), and equivalent spherical grain radius of $\sim 0.5 \mathrm{~mm}$ ), the extinction coefficient is $\sim 1 \mathrm{~mm}^{-1}$, and in this case, the depth would be equivalent to a few millimeters within the snowpack. The asymmetry factor, $g$, is 0.886 . The single scattering albedo of the snow is $\omega_{\mathrm{w}}=0.99995$, indicating that the absorption coefficient is 0.00005 times smaller than the extinction, which is typical of pure snow in the UV. Four cases of incident light are shown. Cases (a)-(c) have purely direct sunlight at three solar zenith angles (a) $\theta_{0}=0^{\circ}$, (b) $\theta_{0}=60^{\circ}$, (c) $\theta_{0}=84^{\circ}$, while case (d) is for purely diffuse incoming radiation. One observes nonexponential behavior in the near surface region, generally with enhancement of photolysis rates in the snowpack $\left(F / F_{0}>1\right.$ indicates light enhancement). Deeper in the snowpack, in the asymptotic region, the light is completely diffused and decays exponentially, with an $e$-folding depth of approximately $20 \mathrm{~cm}$.

stream theory calculations through the asymmetry factor, $g$, defined as the average of cosine of the scattering angle:

$g=\frac{1}{2} \int_{0}^{\pi} x(\theta) \cos \theta \sin \theta d \theta$

where $x(\theta)$ is the phase function describing the angular distribution of the singly scattered light, or more advanced theories, such as the delta-Eddington (Wiscombe, 1977) or the discrete ordinate method, DISORT (Stamnes et al., 1988), which is included in the Tropospheric Ultraviolet and Visible (TUV) model (Lee-Taylor and Madronich, 2002). These more advanced models relate the scattering and absorption coefficients to snow physical properties. Specifically, the scattering coefficient is related to the snow specific surface area, and the absorption coefficient is related to the wavelength-dependent absorption of ice (Perovich and Govoni, 1991; Ackermann et al., 2006; Warren et al., 2006) plus impurity absorption and grain shape. Earlier measurements were likely affected by scattering in the ice samples, and more recent measurements show very low absorption in the blue region. However, surface snow and in particular seasonal snowpacks, is nearly always significantly contaminated by absorbing material that greatly exceeds the inherent absorption of ice.

The relationship between light intensity and depth is complex near the snow surface. This complexity is caused by a combination of upwelling radiation escaping from the snowpack and direct radiation converting to diffuse radiation by scattering near the snow surface. This results in the light intensity being greater in the subsurface than at the surface. Figure 10 shows calculations of the actinic flux in the snow as a function of optical depth, for several solar zenith angles (SZA), using the delta-Eddington method (Wiscombe, 1977). The enhancement of actinic flux near the surface decreases with increasing SZA. For SZA $=84^{\circ}$, surface reflection is so high that little light is transmitted. With the log scale of Fig. 10, the maximum in intensity does not appear for high SZAs, because it is so close to the surface. Below this level in a deep uniform snowpack, the light intensity decreases exponentially (e.g. Bohren and Barkstrom, 1974; Zege et al., 1991). The calculations of Fig. 10 are very similar to those of Lee-Taylor and Madronich (2002) (their Fig. 4b), who used a discrete ordinance model. Below the surface region, the light intensity as a function of depth, $I(z)$ is described by:

$I(z) \propto e^{-\alpha_{0}(\lambda) z}$

where $\alpha_{0}(\lambda)$ is the asymptotic flux extinction coefficient (AFEC). The inverse of $\alpha_{0}$ is the depth over which light intensity decreases by a factor of $e$ and is called the $e$-folding depth, $\varepsilon(\lambda)$,

$\varepsilon(\lambda)=1 / \alpha_{0}(\lambda)$

The transmission of radiation in snow has been measured in several studies (Liljequist, 1956; Grenfell and Maykut, 1977; Kuhn and Siogas, 1978; Beaglehole et al., 1998; King and Simpson, 2001; Perovich, 2007). The general result is that the $e$-folding depth in the visible and near UV is between 5 and $25 \mathrm{~cm}$ for most snowpacks. Larger values around $50 \mathrm{~cm}$ are sometimes found in temperate snowpacks with large grains formed by melt-freeze cycles (Fisher et al., 2005). Even in Antarctica, where the impurity concentration in snow is very low, values in the range 10 to $20 \mathrm{~cm}$ are observed in layers $50 \mathrm{~cm}$ below the surface for wavelengths around $600 \mathrm{~nm}$ (Warren et al., 2006). Below $1 \mathrm{~m}, e$-folding depth values increase, but the interest of this paper is on surface snow. Warren et al. (2006) argue that the short $e$-folding 
depths $50 \mathrm{~cm}$ below the surface are caused by soot deposited after the establishment of the Dome C station. However, we feel that it is not certain that the low soot concentrations ( 1 ppb by weight) can actually explain this. Another possibility, also mentioned by Warren et al. (2006) is that the small snow grains encountered on the Antarctic ice cap enhance light scattering.

The AFEC, $\alpha_{0}$, is directly observable by light transmission measurements and is affected by both light absorption and scattering. In simple two-stream theory, one derives for AFEC:

$\alpha_{0}(\lambda)=\sqrt{K^{2}(\lambda)+2 K(\lambda) S_{\text {sca }}}$

Here $K$ and $S_{\text {sca }}$ are Kubelka-Munk absorption and scattering coefficients, respectively. They are related to $K_{\text {abs }}$ and $K_{\text {sca, }}$, respectively, but as mentioned above, they do not have direct physical meaning due to their disregard of the angular nature of scattering. $K$ and $S_{\text {sca }}$ can be determined from experimental measurements of light and transmission by a snow layer using Kubelka-Munk theory (Kubelka and Munk, 1933; Kubelka, 1948). This formulation shows that both scattering and absorption are important to light transmission. In the limit of low absorption snow, $K$ is small, and the $K^{2}$ term is small compared to the product of $K^{*} S_{\text {sca }}$. Therefore, the dependence of light transmission is on $\sqrt{2 K S_{\text {sca }}}$. The accuracy of the Kubelka-Munk theory as compared to exact radiative transfer calculations was studied by Kokhanovsky (2007). Many authors have generated radiation transfer theories for snow that can predict the AFEC (Bohren and Barkstrom, 1974; Wiscombe and Warren, 1980; Warren 1982; Zege et al., 1991; Lee-Taylor and Madronich, 2002) including consideration of the angular asymmetry of scattering. In particular, Zege et al. (1991) show that :

$\alpha_{0}=\sqrt{3\left(1-\omega_{0}\right)(1-g)} K_{\text {ext }}$

Because snow grains tend to forward scatter radiation ( $g \sim 0.8)$ (Warren 1982; Grenfell and Warren, 1999; Neshyba et al., 2003; Kokhanovsky and Zege, 2004) the AFEC is lower than predicted based by simple two-stream theory that assumes light scattering is equal into the forward and backward hemispheres.

The density scaling of snow optics is somewhat complex because the density affects both the amount of ice absorption and the number of ice-air surfaces encountered by light rays propagating in snow. Therefore, density affects both $K$ and $S_{\text {sca }}$ absorption and scattering terms. It is common to create density-normalized "cross sections" to $K$ and $S_{\text {sca, }}$,

$k_{\text {tot }}(\lambda)=K(\lambda) / \rho$ and $\sigma_{\text {scat }}=S_{\text {sca }} / \rho$

Here, we have explicitly listed the wavelength dependence of the absorption, while the scattering cross section is relatively independent of wavelength. Substituting the cross sections for their analogs in Eq. (22) and in the weak absorption limit gives

$\alpha_{0}(\lambda)=\rho \sqrt{2 k_{\mathrm{tot}}(\lambda) \sigma_{\mathrm{scat}}}$ which is valid as long as $\omega_{0}$ is close to 1 . This applies to pure snow in the visible, but may also apply to snow with some degree of contamination. Most commonly, $k_{\text {tot }}$ can be derived by measurements of impurities in snow and the inherent absorption of ice, which is particularly important in the near IR and mid IR, where water vibrations of the ice lattice are strong absorbers.

Modeling studies have suggested that using measurements of the largest axis of a snow grain to determine the snow scattering results in scattering coefficient values that are too low (Grenfell et al., 1981). Grenfell and Warren (1999), Neshyba et al. (2003) and Grenfell et al. (2005) discuss different methods for representing ice crystals to calculate their scattering and absorption properties in clouds. They recommend the use of independent spheres with the same volume-to-surface area ratio, $V / S$, as a non-spherical ice crystal for calculating optical parameters and conclude that the approximation is good for the range of sizes that were studied. The $V / S$ ratio is related to the specific surface area (SSA) of snow, thus the scattering coefficient of snow should be related to the SSA.

Since by definition the SSA is the surface area per mass, we have:

$S S A=\frac{S}{\rho_{i} V}=\frac{3}{\rho_{i} a_{e f}}$

where $a_{e f}=3 \mathrm{~V} / \mathrm{S}$ is the effective radius that coincides with the radius for monodisperse spheres.

The snow extinction coefficient is given by (Kokhanovsky and Zege, 2004):

$K_{\text {ext }}=\frac{3(1-\phi)}{2 a_{e f}}$

where $\phi$ is the porosity. This means that

$K_{\mathrm{ext}}=\frac{\rho}{2} S S A=\frac{3 \rho}{2 \rho_{\mathrm{ice}} a_{e f}}$

This expression is also valid for the scattering coefficient because $K_{\text {sca }} \approx K_{\text {ext }}$ for snow in the visible.

Therefore, we can see that the scattering coefficient of snow is proportional to the density of the snow divided by the ice density (i.e. to the volumetric concentration of ice in snow) and inversely related to the equivalent-sphere grain radius $a_{e f}$. For aged snow, we typically have $\rho \sim 0.3 \mathrm{~g} \mathrm{~cm}^{-3}$, and $a_{e f} \sim 0.5 \mathrm{~mm}$, so that $K_{\text {ext }} \sim K_{\text {sca }} \sim 1 \mathrm{~mm}^{-1}$. This result implies that light is scattered roughly every millimeter in the snow. The direct solar beam is scattered into diffuse radiation on this length scale, while the diffuse component decays much more slowly (5-25 cm length scale).

The key findings of this section are that radiative transfer in snow is relatively well understood and actinic fluxes in snow can be reliably predicted, as verified by Phillips and Simpson (2005). The asymptotic flux extinction coefficient (AFEC) scales as the square root of the snow scattering and 


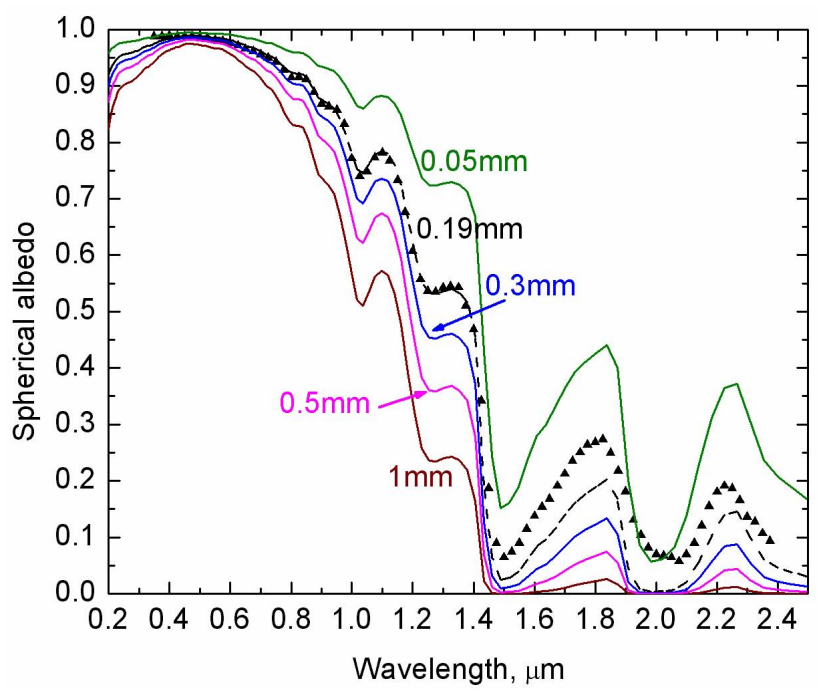

Fig. 11. Calculated spherical albedo of snow with different grain sizes, based on Eqs. (34). The triangles overlapping the curve for the $0.19 \mathrm{~mm}$ grain size are measurements by Hudson et al. (2006), showing the excellent agreement between theory and experiments in the visible and near IR. In the mid IR, the greater absorption limits the validity of the theory.

absorption coefficients. The AFEC can be modeled using an approximation of equivalent spheres that have the same effective diameter as non-spherical snow grains. The scattering coefficient is thus directly related to SSA and inversely related to the equivalent-spherical radius. The equivalent sphere radius of a snow grain is significantly smaller than the "snow grain radius" because it takes into account scattering from small features within the snow grain.

\subsubsection{Light reflection}

The photochemistry of snow requires information on the total amount of light absorbed in the snow at each wavelength. Therefore, it is of advantage to study the spectral absorptance $a$. For a semi-infinite snow layer, the absorptance can be calculated from the reflectance data. Namely, it follows from the energy conservation law in this case:

$a=1-r_{d}$

where $r_{d}$ is the diffuse reflectance under directional illumination (e.g. clear sky). For non-absorbing snow, by definition: $r_{d}=1$ and $a=0$. In reality snow absorbs some amount of solar energy at each wavelength and therefore, $a \neq 0$. The value of $r_{d}$ can then be calculated using the following simple approximation, valid as $\omega_{0} \rightarrow 1$ (Zege et al., 1991; Kokhanovsky, 2006):

$r_{d}(\lambda)=\exp \left(-\rho(\lambda) u\left(\vartheta_{0}\right)\right.$
Here $\vartheta_{0}$ is the solar zenith angle, $\lambda$ is the wavelength, $p=$ $4 \sqrt{\left(1-\omega_{0}\right) / 3\left(1-\omega_{0} g\right)}$ and the function $u\left(\vartheta_{0}\right)$ can be parameterized as discussed by Kokhanovsky and Zege (2004):

$u\left(\vartheta_{0}\right)=3\left(1+2 \cos \vartheta_{0}\right) / 7$

These last three equations indicate that the absorptance of snow, $a$, is larger for a higher sun position $\left(\vartheta_{0} \rightarrow 0\right)$. The physical basis for this effect is that it is more difficult for photons to escape from the snow if they are injected along the normal to the layer because scattering occurs predominantly in the forward direction.

Under diffuse illumination such as complete cloud cover, snow reflectance $r_{s}$ is calculated by integrating the diffuse reflectance $r_{d}$ over all incidence angles (Kokhanovsky, 2006):

$r_{s}=\int_{0}^{\pi / 2} r_{d}\left(\vartheta_{0}\right) \sin 2 \vartheta_{0} d \vartheta_{0}$

The value of $r_{s}$ is called the diffuse reflectance under diffuse illumination conditions or, in short, spherical albedo. It follows in the same approximation (Kokhanovsky and Zege, 2004):

$r_{s}(\lambda)=\exp (-p(\lambda))$

Kokhanovsky (2006) has proposed to use the following relationship between the parameter $p(\lambda)$ and the grain diameter $d_{e f}=2 a_{e f}$ for the case of pure snow:

$p(\lambda)=8 \sqrt{\pi \chi(\lambda) d_{e f} / \lambda}$

Here $\chi(\lambda)$ is the imaginary part of the refractive index of ice, as reported for example in Warren (1984). Then it follows:

$r_{s}(\lambda)=\exp \left(-8 \sqrt{\pi \chi(\lambda) d_{e f} / \lambda}\right)$

This simple equation has been used to calculate the spherical albedo of pure snow for different grain diameter, treating snow as ice spheres (Fig. 11). Similarly, we have for the diffuse reflectance, $r_{d}$, (see Eqs. 28, 29):

$\left.r_{d}(\lambda)=\exp \left(-24 \sqrt{\pi \chi(\lambda) d_{e f} / \lambda}\right)\left(1+2 \cos \vartheta_{0}\right) / 7\right)$

In the presence of absorbing impurities this equation must be modified. In particular, in the case of absorption of light by impurities that show much stronger absorption than ice, the value of $\chi(\lambda)$ in Eqs. (37) and (38) must be substituted by the function proportional to the product of the imaginary part of the refractive index of an absorber $\chi_{a}(\lambda)$ and its volumetric concentration, $c_{s}$, (Kokhanovsky and Zege, 2004):

$\chi(\lambda)=A \chi_{a}(\lambda) c_{s}$

where the value of $A$ depends on the type of impurities. $A$ can be determined using Eqs. (37) and (38) and adequate measurements. It can also be calculated using various theoretical models (Warren and Wiscombe, 1980).

In particular, the following model for the calculation of the parameter $p$ in Eq. (32) can be used. It is supposed in 


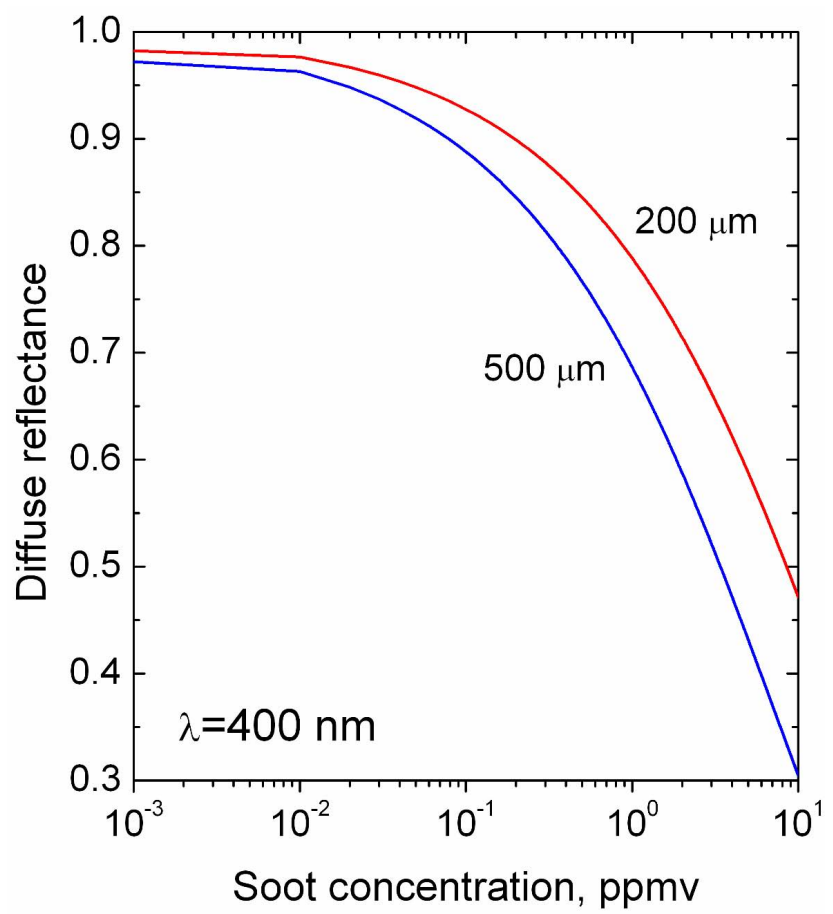

Fig. 12. The dependence of the diffuse reflectance at $400 \mathrm{~nm}$ on the soot concentration (in ppm by volume, i.e. the volume fraction of the snow occupied by soot particles), following Eq. 42. The solar zenith angle is $60^{\circ}$. Snow is composed of non-absorbing grains with the effective grain diameter 200 or $500 \mu \mathrm{m}$, the snow density is $0.275 \mathrm{~g} \mathrm{~cm}^{-3}$ in both cases, the asymmetry factor $g$ is 0.75 . Soot particles are treated as Rayleigh scatterers with the refractive index equal to $1.8-0.5 \mathrm{i}$.

this model that the extinction is only due to scattering of light by snow grains and by absorption caused by impurities (e.g. soot) treated as small Rayleigh scatterers. Then the absorption coefficient is given by (Kokhanovsky, 2004):

$K_{\mathrm{abs}}=N_{s} f(n) \gamma(\lambda) V_{s}$

where $N_{s}=c_{s} / V_{s}$ is the number concentration of absorbing particles, $V_{s}$ is their average volume, $c_{s}$ is their average volumetric concentration, $\gamma(\lambda)=4 \pi \chi_{a}(\lambda) / \lambda, \chi_{a}(\lambda)$ is the imaginary part of the refractive index of absorbing particles and $f(n)=9 n /\left(n^{2}+2\right)^{2}$, where $n$ is the refractive index of absorbing particles. On the other hand, it follows for the extinction coefficient of large snow grains:

$K_{\text {ext }}=\frac{3 c_{g}}{d_{e f}}$

where $c_{g}$ is the volume fraction of snow occupied by snow grains, i.e. $\rho=c_{g} \rho_{\text {ice }}$, and $d_{e f}$ is the diameter of ice spheres with the same SSA as the snow. Therefore, one derives finally:

$1-\omega_{0} \equiv \frac{K_{\mathrm{abs}}}{K_{\mathrm{ext}}}=\frac{f(n) \gamma(\lambda) c_{s} d_{e f}}{3 c_{g}}$

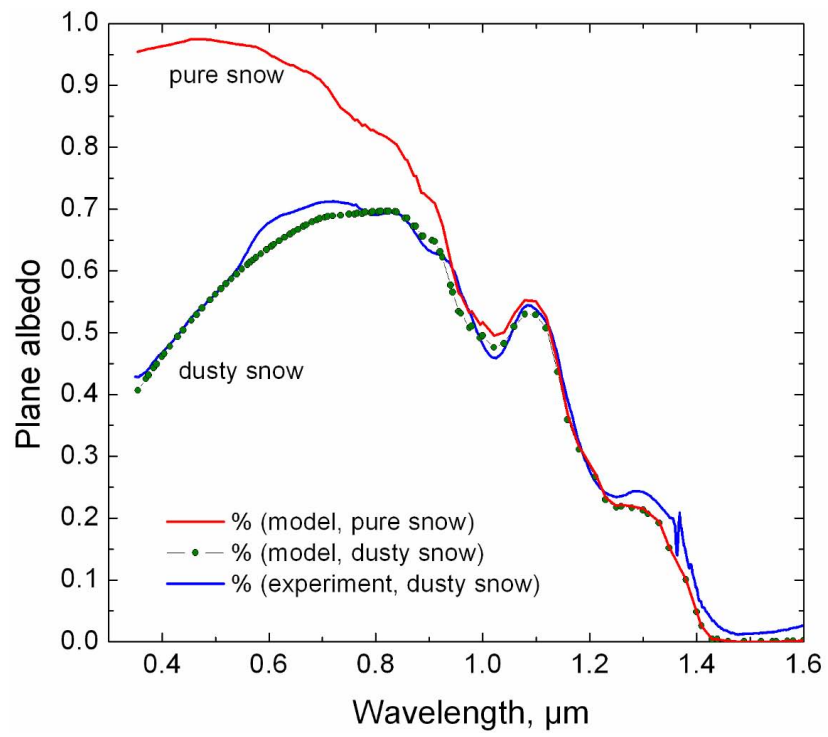

Fig. 13. The plane albedo of snow at the solar zenith angle $\vartheta_{0}=30^{\circ}$. The measurements are from Painter et al. (2007). Calculations use an effective grain diameter $d_{e f}=620 \mu \mathrm{m}$. The measured dust concentration is $0.37 \mathrm{mg} / \mathrm{g}$.

and, therefore,

$p=\frac{4}{3} \sqrt{\frac{f(n) \gamma(\lambda) c_{s} d_{e f}}{c_{g}(1-g)}}$

where we accounted for the fact that $\omega_{0} \rightarrow 1$ in the spectral region under study.

Using this result, one derives:

$r_{s}=\exp \left\{-\frac{4}{3} \sqrt{\frac{f(n) \gamma(\lambda) c_{s} d_{e f}}{c_{g}(1-g)}}\right\}$

and

$r_{d}=\exp \left\{-\frac{4 u\left(\vartheta_{0}\right)}{3} \sqrt{\frac{f(n) \gamma(\lambda) c_{s} d_{e f}}{c_{g}(1-g)}}\right\}$

The dependence of $r_{d}$ on the concentration of impurities $c_{s}$ is presented in Fig. 12, showing that volume fractions of soot as low as $10 \mathrm{ppb}$, as encountered even in fairly pristine Arctic areas (Clarke and Noone, 1985; Warren and Wiscombe, 1985) can have a noticeable impact on albedo. Figure 13, based on recent data by Painter et al. (2007) shows that mineral dust also greatly decreases snow albedo. We were able to reproduce the spectral plane albedo as described by Painter et al. (2007) using the following equation :

$r_{d}=\exp \left[-4 u\left(\vartheta_{0}\right) \sqrt{\gamma_{e f} d_{e f}}\right]$

The effective absorption coefficient of snow was modeled as:

$\gamma_{e f}(\lambda)=\sum_{l=1}^{4} c_{l} \gamma_{l}(\lambda)$ 
where $\gamma_{l}=\frac{4 \pi \chi_{l}}{\lambda}$ and parameters with $l=1,2,3,4$ give the contribution of absorption processes due to ice, liquid water, dust, and soot in snow, respectively. The imaginary part of the refractive index of ice, $\chi_{1}$, was taken from Warren (1984), $\chi_{2}$ for water from Segelstein (1981) and Kou et al. (1993). The dust refractive index was modeled using the following equation:

$\chi_{3}(\lambda)=0.0013+0.036 \exp (-4.9 \lambda)$

where $\lambda$ is in $\mu \mathrm{m}$. The best fit procedure gave the following values of coefficients: $c_{2}=0.34, c_{3}=0.00022$ under the assumption that $\mathrm{c}_{1}=1$ and $\mathrm{c}_{4}=0$. The spectrum could not be fitted well without including liquid water.

\subsubsection{Photochemistry in snow}

Radiation, particularly UV, drives photochemistry both above and inside the snow. The radiation above the snow is enhanced by the high albedo of the snow. Many studies have documented this effect (Madronich, 1987; Meier et al., 1997; Simpson et al., 2002b). Additionally, the radiation in the snow is enhanced. The snowpack enhancement comes from the conversion of direct to diffuse radiation (Madronich, 1987; Simpson et al., 2002a; Lee-Taylor and Madronich, 2002). Laboratory studies have demonstrated that photolysis rate coefficients modeled in snow agree with those measured by chemical actinometry (Phillips and Simpson, 2005). A number of studies have used chemical actinometry in snow to measure photolysis rates directly (Qiu et al., 2002). Laboratory studies have measured quantum yields for important photochemical reactions in the snow; e.g. nitrate photolysis (Honrath et al., 1999; Jones et al., 2000; Beine et al., 2002; Simpson et al., 2002a), and hydrogen peroxide photolysis (Chu and Anastasio, 2005). More details on photochemistry in snow can be found in Grannas et al. (2007).

\section{Physical properties of snow, as determined from re- mote sensing}

\subsection{General remarks}

Modeling the regional or global impact of snowpack photochemistry requires the input of the physical properties of the snowpack averaged over large areas. Obtaining such large scale data from field observations is at best tedious and usually impossible, as in the case of large ice caps and snow on sea ice, and upscaling ground observations to regional scales requires remote sensing. Remote sensing methods are based on measurements performed by optical and microwave instruments onboard satellites, and the combination of data from different spectral ranges offers the best potential to complement field studies, as reviewed by Dozier and Painter (2004). At present, however, the data that can be retrieved from remote sensing is limited in its nature and accuracy. Regarding the nature of the data, properties such as albedo can be retrieved from optical instruments, but there is no conceivable way to access properties such as heat conductivity or permeability. Regarding accuracy, retrieval of properties from satellite signals requires a number hypotheses regarding the shape of grains, the choice of a radiative transfer and atmospheric correction model, the surface roughness, the existence of sub-pixel bare soil or forest and the presence of clouds, all of which are sources of error.

Despite those severe limitations, the need for data over large areas makes remote sensing an invaluable tool for snow studies. It is therefore essential to present here the current state of remote sensing methods, and to stress their current and foreseeable achievements, while mentioning clearly their current limitations and the need for future progress.

\subsection{Optical remote sensing}

In the visible, the reflection function of snow-covered areas observed from satellites is not very sensitive to grain size (Fig. 11) but it is highly sensitive to the fraction of the ground covered by snow and to snow pollution. The low sensitivity to grain size is due to the fact that grain sizes are quite large and their scattering characteristics are hardly influenced by the size of particles outside of the diffraction cone. However, the influence on the shape of particles remains (Grenfell and Warren, 1999; Mischenko et al., 1999; Neshyba et al., 2003; Zege and Kokhanovsky, 2004; Grenfell et al., 2005). A great simplification arises from the fact that snow of sufficient thickness can be considered as a semi-infinite scattering medium in the optical range. In general, for fairly pure snow semi-infinite means about $50 \mathrm{~cm}$ in the visible and $3 \mathrm{~cm}$ in the IR (Zhou et al., 2003). For example, we calculate using methods mentioned in Sect. 2.9 and detailed in Kokhanovsky (2006) that for pure snow with $S S A=200 \mathrm{~cm}^{2} \mathrm{~g}^{-1}\left(d_{e f}=320 \mu \mathrm{m}\right)$, a $17 \mathrm{~cm}$ thick snowpack will have an albedo value within $1 \%$ of a similar semiinfinite snowpack. In the case of snow with impurities, the semi-infinite approximation will be valid for much shallower snowpacks. Adding $100 \mathrm{ppb}$ of soot to the above example will lower the previous value from $17 \mathrm{~cm}$ to $1.4 \mathrm{~cm}$.

Yet another simplification is due to the fact that the standard radiative transfer equation can be used for the interpretation of optical measurements for densely packed snow grains (Bohren and Beschta, 1979; Kokhanovsky and Zege, 2004). This is due to the fact that grains are quite large as compared to the wavelengths in the visible and near IR. Also, they are only weakly absorbing. Therefore, coherent scattering effects are of no importance. This assumption, however, does not hold for microwaves. Grains are then on the order of the wavelength and the dense media theories must be used instead of the standard radiative transfer equation. In particular, the spatial correlation of scatterers and its influences on scattering characteristics must be fully accounted for (Tsang et al., 2000). 
A third complication is that snow properties vary in the vertical direction. Therefore, the retrieval of the grain size using near IR measurements, where the snow reflection function is sensitive to the size of grains, combined with the assumption of a vertically homogeneous layer will give different answers depending on the wavelength used ( $\mathrm{Li}$ et al., 2001; Zhou et al., 2003). Light of smaller wavelengths will penetrate to deeper layers, because generally light absorption by ice grains is smaller for smaller wavelengths. This means that smaller wavelengths bring information not only from the upper snow layer but also from much deeper regions. This is generally not the case for larger wavelengths. Sizes retrieved for different wavelengths can be used to estimate the vertical inhomogeneity of a snow layer (Li et al., 2001). Future methods of snow grain size retrieval must rely on the measurements for a number of wavelengths (e.g., with a high spectral resolution). This will enable the determination of the grain size profile from the corresponding fitting routines.

The retrieval of the grain size is based on the fact that the snow grain single scattering albedo, which can be determined from the reflection function measurements and theoretical model based on the radiative transfer theory (see, e.g., Mishchenko et al., 1999), is highly dependent on the size of particles. Indeed larger sizes imply larger absorption of light by grains, which can be detected from measurements of the reflection function. For the retrieval of the single scattering of albedo, one must assume the phase function of snow. In the past, Mie theory (Mie, 1908) has been used for this purpose (Nolin and Dozier, 1993, 2000). Nowadays, various non-spherical models are used (Mishchenko et al., 1999; Kokhanovsky and Zege, 2004; Xie et al., 2006). We underline that equivalent spherical grain models can perform well in the case of snow albedo measurements. However, satellite instruments measure the reflection function for a given incidence and observation directions. Therefore, they are based on the measurements of the directional properties of a surface, which differ for non-spherical and spherical scattering models (Mishchenko et al., 1999). The application of spherical models leads to the unphysical dependence of the grain size on the illumination or observation geometry.

The grain size retrieved from near IR measurements can be used to estimate the snow reflection function in the visible. In ideal cases, i.e. if the snow layer can be considered semiinfinite and vertically homogeneous, and in the absence of outcropping rocks and vegetation, the difference between the measured reflection function and the corresponding theoretical model can be attributed to pollutants in snow, at least for dry snow. This enables the determination of the concentration of pollutants (Tanikawa et al., 2002) from space-borne instrumentation assuming a type of a pollutant (soot, dust, etc.). This is of importance because dirty snow reduces the albedo of the planet and contributes to warming of the Earthatmosphere system (Hansen and Nazarenko, 2004; Flanner et al., 2007). The reduction of snow albedo due to snow melting must be not misinterpreted as the appearance of an additional light absorber. For instance, Perovich (2007) found that the snow albedo at $400 \mathrm{~nm}$ is reduced from 0.9 to 0.8 just due to snowmelt.

The retrieval of snow grain size and concentration of pollutants relies on the atmospherically corrected radiances. In particular, atmospherically corrected satellite products from the MODerate ResolutIon Spectrometer data (MODIS) (Vermote and Vermeulen, 1999; Hall et al., 2001; Tedesco and Kokhanovsky, 2007) or Global Imager (GLI) (Aoki et al., 2007; Hori et al., 2007; Stamnes et al., 2007) data can be used. The snow cover can be assessed directly from the snow mask algorithm, e.g., as described by Hall et al. (2001) for MODIS. MODIS enables the determination of snow cover with the resolution of $250 \mathrm{~m} \times 250 \mathrm{~m}$ in the visible and near IR, and $500 \times 500 \mathrm{~m}$ in the mid IR. Remotely sensed snow parameters using the visible and near IR can be used in the retrieval of other snow parameters (e.g., the snow depth) from microwave measurements.

The current capabilities of snow retrieval algorithms are demonstrated by works of Bourdelles and Fily (1993); Fily et al. (1997); Aoki et al. (2000); Nolin and Dozier (1993, 2000), and Painter et al. (2003). In particular, Painter et al. (2003) have found a good correlation between the retrieved grain size and that measured on the ground. We stress here that the grain size measured by an orbiting instrument corresponds to the ratio of the volume of a grain to its surface area. This information is not readily available from 2-D image processing in field studies, and SSA measurements would be preferable.

In many cases, however, complications arise because of:

- clouds, which can be difficult to differentiate from snow;

- reflectance reduction by vegetation, soil, and rock;

- snow surface roughness;

- vertical inhomogeneity of pollutants in snow;

- atmospheric corrections including the discrimination of soot in air above snow from soot deposited in snow;

- thin bright snow layers over dirty snow such as surface hoar and diamond dust;

- the difficulty to separate the effects of snowmelt from those of snow impurities on snow albedo.

These difficulties can result in large error in the analysis of optical remote sensing data. These errors can in theory be reduced by multispectral analysis, i.e. by using data from several optical bands, or even better, from hyperspectral analysis, i.e. by using data from an even larger number of bands that will include microwave frequencies. The current state of such complex analysis methods have been nicely detailed by Dozier and Painter (2004). Further up-to-date information on the satellite remote sensing of snow using the broad spectral range from UV to microwaves is given in a recent special issue of Remote Sensing of Environment (Tedesco, 2007). 


\subsection{Microwave remote sensing}

Microwave sensors usually operate at a single or at several frequencies in the range $1 \mathrm{GHz}-100 \mathrm{GHz}$ (or higher for atmospheric sounding). This range corresponds to wavelengths from a few millimeters (a bit larger than snow grains diameter) up to $30 \mathrm{~cm}$ (the depth of an Arctic snowpack or of an Alpine snow layer). Passive microwave sensors (called radiometers) measure the radiation naturally emitted by the surface. Their spatial resolution is coarse, typically a few tens of kilometers. Active sensors illuminate the surface and measure the echo. Active instruments include scatterometers (imagers with resolution of few kilometers), synthetic aperture radars (SAR, imagers with decametric resolution) and altimeters (nadir looking radar).

Microwave remote sensing has the advantages that it observes the surface even in cloudy conditions, that it is weakly sensitive to the water vapor or aerosol thickness (except at some frequency bands) and that it does not rely on solar illumination. These advantages are crucial for applications requiring high temporal resolution such as the daily monitoring of the snow cover, or studies during the polar winter.

Methods to retrieve several snow physical variables using microwave remote sensing have been developed and improved for about 3 decades, initially, methods were developed to derive a single variable from the data. This concerns the following variables:

- The presence of snow on the ground.

- The snow depth and snow water equivalent (SWE) on the ground.

- The net accumulation. This is inherently the same variable as the SWE, but applied to ice caps.

- The presence (and possibly in the future the amount) of liquid water in the snowpack.

In most cases, the accuracy of the retrieval is difficult to assess especially at the continental and global scales but it is often found insufficient for numerous applications. Nevertheless further improvements are still expected since more sophisticated algorithms are being written to retrieve simultaneously several interdependent variables, that include the former ones as well as:

- The snowpack temperature profile.

- The grain size.

- The layering of the snowpack.

- The surface roughness.

Before addressing the specific retrieval methods of each variable, we briefly recall in the next section the bases of the interactions between microwaves and snow. We also review the forward models developed to predict microwave observations from snow characteristics.
3.3.1 Background: interactions between microwaves and snow

Interactions between snow and microwaves differ from those with visible/infrared radiation by two main features:

- Microwaves penetrate deeper through dry snow. The $e$-folding depth depends on the absorption within the ice, scattering by the snow grains, and on reflection at the boundaries between snow layers. Absorption mainly increases with density and scattering increases with grain size and frequency. The typical one-way $e$-folding depth is as large as hundreds of meters at $1 \mathrm{GHz}$ (e.g. frequency of the SMOS radiometer and ALOS radar), about $10 \mathrm{~m}$ at $5 \mathrm{GHz}$ (e.g. ENVISAT ASAR radar and ERS altimeter), 2 or $3 \mathrm{~m}$ at $19 \mathrm{GHz}$ (e.g. $\mathrm{SSM} / \mathrm{I}$ radiometer), $0.5 \mathrm{~m}$ at $37 \mathrm{GHz}(\mathrm{SSM} / \mathrm{I})$.

- The presence of liquid water in the snow radically increases the absorption of microwaves and as a consequence greatly reduces the $e$-folding depth (to $1 \mathrm{~cm}$ at $19 \mathrm{GHz}$ ). Even a few percent of liquid water content efficiently absorbs microwaves. In practice, this difference between wet and dry snow implies that 1) differentiating wet from dry snow is easy, but 2) variableretrieval algorithms work for dry snow only. Microwave measurements, therefore, can be used to screen snowmelt cases for snow optical remote sensing algorithms. This can be done, e.g., using synergy of microwave and optical sensors on European Space Agency Environmental Satellite (ENVISAT) (http://envisat.esa. int/).

\subsubsection{Passive measurements}

Radiometers measure the thermal emission of the Earth expressed by the brightness temperature. The brightness temperature $T_{b}$ of an opaque medium such as soil or rock is given by:

$T_{b}=\varepsilon_{m w} \times T_{s}$

where $\varepsilon_{m w}$ is the emissivity and $T_{s}$ the surface temperature.

For a transparent medium such as the snowpack, the relationship is more complex, as emission reaching the surface originates from a depth related to the $e$-folding depth. Soil covered by snow can therefore contribute to the emission. Usually, radiometers acquire $T_{b}$ at several frequencies (e.g. 19, 22, 37 and $85 \mathrm{GHz}$ for SSM/I) and two polarisations: vertical and horizontal. For a rigorous calculation of $T_{b}$, radiative transfer equations need to be solved in the snowpack and at some frequencies in the atmosphere (e.g. $22 \mathrm{GHz}$ is highly sensitive to water vapor, $37 \mathrm{GHz}$ and higher are sensitive to intense liquid precipitation). Earlier snow radiative transfer models were based on the strong fluctuation theory (Stogryn 1986, Surdyk and Fily, 1993 and 1994). The HUT (Helsinki University of Technology) snow emission model 
is semi-empirical (Pulliainen et al., 1999). It treats homogeneous snowpacks and includes vegetation effects, which are especially important in boreal regions. MEMLS (Microwave Emission Model of Layered Snowpacks, Wiesmann and Mätzler, 1999) or the model based on Dense Media Radiative Transfer (Macelloni et al., 2001) are more complex, accounting for a multi-layered snowpack and for reflections, interference effects, etc.

\subsubsection{Active measurements}

Active sensors measure the energy emitted by an antenna and scattered in the backward direction expressed by the backscattering coefficient $\sigma_{0}$. The coefficient $\sigma_{0}$ is sensitive to the scattering properties of the snowpack while thermal emission is negligible. Modeling the backscattering coefficient knowing the snow properties is also based on the radiative transfer theory (Zurk et al., 1996; Wen et al., 1990; Bingham and Drinkwater, 2000) and share common issues with modeling in passive mode.

\subsubsection{Application 1: Continental snow cover extent}

The most advanced application of microwave remote sensing on continental surfaces is probably the large scale determination of the areal extent of the snow cover (Grody and Basist, 1996; Mialon et al., 2005). The detection is based on the fact that snow attenuates the waves coming from the soil. In passive mode, the soil has a higher $T_{b}$ than dry snow because it is both warmer and has an higher emissivity. As snow depth increases, the soil upwelling waves are attenuated and the brightness temperature decreases. The decreased amplitude depends on the snow scattering properties and this is usually enhanced at higher frequencies (except in special cases: Rosenfeld and Grody, 2000). This specific spectral signature is used to discriminate snow from soil. In active mode, the soil acts as an opaque rough surface that backscatters efficiently the incoming wave. Soil backscattering coefficients are about one order of magnitude higher than those of dry snow. The snow layer attenuates the backscattered energy, thus decreasing the backscattering coefficient of bare soil.

The monitoring of snow areal extent using microwaves is possible daily even during polar winter because it does not require sun illumination (Groody et al., 1991), and is insensitive to cloud cover. However, thin snow covers are undetected by microwave because of their larger penetration depth than in the visible/infrared, especially at the lowest frequencies (Armstrong and Brodzik, 2001). The combination of both microwave and visible/infrared observations offers the best potential (Romanov et al., 2000) but requires accurate cloud detection and daylight.
3.3.5 Application 2: Snow Depth and Snow Water Equivalent

A lot of effort has been devoted to retrieve Snow Depth (SD) and Snow Water Equivalent (SWE: the height of water that would be obtained by melting a column of snow), for instance for hydrological applications (Grippa et al., 2005). SD and SWE retrieval is based on the same principle as the snow areal extent, but the idea is here to quantify the absorption due to the snow covering the soil. Most studies use passive microwave techniques as in the early work of Chang et al. (1987). The uncertainties in the method are mainly caused by the variations of attenuation due to grain size and density that change both spatially and through the season due to metamorphism. Other effects such as the presence of forest or wet snow further complicate the interpretation. Many methods have been developed to deal directly or indirectly with metamorphism including empirical methods (Josberger and Mognard, 2002; Grippa et al., 2004), statistical methods (Davis et al. 1993; Tedesco et al. 2003; Chang and Rango, 2000) and physical model-based methods (Pulliainen et al., 1999; Pulliainen, 2006; Wilson et al., 1999; Guo et al., 2003). Figure 14 shows the snow depth retrieved in Siberia with metamorphism accounted for using an empirical approach (Grippa et al., 2004).

Even under favorable conditions, such as over grassland, these methods are still insufficient for most applications but improvements can be expected as more prior information and physical constraints will be added in the retrieval process (see Sect. 3.3.8).

Methods using SAR (high resolution radar) have also been proposed (Bernier et al., 1999) to get much finer resolution ( $\sim 100 \mathrm{~m}$ versus $25 \mathrm{~km}$ with passive microwave) at the expense of temporal resolution (monthly versus daily). Retrieval of SWE using both the ERS altimeter and passive measurements were also investigated (Papa et al., 2002).

\subsubsection{Application 3: Net accumulation}

On ice sheets (Antarctica, Greenland), annual net accumulation is a key-variable of the mass balance and measures the amount of snow (in water equivalent height) left each year. A dedicated method was developed for Greenland (Winebrenner et al., 2001) and Antarctica (Arthern et al., 2006) using passive microwaves at low frequency $(6 \mathrm{GHz})$.

Snow is usually a stratified medium where the dielectric constant varies due to vertical variations in density. These variations are seen as interfaces by microwaves and at each interface, wave reflection and transmission occur. The interesting point is that vertically $(\mathrm{V})$ polarized waves are more transmitted than horizontally $(\mathrm{H})$ polarised waves, especially near the Brewster angle (about $50^{\circ}$ ). In passive mode, the $\mathrm{V}$ polarized waves emitted by the lowest layers are more transmitted than the $\mathrm{H}$ polarized ones and escape more easily from the medium. As a consequence, the difference between $\mathrm{H}$ 

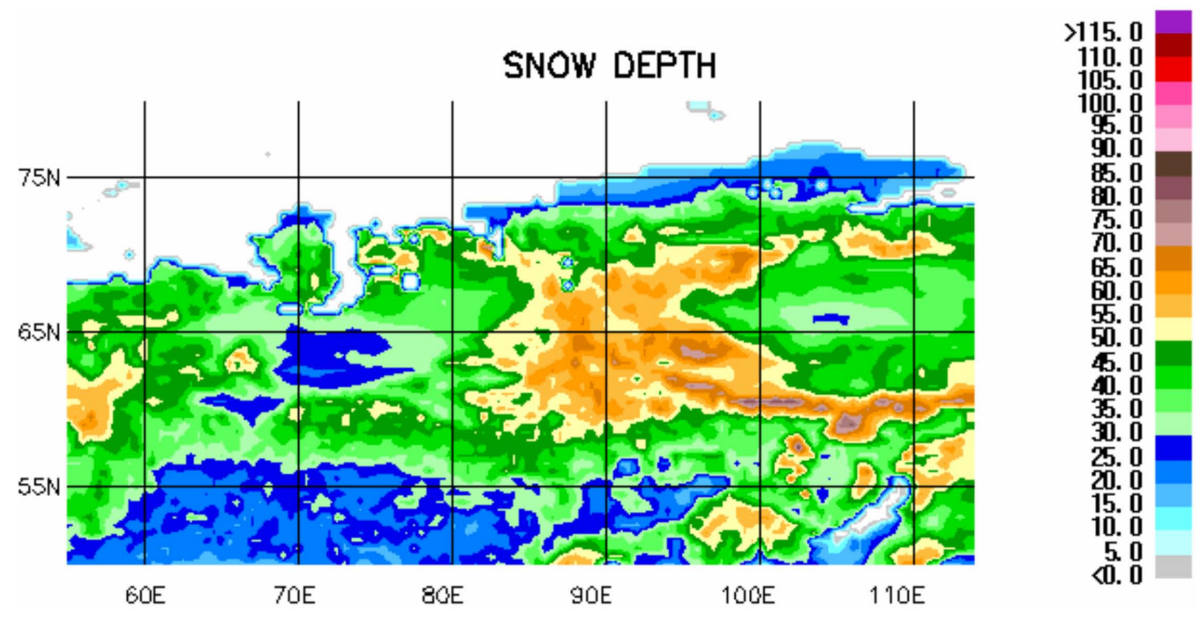

Fig. 14. Mean February Snow Depth (1989-2001) in Siberia retrieved using passive microwave data (Grippa et al., 2004). The algorithm uses the difference between the brightness temperatures at 19 and $37 \mathrm{GHz}$. It accounts empirically for the increase in snow grain size during the season.

and $\mathrm{V}$ polarized brightness temperatures is roughly proportional to the number of layers within the penetration depth. Furthermore, using the observed inverse correlation between the accumulation rate and the number of layers in a given snow depth (Shuman et al., 2001) allows an estimation of the snow accumulation rate. The validation of the method is still needed.

In active mode, a different method to derive accumulation based on the difference between backscattering coefficients at various incidence angles was developed for Greenland (Drinkwater et al., 2001; Forster et al., 1999).

\subsubsection{Application 4: Melting/refreezing and liquid water content}

The presence of liquid water is easy to detect as it significantly increases the absorption. In passive mode, as absorptivity equals emissivity (Kirchhoff's law), emissivity and in turn brightness temperature increase from dry to wet snow. In active mode, the increased absorption decreases the backscattering coefficient coming from the soil. Various techniques were developed for both passive and active, for Greenland (Albdalati and Steffen, 1997 and 2001; Wiesmann, 2000), Antarctica (Torinesi et al., 2003; Picard and Fily, 2006; Liu et al., 2006) and boreal regions (Kimball et al., 2004). These methods have been successful to detect the presence/absence of water and the next step in the future may be to derive quantitatively the liquid water content.

\subsubsection{Application 5: Other variables: density, grain size and temperature}

While it has been known for a long time that microwaves were sensitive to snow variables such as density, grain size and temperature (e.g. Ulaby et al., 1981; Mätzler, 1994; Sherjal and Fily, 1994; Surdyk 2002), retrieving these variables is difficult even with a moderate accuracy. It is now clear that it is not possible to retrieve these variables individually, i.e. by stand-alone algorithms. The simultaneous retrieval of many snow variables based on complex physical models and inversion techniques seems the most promising route. Earlier works on this route use neural network (NN) trained by an electromagnetic emission model (Tsang et al., 1992; Davis et al., 1993). Recently, various inversion techniques were used instead of the NN (Pulliainen et al., 2006; Flach et al., 2005; Guo et al., 2003; Wilson et al., 1999). In any case, the idea is the same: add physical information provided by forward models to constrain as much as possible the inversion. Future developments will likely make use of forward radiative transfer models at multiple wavelengths from UV to microwaves coupled with models of the physical evolution of the snowpack.

\section{Developing snow photochemistry models from snow physics models}

\subsection{General considerations}

Mathematical and numerical models are useful for testing hypotheses about snow-air interactions, the impact of snow photochemistry on atmospheric chemistry, and postdepositional changes of snow properties and chemistry. The choice of conceptual approach, model development, and use of models depends strongly on the desired application. There are over a hundred different snow models, and their detailed description is beyond the scope of this paper. Here we discuss some of the existing models that simulate aspects of the physics relevant to air-snow exchange for the study of atmospheric chemistry. Similarly, there are hundreds of atmospheric chemistry models that simulate heat, momentum, and chemical exchange within the atmosphere, and it 
is beyond the scope of this chapter to describe all of them, since none of them currently address processes in the underlying snow. Below, we describe classes of existing models and stress where aspects of those models may be useful to the current topic.

The dimensionality of any model constrains the processes that it can explicitly address. Zero-dimensional models cannot include effects of physical processes or movement, and are not used in physical modelling, however "box" models are used in atmospheric chemistry where they perform an accounting of the species for what is put into and taken out of the box. This is useful for problems involving complicated stoichiometry. One-dimensional (1-D) models are needed for gradient-driven processes, such as diffusion, when the driving gradients act along a straight line. One-dimensional models are reasonable choices in snowmelt hydrology and in boundary layer atmospheric chemistry when the energy driving the exchange is primarily in the vertical direction, and in cases where movement in other directions can be ignored. Because situations involving flow and advection are rarely unidirectional, parameterizations of multidimensional phenomena must be developed if they are to be simulated in 1-D models. The use of eddy diffusivities is an example of a parameterization of a multidimensional situation for use in 1-D modeling. Multidimensional models are used when any geometry other than a straight line is important in the problem, and usually involve problems of convective flow and transport, although they are used in cases of diffusion when the geometry of the problem requires it. Examples where multidimensional models are needed include wind-driven interstitial air flow and transport over and through rough surfaces, investigations of flow and transport around sampling equipment, etc.

\subsection{Snow physics models}

A number of 1-D models exist for snow that are driven by a surface energy balance boundary condition and use data input for changing meteorological conditions to drive simulations of snow accumulation, densification, and melt. The domain of these models extends from the snow surface down to the ground or underlying strata. Examples of such models include SNTHERM (Jordan, 1991), CROCUS (Brun et al., 1992) and SNOWPACK (Lehning et al., 1999). The governing equation is 1-D heat conduction, snow is assumed to be a continuum, and parameterizations for effects of grain growth and changing snow properties over time are included. Models of this type are most often used for forecasting snow conditions for hydrological applications (e.g. Mote et al., 2003), solving heat transfer problems (e.g. Jordan and Andreas, 1999), and for use in modelling snow parameter evolution (e.g. Lefebre et al., 2003; Zappa et al., 2004).

Multidimensional snow physics models have been developed to study issues of flow and transport in snow. Like the models described above, their domain usually extends from the snow surface down to the ground or underlying strata, and they sometimes also have an upper boundary condition involving a surface energy balance using meteorological data to drive time-varying simulations. The governing equations involve a coupled set of partial differential equations, one that solves for the flow field using boundary conditions of pressure or prescribed flow, along with a partial differential equation describing advective-diffusive transport of a scalar (temperature or chemical species) with the flow. Examples of models in this category include the ventilation models of Albert (1996), Albert and Shultz (2002), and Neumann and Waddington (2004). Modelling has shown that layering is a first-order effect in transport in the snow and that buried high-permeability layers can act as conduits for faster flowing air (Albert, 1999), that ventilation impacts the sublimation of snow (Albert, 2004) and the isotopic content of snow (Neumann and Waddington, 2004), and that sampling of firn air needs to account for surface air filtration to the subsurface for sampling chemistry in firn air (Albert et al., 2002). The snow properties that are required input for the snow physics models above include snow density, permeability, and thermal conductivity.

Since atmospheric input data cannot be obtained with the necessary resolution to make two- or three dimensional simulations of the snow in a real domain, the higher dimensional models have only been used for idealized process studies. Any real domain simulation of the snow cover will be with distributed 1-D models (Lehning et al., 2006) for any foreseeable future. The most advanced process representation has been achieved with physical models used for avalanche warning. The models SNOWPACK (Lehning et al., 1999) and CROCUS (Brun et al., 1991) have a full set of metamorphism parameters, which help describe not only the energy and mass balance in snow but also the development of snow types, storing the full metamorphic history of deposited snow and linking the bulk properties conductivity and viscosity to snow microstructure (Lehning et al., 2002a). Lehning et al. (2002b) also show that the effect of snow ventilation can be included in a one-dimensional model using a parameterization of the thermal conductivity and diffusivity, although recent wind tunnel measurements show that this effect may have been overestimated previously.

\subsection{Current approaches to model snow photochemistry}

Models for investigating snow chemistry to date have each concentrated on one chemical species or one class of species, and have parameterized the creation and decay of that species in the code. Thus they have not included details of heterogeneous chemistry or photochemical processes. Models of this type include one-dimensional investigations of hydrogen peroxide in snow by McConnell et al. (1998) and formaldehyde in snow by Hutterli et al. (1999). The models of McConnell and Hutterli incorporate the 1-D snow physics model SNTHERM (Jordan, 1999) to calculate the 
snow temperature under varying meteorological conditions, but also include separate modules to calculate the diffusion of chemical species. Ventilation was accommodated in the McConnell model by increasing the gas diffusivity parameter. None of the 1-D models explicitly calculate the flow field, which is a multidimensional phenomenon. Two-dimensional models that calculate both the flow field and transport of chemical species have been used to investigate ozone destruction (Albert et al., 2002) and isotopic evolution in snow (Neumann and Waddington, 2004), both with parameterization of the chemical source/sink.

The aspects that these models need to describe include the transport of scalars such as heat, mass or chemical species. Such transports can be described by the governing transport equations for non-reactive gases, or reactive gases for which the reactions have been parameterized. For example, gas transport through snow is described by the following equation in one dimension, which allows for the parameterization of chemical reactions:

$\phi_{a} \frac{\partial C_{a}}{\partial t}+\phi_{a} v \frac{\partial C_{a}}{\partial x}=\phi_{a} \frac{\partial}{\partial x}\left[D_{a} \frac{\partial C_{a}}{\partial x}\right]+S_{c}$

where $C_{a}$ is the concentration of the species in the air space, $t$ is time, $x$ is spatial location, $v$ is the interstitial air flow velocity (usually taken to be Darcy flow through snow), $D_{a}$ is the diffusivity of the gas in snow, $\phi_{a}$ is the porosity, and $S_{c}$ is the source term. If there is no air flow through the snow, then $v=0$, the velocity term on the left hand side of Eq. (47) drops out, and the interstitial transport in that case is by simple gas diffusion. The source term, $S_{c}$, may take on various forms depending on the type of chemistry modeling being used to estimate reversible transfer between the ice crystals and the interstitial air. Firn air chemistry models published to date can be considered parameterized models, in that they use parameterizations to relate gas concentrations in the ice to those in the firn air, rather than tackle the detailed stoichiometry involved in the reactions. A typical parameterized model estimates the chemical exchange between the ice crystal and the firn air as :

$-S_{c}=\theta_{i} k_{b}\left(C_{a} K_{D}-C_{i}\right)$

where $k_{b}$ is a mass transfer coefficient, $K_{D}$ is the ice-air equilibrium partition coefficient (both of which are temperature dependent), $\theta_{i}$ is the ice fraction, $C_{a}$ is the concentration in air and $C_{i}$ is the concentration in ice. Models of this type include those of McConnell et al. (1998) and Hutterli et al. (1999).

The interstitial air flow velocity is given by Darcy's law (Eq. 6) and depends on the viscosity of air, on the snow permeability, and on the spatial pressure gradient. The analogous equations for heat transfer are given by Albert and McGilvary (1992). The transport of water vapor through the snow is described by:

$\frac{\partial \rho_{v}}{\partial t}+v \frac{\partial \rho_{v}}{\partial x}=\frac{\partial}{\partial x}\left[D_{s} \frac{\partial \rho_{v}}{\partial x}\right]+S_{v}$ where $\rho_{v}$ is water vapor density, $v$ is the interstitial air flow (ventilation) velocity, $D_{s}$ is the diffusion coefficient for vapor flow in snow, and $S_{v}$ is the source of water vapor due to phase change, where

$S_{v}=h_{m} S S A\left(\rho_{v, \text { sat }}-\rho_{v}\right)$

where $h_{m}$ is the mass transfer coefficient, SSA is the specific surface area of the snow, and $\rho_{v \text {, sat }}$ is the saturated vapor density (Albert and McGilvary, 1992). Experimental determination of the mass transfer coefficient in snow is given in Neumann et al. $\left(2008^{2}\right)$.

Albert and McGilvary (1992) demonstrated that the heat transfer associated with vapor transport is significant in the determination of the overall temperature profile of a ventilated snow sample, but that the major temperature effects are controlled by the balance between the heat carried by the dry air flow through the snow and heat conduction due to the temperatures imposed at the boundaries. For high porosity snows such as fresh snow or depth hoar, the thermal conductivity is sufficiently low that air flow through snow can cause advection-controlled temperature profiles. This was demonstrated in a field experiment (Albert and Hardy, 1995) where the immediate temperature effects from ventilation appeared when flow was induced in natural seasonal snow. For lower porosity, higher conductivity snow, such as windpacked snow or firn, the thermal conductivity is sufficiently high that the temperature profile will be dominated by the heat conduction profile, even though there may be significant air flow through the snow (Albert and McGilvary, 1992).

Some simpler approaches have attempted to model snow chemistry without describing transport. In particular, persistent organic pollutants have a simple behavior in snow, because they are unreactive and are thought to undergo only adsorption/desorption processes, and box models have been used to describe their exchanges between the atmosphere and the snow (Daly and Wania, 2004). However, these models are not able to treat detailed snow processes and the numerical solution of a joint atmosphere-snow model with a detailed representation of snow models has not yet been achieved.

Next-generation snow photochemistry models will need to improve upon the 1-D modeling above by including variables that are crucial to quantify chemistry, such as specific surface area (SSA) and light fluxes in the snow, and a more sophisticated description of the actual photochemical processes taking place in the snow. Coupling with 1-D modeling of atmospheric chemistry will be required to permit investigations of the complicated phenomena across the atmosphere-snow interface.

Regarding SSA, this variable can change rapidly during metamorphism (Cabanes et al., 2003; Legagneux et al., 2004; Taillandier et al., 2007) and these changes must be described.

\footnotetext{
${ }^{2}$ Neumann, T. A., Albert, M. R., Engel, C., Courville, Z. R., and Perron, F. E.: Sublimation rate and the mass-transfer coefficient for snow sublimation, in review, Int. J. Heat. Mass. Tran., 2008.
} 


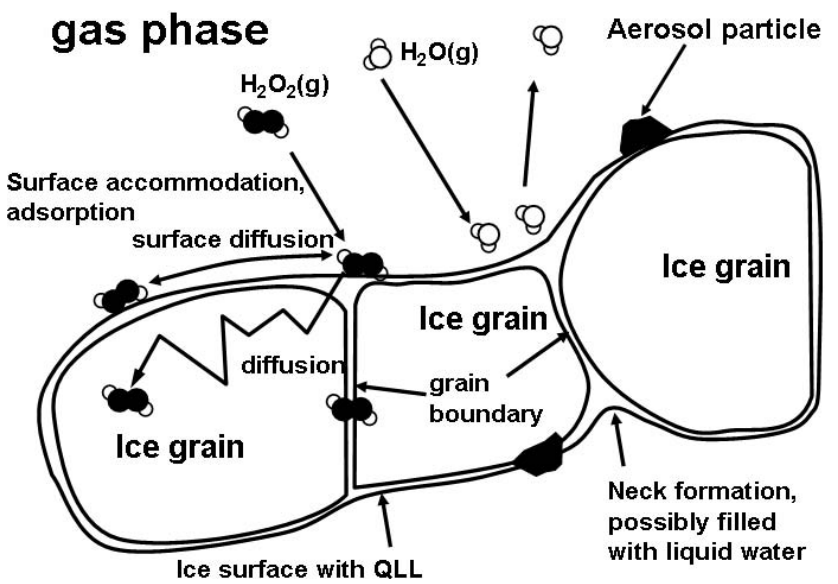

Fig. 15. Possible locations of reactive species in snow, using the example of $\mathrm{H}_{2} \mathrm{O}_{2} \cdot \mathrm{H}_{2} \mathrm{O}_{2}$ can be located in the gas phase, adsorbed on the surface of snow grains, or dissolved within snow grains or at the boundary between grains, and move between these compartments. Other species can also be contained in aerosol particles trapped in the snow.

Since models such as SNOWPACK and CROCUS provide a detailed description of known snow metamorphism, it is possible that they can also be used to parameterize snow SSA. Likewise, SNTHERM describes crystal size distribution and might be used to predict SSA. Domine et al. (2007) propose to determine SSA from density using empirical correlations, and show that also taking into account the snow crystal type, which is predicted by these models, leads to good predictions. Alternatively, it may be possible to use Eqs. (14) and (15) detailed in Sect. 2.3 to predict SSA from the age and metamorphic history of the snow. The model of Flanner and Zender (2006) may also be used, although it would increase computing time. A thorough assessment of the error on the rate of SSA decreases induced by approximating crystals by spheres is also in order. Regarding the light flux in snow, models such as SNOWPACK and CROCUS also have versions that calculate the shortwave radiation flux in wavelength bands for each snow layer (MeiroldMautner and Lehning, 2004), and this may represent a first step towards predicting light fluxes in snow photochemistry models. However, as detailed in Sect. 2e, the attenuation of $\mathrm{UV}$ and visible light in snow is mostly due to absorption by impurities. Since these absorbers mostly come from the atmosphere, an atmosphere-snow coupled model will probably be required to predict depth-resolved light fluxes in snow.

But the greatest difficulty in writing an integrated snow photochemistry model is doubtless the description of the photochemistry itself. Our current limitations in our understanding of this field are detailed in Grannas et al. (2007). In the next section, we briefly develop those aspects most related to snow physics.

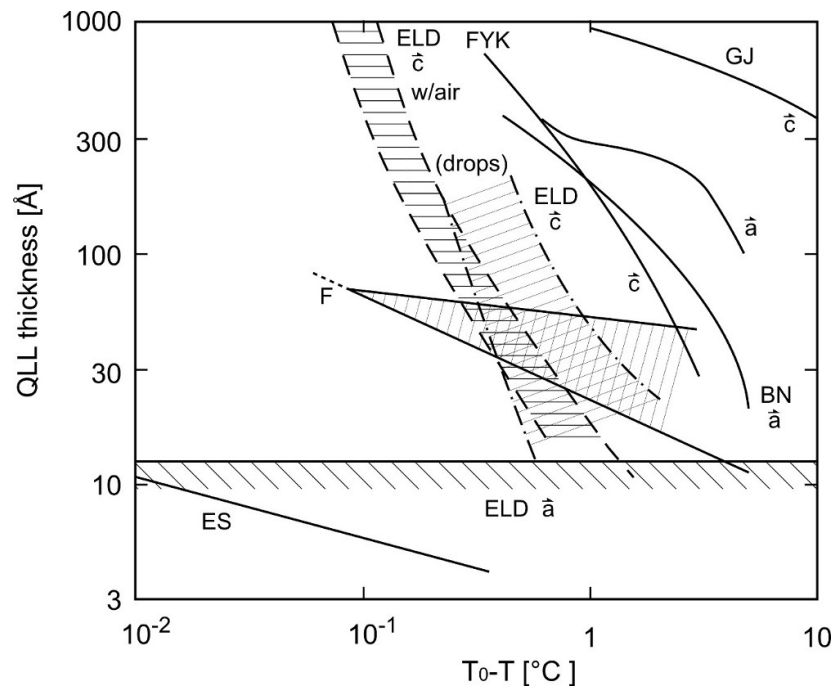

Fig. 16. Measurements and calculations of the thickness of the surface premelt layer as given by various authors using several methods: ellipsometry, ELD (Elbaum et al., 1993), FYK (Furukawa et al., 1987) and BN, (Beaglehole and Nason, 1980); proton channeling, GJ (Golecki and Jaccard, 1978); theoretical predictions, F (Fletcher, 1962, 1968) and ES (Elbaum and Schick, 1991). $c$ : basal surfaces; $\boldsymbol{a}$ : prismatic surfaces (Adapted with permission from Ebaum et al., 1993. Copyright 1993 Elsevier).

4.4 The challenge of describing actual snow photochemistry in snow physics models

Snow forms a complex multiphase photocatalytic reactor under the influence of the solar radiation (e.g. Domine and Shepson, 2002) where reactive species can be located in the interstitial air, in aerosol particles trapped in the snow, within ice crystals, at the ice-air interface, or in the disordered surface layer of ice crystals (Fig. 15). A full snow photochemistry model has to consider chemical reactions in these different compartments, although the properties of some of these compartments are poorly characterized. In particular, the surface layer of ice crystals has stirred much interest, interrogations, and controversy (Baker and Nelson, 1996; Baker and Dash, 1996; Chen and Crutzen, 1994, 1996; Knight, 1996a, b). Various experimental studies using ellipsometry (Beaglehole and Nason, 1980; Elbaum et al., 1993; Furukawa et al., 1987b), atomic force microscopy (Döppenschmidt and Butt, 2000), or X-Ray diffraction (Dosch, 1992; Dosch et al., 1995; Lied et al., 1994) have provided clear evidence that a special disordered surface layer exists on ice with a thickness of a few tens of nanometers down to temperatures of $10-20^{\circ} \mathrm{C}$ below the ice melting point (e.g. Dash et al., 1995; 2006). This layer is often called the quasi-liquid layer (QLL) because it has some liquid-like properties. For example, the refractive index (Furukawa et al., 1987a, b) and the diffusion constant (Mizuno and Hanafusa, 1987) are intermediate between those of water and ice. Moreover, further observed 
effects such as the degree of disorder and layer thickness increase with rising temperature (Fig. 16), which is consistent with theoretical predictions based on molecular dynamics calculations (e.g. Girardet and Toubin, 2001), wetting theory (Dash et al., 2006; Petrenko and Whitworth, 1999), or multimolecular adsorption (Henson, 2005).

Recently Kahan and Donaldson (2007) have used molecules and chemical processes to probe the very surface of the QLL. By comparing fluorescence spectra and photolysis rates of polycyclic aromatic hydrocarbons adsorbed on ice and water surfaces, they concluded that the surface of the QLL is different from that of water. This conclusion was later confirmed by a Raman spectroscopic study of the surfaces of ice and water, which showed different degrees of hydrogen bonding between the water molecules at the surface of ice and water (Kahan et al., 2007).

Physical and chemical methods therefore indicate that both the QLL and its very surface are different from liquid water. The QLL therefore is not simply a layer of supercooled water on top of the ice surface, which would freeze readily in contact with ice. It rather exists because it lowers the ice-air interfacial energy. Moreover, the presence of impurities on the ice surface increases surface disorder as suggested from theoretical considerations (Beaglehole, 1991; Wettlaufer, 1999). Indeed, experimental evidence exists that the presence of $\mathrm{HCl}$ induces some disorder on the ice surface down to a temperature of $200 \mathrm{~K}$ (McNeill et al., 2006) and that a disordered phase forms in frozen brine solutions (Cho et al., 2002).

Due to its liquid-like properties, it is tempting to use liquid phase reaction rate coefficients to model QLL chemistry. Laboratory studies concerning photochemical reactions in snow and ice have been analyzed using established liquid phase reaction pathways. For example, liquid phase mechanisms were applied to the photolysis of nitrate in ice and snow (Honrath et al., 2000; Dubowski et al., 2001; Chu and Anastasio, 2003; Cotter et al., 2003; Boxe et al., 2005, 2006; Jacobi et al., 2006). The approach has been justified a posteriori by the good agreement of the experimental results with the description using the liquid phase mechanism. Moreover, Chu and Anastasio $(2003,2005)$ demonstrated that the temperature-dependent quantum yields of the nitrate and hydrogen peroxide photolysis in ice agree well with quantum yields obtained in liquid solutions and extrapolated to subzero temperatures. More recently, Jacobi and Hilker (2007) proposed a simplified reaction mechanism including reaction rates for the photolysis of $\mathrm{NO}_{3}^{-}$in natural snow based on the assumptions described above. After adjusting the liquid phase rate constants, a good agreement was obtained between the calculated and the observed concentration time profiles of nitrate and nitrite. These laboratory studies seem to indicate that for the chosen experimental conditions the investigated reactions proceed in a QLL having properties similar to those of liquid water.

However, it is not clear how these laboratory studies can be applied to natural snow. In some cases, the results of laboratory studies might be biased because concentrations higher than those present in natural snow were applied, leading to the formation of a thicker QLL or even a true aqueous phase as predicted by phase diagrams. Nevertheless, some of these studies used impurity concentrations in the $\mu \mathrm{M}$ range typical of natural snow, and led to the same conclusions. Of more concern is the fact that some studies used droplets of solutions that were flash-frozen in liquid nitrogen as a snow mimic, resulting in very small crystals with a large number of triple junctions, where a true liquid phase may have been present. This interpretation is consistent with the work of Huthwelker et al. (2001) who showed that temperaturedependent $\mathrm{SO}_{2}$ uptake into packed ice bed can be explained by the dissolution into triple junctions, rather than by the uptake into a quasi-liquid layer. This may then explain why the observed chemistry could be described using liquid phase rate coefficients. Clearly, understanding the differences in the microstructure between natural snow and snow mimics is crucial to understand photochemical processes in both natural snow and in laboratory experiments.

Experimental studies of gas adsorption on ice at temperatures relevant to most snowpacks $\left(\mathrm{T}>-35^{\circ} \mathrm{C}\right)$ are limited (Huthwelker et al., 2006) and include compounds like nitric acid, sulphur dioxide, hydrogen peroxide, nitrogen oxides, 1-pentanol, acetic acid, and phenanthrene on ice surfaces (Conklin et al., 1993; Clapsaddle and Lamb, 1989; Laird and Sommerfeld, 1995; Clegg and Abbatt, 2001; BartelsRausch et al., 2002; Sokolov and Abbatt, 2002; Domine et al. 2007b). There are also a few studies of the sorption of organic compounds on snow (Roth et al., 2004; Domine et al., 2007b). While the location of most absorbed trace gases in snow is unknown, laboratory experiments indicate that acidic gases, such as $\mathrm{HCl}, \mathrm{HNO}_{3}, \mathrm{SO}_{2}$, and $\mathrm{HONO}$ also diffuse into a yet unexplained reservoir (Huthwelker et al., 2006). For $\mathrm{H}_{2} \mathrm{O}_{2}$, similar conclusions can be drawn from both laboratory experiments (Conklin et al. 1993b) and field measurements (Jacobi et al., 2002), which showed that more than 80 $\%$ of the hydrogen peroxide in the fresh snow was not located at the surface of the snow crystals. At first sight, bulk uptake processes appear somewhat surprising as ionic species are much more soluble in water than in the ice crystal matrix (e.g. Gross and Svec, 1997; Thibert and Domine, 1997, 1998). Hence, one would expect ionic concentrations to be much higher in any liquid-like or liquid confined reservoirs, such as the QLL, grain boundaries or triple junctions. However, at present, there is no convincing identification of the reservoir. It is noteworthy that, in contrast to acidic gases, the uptake of most organic vapours can be explained solely by adsorption without invoking any bulk process (Roth et al., 2004; Bartels-Rausch et al., 2005).

Similar to the QLL, grain boundaries and triple junctions that form during snow metamorphism are other poorly characterized compartments. They are possibly disordered or may consist of a bulk liquid solution due to the melting point 
depression induced by dissolved impurities and the Kelvin effect of curved surfaces (Nye, 1991; Mader, 1992a, b). Sulphates and other ions have indeed been found in triple junctions using different microscopic techniques (Mulvaney et al., 1988; Fukazawa et al., 1998; Cullen and Baker, 2001, 2002; Barnes et al., 2002; Baker et al., 2003; Barnes and Wolff, 2004). Such reservoirs may be suspected to have a profound impact on chemical processes in snow.

While the QLL may be successfully invoked for qualitative interpretation of chemical processes in snow, it must be stressed that no direct experimental evidence exists for its role in chemical reactions on the ice surface, since it is currently impossible to distinguish between processes on the ice surface or in the QLL. Other uncertainties include the exact nature of the QLL and its volume, the exact distribution of the impurities between the different compartments, and in particular the location (particulate vs. other phases) and speciation of organic impurities in the snow.

From a fundamental point of view, complex chemical transformations in multiphase systems can be treated using differential equations of the following form:

$\frac{d C_{I, n}}{d t}=P_{I, n}-L_{I, n} C_{I, n}+T_{I, n}$

where $C_{I, n}$ is the concentration of the species $I$ in compartment $n, t$ is time, $P_{I, n}$ is the chemical production of species $I$ in compartment $n, L_{I, n}$ is the chemical sink of species $I$ in compartment $n$, and $T_{i, n}$ is the transport loss or gain of species $I$ in compartment $n$ with respect to adjacent compartments. Because the chemical and transport terms depend on concentrations of other species or concentrations in different compartments, these equations constitute a set of dependent differential equations, which need to be solved using established integration schemes.

Further crucial parameters when modelling snowpack processes are the specific surface area (SSA), the number density and size of the grain boundaries and triple junctions, the thickness of the QLL, and the number density and location of aerosol particles trapped in snow.

For practical matters, using all these parameters in a general scheme poses a difficult task, since we lack detailed knowledge about compartment sizes and the concentrations, solubility, reaction and photolysis rates of the various species involved in the different compartments. Another possible approach, avoiding the difficulty of knowing where reactants are in the vicinity of the ice surface, would be to use effective rate coefficients including reactions in all compartments. This would enable the description of snow chemistry without requiring data that will probably not be available in the near future. However, such effective coefficients will probably depend on overall snow chemistry and physical properties, so that their predictive value will be limited.

\section{Conclusions}

This overview shows that snow is a complex multiphase medium whose physical properties change over time. Even though the physics governing these changes is not fully understood, many experimental studies have produced empirical relationships that have allowed the construction of snow physics models that reproduce in a satisfactory manner observations of snow evolution. Several complications arise if snow photochemistry is to be described by snow models.

The first one is to parameterize adequately variables of specific importance to photochemistry such as specific surface area (SSA) and the light flux in the snow. Recent experimental and modeling studies of SSA (Legagneux et al., 2002; Flanner and Zender, 2006; Taillandier et al., 2007; Domine et al., 2007a) provide some basis for the parameterization of SSA in future models. Regarding the light flux in snow, we have explained above that it could be predicted knowing snow scattering properties and absorption. Scattering is explained by snow physics, so that being able to predict snow density, SSA and grain shape will allow the parameterization of scattering. Absorption at the photochemically active wavelengths (UV and visible) is mostly due to deposited aerosols, whose amounts in snow depend on meteorology, atmospheric composition, snow permeability and surface structure. Therefore, coupling to an atmospheric model treating aerosols appears mandatory if light fluxes in snow are to be predicted with confidence.

The second difficulty is to be able to describe the complex chemistry taking place in snow, and this is certainly the toughest challenge. At present, we do not understand where impurities are located in snow, so that writing the correct chemical reactions is for the most part a guessing game. For example, in the photolysis reaction of the nitrate ion that produces nitrogen oxides, is the nitrate ion present as a mineral salt in particles trapped in snow, as suggested by Beine et al. (2006), or as a species dissolved in the quasi liquid layer at the surface of snow grains, as proposed in many laboratory studies and inferred from some field studies (e.g. Beine et al., 2002; Jacobi and Hilker, 2007)? The nitrate ion could also be in triple junctions, as suggested here in the proposed re-interpretation of the data of Jacobi and Hilker (2007).

From a wider point of view, the ultimate aim of any physico-chemical snow model is to understand and predict natural systems. Field measurements provide information about the behaviour of the overall complex system. However, as the predictive capability of field measurements is limited, laboratory measurements which address the thermodynamics and kinetics of individual processes are essential to understand the importance of specific processes, and hence to build predictive models.

Clearly novel approaches that require close collaboration between field, laboratory, and modeling studies are required to determine the nature and location of reactants in natural snow. Until a better understanding of these crucial aspects 
is reached, our progress in designing a predictive model of snow photochemistry will be severely limited.

Acknowledgements. This paper arose from a meeting held at LGGE, Grenoble, in May 2006. The meeting was sponsored by the International Global Atmospheric Chemistry program (IGAC), the British Antarctic Survey, LGGE, Région Rhone-Alpes, Université Joseph Fourier and the city of Grenoble. This paper is a contribution to the IGAC task on Air-Ice Chemical Interactions (AICI). The contribution of M. Albert was made possible by National Science Foundation grant NSF-OPP-0220990. This paper benefited from comments by M. Ammann, R. Essery, S. Warren and an anonymous reviewer. We thank T. Painter for kindly providing the experimental data for Fig. 13, M. Grippa for providing Fig. 14 and E. W. Wolff for his encouragements.

Edited by: E. W. Wolff

\section{References}

Abdalati, W. and Steffen, K.: Snow melt on the Greenland ice sheet as derived from passive microwave satellite data, J. Climate, 10, $165-175,1997$.

Abdalati, W. and Steffen, K.: Greenland ice sheet melt extent: 1979-1999, J. Geophys. Res., 106, 33 983-33 989, 2001.

Ackermann, M., Ahrens, J., Bai, X., et al.: Optical properties of deep glacial ice at the South Pole, J. Geophys. Res., 111, D13203, doi:10.1029/2005JD006687, 2006.

Adams, E. E. and Sato, A.: Model for effective thermal conductivity of dry snow cover composed of uniform spheres, Ann. Glaciol. 18, 300-304, 1993

Albert, M. R. and McGilvary, W. R.: Thermal Effects Due to Air Flow and Vapor Transport in Dry Snow, J. Glaciol., 38, 273-281, 1992.

Albert, M. R.: Modeling heat, mass, and species transport in polar firn, Ann. Glaciol., 23, 138-143, 1996.

Albert, M. R., Koh, G., and Perron, F.: Radar investigations of melt pathways in a natural snowpack, Hydrol. Process., 13, 29913000, 1999.

Albert, M. R. and Perron, F. E., Jr.: Ice layer and surface crust permeability in a seasonal snow pack, Hydrol. Process., 14(18), 3207-3214, 2000.

Albert, M. R., Shultz, E., and Perron, F. E., Jr.: Snow and firn permeability measurements at Siple Dome, Antarctica, Ann. Glaciol., 31, 353-356, 2000.

Albert, M. R., Grannas, A. M., Bottenheim, J. W., Shepson, P. B., and Perron, F. E. Jr.: Processes and Properties of Snow-Air Transfer in the High Arctic with Application to Interstitial Ozone at Alert, Canada. Atmos. Environ., 36, 2779-2787, 2002.

Albert, M. R. and Shultz, E.: Snow and firn properties and transport processes at Summit, Greenland, Atmos. Environ., 36, 27892797, 2002.

Albert, M. R., Shuman, C., Courville, Z., Bauer, R., Fahnestock, M., and Scambos, T.: Extreme Firn Metamorphism: Impact of Decades of Vapor Transport on Near-Surface Firn at a LowAccumulation Glazed Site on the East Antarctic Plateau, Ann. Glaciol., 39, 73-78, 2004.
Alley, R. B. and Koci, B. R.: Ice-core analysis at site A, Greenland : preliminary results, Ann. Glaciol. 10, 1-4, 1988.

Alley, R. B., Saltzman, E. S., Cuffey, K. M., and Fitzpatrick, J. J.: Summertime formation of depth hoar in central Greenland, Geophys. Res. Lett, 17, 2393-2396, 1990.

Aoki, T., Aoki, T., Fukabori, M., Hachikubo, A., Tachibana, Y., and Nishio, F.: Effects of snow physical parameters on spectral albedo and bidirectional reflectance of snow surface, J. Geophys. Res., 105D, 10 219-10 236, 2000.

Aoki, T., M. Hori, H. Motoyoshi, et al.: ADEOS-II/GLI snow/ice products - Part II: Validation results using GLI and MODIS data, Remote Sens. Environ., 111, 274-290, 2007.

Armstrong, R. L. and Brodzik, M. J.: Recent Northern Hemisphere snow extent: a comparison of data derived from visible and microwave sensors, Geophys. Res. Lett., 28(19), 3673-3676, 2001.

Arthern, R. J., Winebrenner, R. J, and Vaughan, D. G.: Antarctic snow accumulation mapped using polarisation of $4.3 \mathrm{~cm}$ wavelength microwave emission, J. Geophys. Res., 111, D06107, doi:10.1029/2004JD005667, 2006.

Baker, M. and Nelson, J.: Comment on solute effects on the evaporation of ice particles by J.-P. Chen and P. J. Crutzen, J. Geophys. Res., 101(D17), 23 035-23 038, 1996.

Baker, M. B. and Dash, J. G.: Surface layers on ice - Comment, J. Geophys. Res., 101(D8), 12 929-12931, 1996.

Baker, I., Cullen, D., and Iliescu, D.: The microstructural location of impurities in ice, Can. J. Phys., 81, 1-9, 2003.

Barnes, P. R. F., Mulvaney, R., Wolff, E. W., and Robinson, K.: A technique for the examination of polar ice using the scanning electron microscope, J. Micros.-Oxford, 205, 118-124, 2002.

Barnes, P. R. F. and Wolff, E. W.: Distribution of soluble impurities in cold glacial ice, J. Glaciol., 50(170), 311-324, 2004.

Barnola, J. M., Pimienta, P., Raynaud, D., and Korotkevich, Y. S.: $\mathrm{CO}_{2}$-climate relationship as deduced from the Vostok ice core: a re-examination based on new measurments and on a reevaluation of the air dating, Tellus, 43 B, 83-90, 1991.

Bartels-Rausch, T., Eichler, B., Zimmermann, P., Gäggeler, H. W., and Ammann, M.: The adsorption enthalpy of nitrogen oxides on crystalline ice, Atmos. Chem. Phys., 2, 235-247, 2002, http://www.atmos-chem-phys.net/2/235/2002/.

Bartelt, P. B. and Lehning, M.: A physical SNOWPACK model for Avalanche Warning Services. Part I: Numerical Model, Cold Reg. Sci. Technol., 35/3, 123-145, 2002.

Beaglehole, D.: Surface Melting of Small Particles, and the Effects of Surface Impurities, J. Cryst. Growth, 112(4), 663-669, 1991.

Beaglehole, D. and Nason, D.: Transition Layer on the Surface on Ice, Surf. Sci., 96(1-3), 357-363, 1980.

Beaglehole, D., Ramanathan, B., and Rumberg J.: The UV and IR transmission of Antarctic snow, J. Geophys. Res., 103 (D8), 8849, 1998.

Beine, H. J., Honrath, R. E., Domine, F., Simpson, W. R., and Fuentes J. D.: $\mathrm{NO}_{\mathrm{x}}$ During Background and Ozone Depletion Periods at Alert: Fluxes Above the Snow Surface, J. Geophys. Res., 107(D21), 4584, doi:10.1029/2002JD002082, 2002.

Beine, H. J., Domine, F., Simpson, W. R., Honrath, R. E., Sparapani, R., Zhou, X., and King, M. D.: Snow-pile and chamber experiments during the Polar Sunrise Experiment "Alert 2000": Exploration of nitrogen chemistry, Atmos. Environ., 36, 27072719, 2002.

Beine, H. J., Domine, F., Ianniello, A., Nardino, M., Allegrini, I., 
Teinilä, K., and Hillamo, R.: Fluxes of Nitrates Between Snow Surfaces and the Atmosphere in the European High Arctic, Atmos. Chem. Phys., 3, 335-346, 2003, http://www.atmos-chem-phys.net/3/335/2003/.

Beine, H. J., Amoroso, A., Dominé, F., King, M. D., Nardino M., Ianniello, A., and France, J. L.: Small HONO emissions from snow surfaces at browning pass, Antarctica, Atmos. Chem. Phys., 6, 2569-2580, 2006, http://www.atmos-chem-phys.net/6/2569/2006/.

Bernier, M., Fortin, J. P., Gauthier, Y., Gauthier, R., Roy, R., and Vincent, P.: Determination of Snow Water Equivalent using RADARSAT in Eastern Canada, Hydrol. Process., 13(18), 3031-3042, 1999.

Bohren, C. F. and Barkstrom, B. R.: Theory of the optical properties of snow, J. Geophys. Res., 79, 4527-4535, 1974.

Bohren, C. F. and Beschta, R. L.: Snowpack albedo and snow density, Cold Reg. Sci. Technol., 1, 47-50, 1979.

Bottenheim, J. W., Barrie, L. W., Atlas, E., Heidt, L. E., Niki, H., Rasmussen, R. A., and Shepson, P. B.: Depletion of lower tropospheric ozone during Arctic spring: The Polar Sunrise Experiment 1988, J. Geophys. Res., 95, 18 555-18 568, 1990.

Bourdelles, B. and Fily, M.: Snow grain-size determination from Landsat imagery over Terre Adelie, Antarctica, Ann. Glaciol., 17, 86-92, 1993.

Boxe, C. S., Colussi, A. J., Hoffmann, M. R., Murphy, J. G., Wooldridge, P. J., Bertram, T. H., and Cohen, R. C.: Photochemical production and release of gaseous $\mathrm{NO}_{2}$ from nitrate-doped water ice, J. Phys. Chem. A, 109, 8520-8525, 2005.

Boxe, C. S., Colussi, A. J., Hoffmann, M. R., Perez, I. M., Murphy, J. G., and Cohen, R. C.: Kinetics of $\mathrm{NO}$ and $\mathrm{NO}_{2}$ evolution from illuminated frozen nitrate solutions, J. Phys. Chem. A, 110, 3578-3583, 2006.

Bremond, L., Alexandre, A., Hély, C., and Guiot, J.: A phytolith index as a proxy for tree cover density in tropical areas: calibration with Leaf area Index along a forest-savanna transect in southeastern Cameroon, Global Planet. Change, 45, 277-293, 2005.

Brun, E. and Touvier, F.: Experimental study of thermal convection in snow, J. Phys. Colloque, 48(C-1), 257-62, 1987.

Brun, E.: Investigation on wet-snow metamorphism in respect of liquid-water content, Ann. Glaciol., 13, 22-26, 1989.

Brun, E., Martin, E., Simon, V., Gendre, C., and Coleou, C.: An energy and mass model of snow cover suitable for operational avalanche forecasting, J. Glaciol., 121, 333-342, 1989.

Brun, E., David, P., Sudul, M., and Brunot, G.: A numerical model to simulate snow-cover stratigraphy for operational avalanche forecasting, J. Glaciol., 128, 13-22, 1992.

Brunauer, S., Emmet, P. H., and Teller, E.: Adsorption of gases in multimolecular layers, J. Am. Chem. Soc. 60, 309-319, 1938.

Buser, O. and Good, W.: A rigid frame model of porous media for the acoustic impedance of snow, J. Sound Vibr., 111, 71-92, 1986.

Cabanes, A., Legagneux, L., and Dominé, F.: Rate of evolution of the specific surface area of surface snow layers, Environ. Sci. Technol. 37, 661-666, 2003.

Chen, J.-P. and Crutzen, P.J.: Solute effects on the evaporation of ice particles, J. Geophys. Res., 99(D9), 18 847-18 859, 1994.

Chaix, L., Ocampo, J., and Domine, F.: Adsorption of $\mathrm{CH}_{4}$ on laboratory-made crushed ice and on natural snow at $77 \mathrm{~K}$, Atmospheric implications, Comptes Rendus Acad. Sciences, 322, série II, 609-616, 1996.

Chang, A. T. C., Foster, J. L., and Hall, D. K.: Nimbus-7 SMMR derived global snow cover parameters, Ann. Glaciol., 9, 39-44, 1987.

Chang, A. T. C., Grody, N., Tsang, L., Basist, A., Goodison, B., Walker, A., Carroll, T., Armstrong, R., Josberger, E., and Sun, C.: Algorithm Theoretical Basis Document (ATBD) for AMSRE snow water equivalent algorithm Greenbelt, MD: NASA Goddard Space Flight Center, Nov. 1997.

Chen, J. P. and Crutzen, P. J.: Solute effects on the evaporation of ice particles - Reply, J. Geophys. Res., 101(D17), 23 037-23 038, 1996.

Cho, H., Shepson, P. B., Barrie, L. A., Cowin, J. P., and Zaveri, R.: NMR investigation of the quasi-brine layer in ice/brine mixtures, J. Phys. Chem. B, 106, 11 226-11 232, 2002.

Chu, L. and Anastasio, C.: Quantum yields of hydroxyl radical and nitrogen dioxide from the photolysis of nitrate on ice, J. Phys. Chem. A, 107, 9594-9602, 2003.

Chu, L. and Anastasio, C.: Formation of hydroxyl radical from the photolysis of frozen hydrogen peroxide, J. Phys. Chem. A, 109, 6264-6271, 2005.

Clapsaddle C. and Lamb, D.: The sorption behaviour of $\mathrm{SO}_{2}$ on ice at temperatures between $-30^{\circ} \mathrm{C}$ and $-5^{\circ} \mathrm{C}$, Geophys. Res. Lett., 16, 1173-1176, 1989.

Clarke, A. D. and Noone, K. J.: Soot in the Arctic snowpack: A cause for perturbations in radiative transfer, Atmos. Environ., 19, 2045-2053, 1985.

Clegg, S. M. and Abbatt, J. P. D.: Uptake of gas-phase $\mathrm{SO}_{2}$ and $\mathrm{H}_{2} \mathrm{O}_{2}$ by ice surfaces: Dependence on partial pressure, temperature, and surface acidity, J. Phys. Chem. A, 105, 6630-6636, 2001.

Clifton, A., Manes, C., Rüedi, J.-D., Guala, M., and Lehning, M.: On shear-driven ventilation of snow, Bound-Lay. Meteorol., in press, 2008.

Cockell, C. S., Rettberg, P., Horneck, G., Wynn-Williams, D. D., Scherer, K., and Gugg-Helminger, A.: Influence of ice and snow covers on the UV exposure of terrestrial microbial communities: dosimetric studies, J. Photochem. Photobio. B, 68, 23-32, 2002.

Colbeck, S. C.: An overview of seasonal snow metamorphism, Rev. Geophys. Space Phys. 20, 45-61, 1982.

Colbeck, S. C.: Theory of metamorphism of dry snow, J. Geophys. Res., 88, 5475-5482, 1983.

Colbeck, S., Akitaya, E., Armstong, R., Gubler, H., Lafeuille, J., Lied, K., McClung, D., and Morris, E.: The International Classification for Seasonal Snow on the Ground, ICSI, IGS, 1-23, 1990.

Colbeck, S. C.: The layered character of snow covers, Rev. Geophys. 29, 81-96, 1991.

Coléou, C., Lesaffre, B., Brzoska, J. B., Ludwig, W., and Boller, E.: Three-dimensional snow images by X-ray microtomography, Ann. Glaciol., 32, 75-81, 2001.

Coléou, C., Pieritz, R. A., Lesaffre, B., Brzoska, J. B., and Etchevers, P.: Isothermal metamorphism of a new snow layer: some measurements and simulation, Proceedings ISSW 2004, International Snow Science Workshop, Jackson Hole WY, USA, 19-24 September 2004, 2005.

Compoint, M., Toubin, C., Picaud, S., Hoang, P. N. M., and Girardet, C.: Geometry and dynamics of formic and acetic acids adsorbed on ice, Chem. Phys. Lett., 365, 1-7, 2002. 
Conklin, M. H., Sigg, A., Neftel, A., and Bales, R. C.: Atmospheresnow transfer for $\mathrm{H}_{2} \mathrm{O}_{2}$ : Microphysical considerations, J. Geophys. Res. 98, 18 367-18 376, 1993.

Conway, H. and Abrahamson, J.: Air permeability as a textural indicator of snow, J. Glaciol., 30, 298-333, 1984.

Cotter, E. S. N., Jones, A. E., Wolff, E. W., and Baugitte, S. J.B.: What controls photochemical $\mathrm{NO}$ and $\mathrm{NO}_{2}$ production from Antarctic snow? Laboratory investigation assessing the wavelength and temperature dependence, J. Geophys. Res., 108, 4147, doi: 10.1029/2002JD002602, 2003.

Courville, Z. R., Albert, M. R., Fahnestock, M., Cathles, L. M., IV, and Shuman, C.: Impact of Accumulation Hiatus on the Physical Properties of Firn, J. Geophys. Res., 112, F02030, 2007.

Cullen, D. and Baker, I.: Observation of impurities in ice, Microsc. Res. Techniq., 55(3), 198-207, 2001.

Cullen, D. and Baker, I.: Observation of sulfate crystallites in Vostok accretion ice, Mater. Charact., 48(4), 263-269, 2002.

Cunningham, J. and Waddington, E. D.: Air flow and dry deposition of non-sea salt sulfate in polar firn: paleoclimatic implications, Atmos. Environ., 27A, 2943-2956, 1993.

Dash, J. G., Fu, H., and Wettlaufer, J. S.: The premelting of ice and its environmental consequences, Rep. Prog. Phys., 58, 115-167, 1995.

Dash, J. G., Rempel, A. W., and Wettlaufer J. S.: The physics of premelted ice and its geophysical consequences, Rev. Mod. Phys., 78, 695, 2006.

Davis, R. E., Dozier, J., and Perla, R.: Measurement of snow grain properties, in: Seasonal Snowcovers: Physics, Chemistry, Hydrology, edited by: Jones, H. G. and Orville-Thomas, W. J., D. Reidel Publishing Company, 63-74, 1987.

Davis, D. T., Chen, Z., Tsang, L., Hwang, J.-N., and Chang, A. T. C.: Retrieval of snow parameters by iterative inversion of a neural network, IEEE T. Geosci. Remote, 31, 4, 842-852, 1993.

Dibb, J. E. and Arsenault, M.: Shouldn't snowpacks be sources of monocarboxylic acids?, Atmos. Environ., 36, 2513-2522, 2002.

Dominé, F., Thibert, E., Silvente, E., Legrand, M., and Jaffrezo, J.-L.: Determining past atmospheric $\mathrm{HCl}$ mixing ratios from ice core analyses, J. Atmos. Chem., 21, 165-186, 1995.

Dominé, F., Cabanes, A., and Legagneux, L.: Structure, microphysics, and surface area of the Arctic snowpack near Alert during ALERT 2000, Atmos. Environ., 36, 2753-2765, 2002.

Dominé, F. and Rey-Hanot, L.: Adsorption isotherms of acetone on ice between 193 and 213 K, Geophys. Res. Lett., 29, 18, 1873, doi:10.1029/2002GL015078, 2002.

Dominé, F. and Shepson P. B.: Air-snow interactions and atmospheric chemistry, Science, 297, 1506-1510, 2002.

Dominé, F., Lauzier, T., Cabanes, A., Legagneux, L. Kuhs, W. F., Techmer, K, and Heinrichs, T.: Snow metamorphism as revealed by scanning electron microscopy, Microsc. Res. Tech., 62, 3348, 2003.

Dominé, F. Sparapani, R., Ianniello, A., and Beine, H. J.: The origin of sea salt in snow on Arctic sea ice and in coastal regions, Atmos. Chem. Phys., 4, 2259-2271, 2004,

http://www.atmos-chem-phys.net/4/2259/2004/.

Dominé, F., Salvatori, R., Legagneux, L., Salzano, R., Fily, M., and Casacchia, R.: Correlation between the specific surface area and the short wave infrared (SWIR) reflectance of snow: preliminary investigation, Cold Reg. Sci. Technol., 6, 60-68, doi:10.1016/j.coldregions.2006.06.002, 2006.
Dominé, F., Taillandier, A.-S., and Simpson, W. R.: A parameterization of the specific surface area of snow in models of snowpack evolution, based on 345 measurements, J. Geophys. Res., 112, F02031, doi:10.1029/2006JF000512, 2007a.

Dominé, F., Cincinelli, A., Bonnaud, E., Martellini, T., and Picaud, S.: Adsorption of Phenanthrene on Natural, Snow. Environ. Sci. Technol., 41, 6033-6038, 2007b.

Dosch, H.: Critical phenomena at surfaces and interfaces, Springer, Berlin, pp. 145, 1992.

Dosch, H., Lied, A., and Bilgram, J. H.: Glancing-Angle X-RayScattering Studies of the premelting of Ice Surfaces, Surf. Sci., 327(1-2), 145-164, 1995.

Döppenschmidt, A. and Butt, H.-J.: Measuring the thickness of the liquid-like layer on ice surfaces with atomic force microscopy, Langmuir, 16, 6709-6714, 2000.

Dozier, J. and Painter, T. H.: Multispectral and hyperspectral remote sensing of alpine snow properties, Annual Review of Earth and Planetary Sciences, 32, 465-494, 2004.

Drinkwater, M. R., Long, D. G., and Bingham, A. W.: Greenland snow accumulation estimates from satellites radar scatterometer data, J. Geophys. Res., 106, 33 935-33 950, 2001.

Dubowski, Y., Colussi, A. J., and Hoffmann M. R.: Nitrogen dioxide release in the $302 \mathrm{~nm}$ band photolysis of spray-frozen aqueous nitrate solutions, Atmospheric implications, J. Phys. Chem. A 105, 4928-4932, 2001.

Elbaum, M. and Schick, M.; Application of the theory of dispersion forces to the surface melting of ice, Phys. Rev. Lett., 66, 1713$1716,1991$.

Elbaum, M., Lipson, S. G. and Dash, J. G.: Optical Study of Surface Melting on Ice, J. Cryst. Growth, 129, 491-505, 1993.

Etchevers, P., Martin, E., Brown, R., et al.: Validation of the energy budget of an alpine snowpack simulated by several snow models (SnowMIP project), Ann. Glaciol. 38, 150-158, 2004.

Ewing, G. E.: Thin film water, J. Phys. Chem. B, 108, (41), $15953-$ $15961,2004$.

Fabre, A., Barnola, J.-M., Arnaud, L., and Chappellaz, J., Determination of gas diffusivity in polar firn: comparison between experimental measurements and inverse modeling, Geophys. Res. Lett., 27, 557-560, 2000.

Fierz, C. and Lehning, M.: Assessment of the microstructure-based snow-cover model SNOWPACK: thermal and mechanical properties, Cold Reg. Sci. Technol., 33, 123-13, 2001.

Fily, M., Bourdelles, B., Dedieu J. P., and Sergent, C.: Comparison of in situ and Landsat Thematic Mapper derived snow grain characteristics in the Alps, Remote Sens. Environ., 59, 452-460, 1997.

Fisher, F. N., King, M. D., and Lee-Taylor, J.: Extinction of UV-visible radiation in wet midlatitude (maritime) snow: Implications for increased NOx emission, J. Geophys. Res., 110, D21301, doi:10.1029/2005JD005963, 2005.

Flach, J. D., Partington, K. C., Ruiz, C. Jeansou, E., and Drinkwater, M. R.: Inversion of the surface properties of ice sheets from satellite microwave, IEEE T. Geosci. Remote, 43, 743-752, 2005.

Flanner, M. G. and Zender, C. S.: Linking snowpack microphysics and albedo evolution, J. Geophys. Res., 111, D12208, doi:10.1029/2005JD006834, 2006.

Flanner, M. G., Zender, C. S., Randerson, J. T., and Rasch, P. J.: Present-day climate forcing and response from black carbon in snow, J. Geophys. Res., 112, D11202, 
doi:10.1029/2006JD008003, 2007.

Fletcher, N. H.: Surface structure of water and ice, Philos. Mag., 7, 255-269, 1962.

Fletcher, N. H.: Surface structure of water and ice. 2. A revised model, Philos. Mag., 18, 1287-1289, 1968

Flin, F., Brzoska, J. B., Lesaffre, B., Coléou, C., and Pieritz, R. A.: Full three-dimensional modelling of curvature-dependent snow metamorphism: first results and comparison with experimental tomographic data, J. Phys. D: Appl. Phys., 36, 1-6, 2003.

Forster, R., Jezek, K. C., Bolzan, J., Baumgartner, F., and Gogineni, S. P.: Relationships between radar backscatter and accumulation rates on the Greenland ice sheet, Int. J. Remote Sens., 20, 31313147, 1999.

Franz, T. P. and Eisenreich, S. J.: Snow scavenging of polychlorinated biphenyls and polycyclic aromatic hydrocarbons in Minnesota, Environ. Sci. Technol., 24, 1771-1778, 1998.

Fukazawa, H., Sugiyama, K., Mae, S., Narita, K., and Hondoh, T.: Acid ions at triple junction of Antarctic ice observed by Raman scattering, Geophys. Res. Lett., 25, 2845-2848, 1998.

Furukawa, Y., Yamamoto, M., and Kuroda, T.: Ellipsometric Study of the Ice Surface-Structure Just Below the Melting-Point, J. Phys., 48(C-1), 495-501, 1987a.

Furukawa, Y., Yamamoto, M., and Kuroda, T.: Ellipsometric Study of the Transition Layer on the Surface of an Ice Crystal, J. Cryst. Growth, 82(4), 665-677, 1987b.

George, C., Strekowski, R. S., Kleffmann, J., Stemmler, K., and Ammann, M.: Photoenhanced uptake of gaseous $\mathrm{NO}_{2}$ on solid organic compounds: A photochemical source of HONO?, Faraday Discuss., 130, 195-210, 2005.

Giddings, J. C. and LaChapelle, E. R.: Diffusion theory applied to radiant energy distribution and albedo of snow, J. Geophys. Res., 66, 181-189, 1961.

Girardet, C. and Toubin, C.: Molecular atmospheric pollutant adsorption on ice: a theoretical survey, Surf. Sci. Rep., 44, 159238, 2001.

Golecki I. and Jaccard, C.: Intrinsic disorder in ice near the melting point, J. Phys. C., Solid State Phys., 11, 4429-4237, 1978.

Grannas, A. M., Shepson, P. B., Guimbaud, C., Sumner, A. L., Albert, M., Simpson, W., Dominé, F., Boudries, H., Bottenheim, J. W., Beine, H. J., Honrath, R., and Zhou, X.: A study of carbonyl compounds and photochemistry in the arctic atmospheric boundary layer, Atmos. Environ., 36, 2733-2742, 2002.

Grannas, A. M., Jones, A. E., Dibb, J., Ammann, M., Anastasio., C., Beine, H., Bergin, M., Bottenheim, J., Boxe, C. S., Carver, G., Crawford, J. H., Domine., F, Frey, M. M., Guzman, M. I., Heard, D., Helmig, D., Hoffmann, M. R., Honrath, R. E., Huey, L. G., Jacobi, H.-W., Klan, P., McConnell, J., Sander, R., Savarino, J., Shepson, P. B., Simpson, W. R., Sodeau, J., von Glasgow, R., Weller, R., Wolff, E., and Zhu, T.: Snow photochemistry: Current state of the science, Atmos. Chem. Phys., 7, 4329-4373, 2007 , http://www.atmos-chem-phys.net/7/4329/2007/.

Grippa, M., Mognard, N. M., Letoan, T., and Josberger, E. G.: Siberia snow depth climatology from SSM/I data using a combined dynamic and static algorithm, Remote Sens. Environ., 93, 30-41, 2004.

Grenfell, T. C., Perovich, D. K., and Ogren, J. A.: Spectral albedos of an alpine snowpack, Cold Reg. Sci. Technol., 4, 121-127, 1981.
Grenfell, T. C., Warren, S. G., and Mullen, P. C.: Reflection of solar radiation by the Antarctic snow surface at ultraviolet, visible, and near-infrared wavelengths, J. Geophys. Res., 99, 18 669-18 684, 1994.

Grenfell, T. C. and Warren S. G.: Representation of a nonspherical ice particle by a collection of independent spheres for scattering and absorption of radiation, J. Geophys. Res., 104, $31697-$ $31709,1999$.

Grenfell, T. C., Neshyba, S. P., and Warren, S. G.: Representation of a nonspherical ice particle by a collection of independent spheres for scattering and absorption of radiation: 3 . Hollow columns and plates, J. Geophys. Res., 110, D17203, doi:10.1029/2005JD005811, 2005.

Grippa M., Mognard, N. M., and Letoan T.: Comparison between the interannual variability of snow parameters derived from SSM/I and the Ob river discharge, Remote Sens. Environ., 98, 35-44, 2005.

Grody, N. C. and Basist, A. N.: Global Identification of snowcover using SSM/I measurements, IEEE T. Geosci. Remote, 34, 237249, 1996.

Gross, G. W. and Svec, R. K.: Effect of ammonium on anion uptake and dielectric relaxation in laboratory-grown ice columns, J. Phys. Chem. B, 101, 6282-6284, 1997.

Guo, J., Tsang L., Josberger, E. G. Wood, A. W. Hwang, J.-N., and Lettenmaier, D. P.: Mapping the spatial distribution and time evolution of snow water equivalent with passive microwave measurements, IEEE T. Geosci. Remote , 41, 3 612-621, 2003.

Guo, J., Tsang, L., Josberger, E. G., Wood, A. W., and Hwang, J.N.: Mapping the spatial distribution and time evolution of snow water equivalent with passive microwave measurements, IEEE TGARS, 41, 612-621, 2003.

Hall, D. K., Riggs, G. A., and Salomonson, V.: Algorithm Theoretical Basis Document (ATBD) for the MODIS Snow and Sea Ice-Mapping Algorithms, available at http://modis.gsfc.nasa.gov/data/atbd/atbd_mod10.pdf, 2001.

Hansen, J. and Nazarenko L.: Soot climate forcing via snow and ice albedos, Proc. Nat. Acad. Sci., 101, 423-428, 2004.

Hanson, D. R. and Ravishankara, A. R.: Comment on Porosities of Ice Films Used to Simulate Stratospheric Cloud Surfaces Response, J. Phys. Chem., 97, 2802-2803, 1993.

Harder, S., Warren, S. G., and Charlson, R. J.: Sulfate in air and snow at the South Pole: Implications for transport and deposition at sites with low snow accumulation. J. Geophys. Res., 105D, 22 825-22 832, 2000.

Henson, B. F., Voss, L. F., Wilson, K. R., and Robinson, J. M.: Thermodynamic model of quasiliquid formation on $\mathrm{H}_{2} \mathrm{O}$ ice: Comparison with experiment, J. Chem. Phys., 123, 144707, doi:10.1063/1.2056541, 2005.

Herbert, B. M. J., Halsall, C. J., Jones, K. C., and Kallenborn, R.: Field investigation into the diffusion of semi-volatile organic compounds into fresh and aged snow, Atmos. Environ., 40, 1385-1393, 2006.

Honrath, R. E., Peterson, M. C., Guo, S., Dibb, J. E., Shepson, P. B., and Campbell, B.: Evidence of $\mathrm{NO}_{\mathrm{x}}$ production within or upon ice particles in the Greenland snowpack, Geophys. Res. Lett., 26, 695-698, 1999.

Honrath, R. E., Guo, S., Peterson, M. C., Dziobak, M. P., Dibb, J. E., and Arsenault, M. A.: Photochemical production of gas phase $\mathrm{NO}_{\mathrm{X}}$ from ice crystal $\mathrm{NO}_{3}$, J. Geophys. Res., 105, 24183 
24 190, 2000.

Honrath, R., Peterson, M. C., Lu, Y., Dibb, J. E., Arsenault, M. A., Cullen, N. J., and Steffen, K.: Vertical fluxes of nitrogen oxides above the snowpack at Summit, Greenland. Atmos. Environ. 36, 2629-2640, 2002.

Hori, M., Aoki, T., Stamnes, K., and Li, W.: ADEOS-II/GLI snow/ice products-Part III: Retrieved results Remote Sensing Environ., 111, 291-336, 2007.

Huthwelker, T., Lamb, D., Baker, M., Swanson, B., and Peter, T.: Uptake of $\mathrm{SO}_{2}$ by polycrystalline water ice, J. Colloid. Interf. Sci., 238, 147-159, 2001.

Huthwelker, T., Ammann, M., and Peter, T.: The uptake of acidic gases on ice, Chem. Rev. 106, 1375-1444, 2006.

Hutterli, M. A., Röthlisberger, R., and Bales, R. C.: Atmosphereto-snow-to-firn transfer studies of HCHO at Summit, Greenland, Geophys. Res. Lett., 26, 1691-1694, 1999.

Hutterli, M. A., Bales, R. C., McConnell, J. R., and Stewart, R. W.: $\mathrm{HCHO}$ in Antarctic snow: preservation in ice cores and air-snow exchange, Geophys. Res. Lett., 29, 76-1-76-4, 2002.

Hutterli, M. A., McConnell, J. R., Chen, G., Bales, R. C., Davis, D. D., and Lenschow, D. H.: Formaldehyde and hydrogen peroxide in air, snow and interstitial air at South Pole, Atmos. Environ., 38, 5439-5450, 2004.

Ishimaru, A.: Wave Propagaion in Scattering and Random Media, vol. 1, chap. 10, Academic, San Diego, Californien, 1978.

Iversen, B. V., Moldrup, P., Schjonning, P., and Jacobsen, O. H.: Field application of a portable air permeameter to characterize spatial variability in air and water permeability, Vadose Zone J., 2, 618-626, 2003.

Jacobi, H.-W., Frey, M. M., Hutterli, M. A., Bales, R. C., Schrems, O., Cullen, N. J., Steffen, K., and Koehler, C.: Measurements of hydrogen peroxide and formaldehyde exchange between the atmosphere and surface snow at Summit, Greenland, Atmos. Environ. 36, 2619-2628, 2002.

Jacobi, H.-W., Bales, R. C., Honrath, R. E., Peterson, M. C., Dibb, J. E., Swanson, A. L., and Albert, M. R.: Reactive trace gases measured in the interstitial air of surface snow at Summit, Greenland, Atmos. Environ., 38, 1687-1697, 2004.

Jacobi, H.-W., Annor, T., and Quansah, E.: Investigation of the photochemical decomposition of nitrate, hydrogen peroxide, and formaldehyde in artificial snow, J. Photochem. Photobio. A 179, 330-338, 2006.

Jacobi, H.-W. and Hilker, B.: A mechanism for the photochemical transformation of nitrate in snow, J. Photochem. Photobio. A, 185, 371-382, 2007.

Jones, A. E., Weller, R., Wolf, E. W., and Jacobi, H.-W.: Speciation and rate of photochemical $\mathrm{NO}$ and $\mathrm{NO}_{2}$ production in Arctic Snow, Geophys. Res. Lett., 27(3), 345-348, 2000.

Jones, A. E., Weller, R. Anderson, P. S., Jacobi, H.-W., Wolff, E. W., Schrems, O., and Miller, H.: Measurements of $\mathrm{NO}_{\mathrm{x}}$ emissions from the Antarctic snowpack, Geophys. Res. Lett., 28, 14991502, 2001.

Jordan, R.: A one-dimensional temperature model for a snow cover, Technical Documentation for SNTHERM.89, CRREL special report 91-16, U.S. Army Corps of Engineers, 64, 1991.

Jordan, R. E., Hardy, J. P., Perron, F. E., and Fisk, D. J.: Air permeability and capillary rise as measures of the pore structure of snow: an experimental and theoretical study, Hydrol. Process. 13, 1733-1753, 1999.
Jordan, R., Albert, M., and Brun, E.: Physical Processes in Snow and their Parameterization, in Snow and Climate, eds, Elsevier Press, in press, 2008.

Josberger, E. G. and Mognard, N.: A passive microwave snow depth algorithm with a proxy for snow metamorphism, Hydrol. Processes, 16, 1557-1568, 2002.

Judson, A. and Doesken, N.: Density of freshly fallen snow in the Central Rocky Mountains, Bull. Amer. Meteor. Soc., 81, 15771587, 2000.

Kaempfer, T. U., Schneebeli, M., and Sokratov, S.: Computation and visualization of mass transport during temperature gradient metamorphism of snow, Geophys. Res. Lett. 32, L21503, doi:10.1029/2005GL023873, 2005.

Kahan, T. F. and Donaldson, D. J.: Photolysis of polycyclic aromatic hydrocarbons on water and ice surfaces, J. Phys. Chem. A., 111, 1277-1285, doi:10.1021/jp066660t, 2007.

Kahan, T. F., Reid, J. P., and Donaldson, D. J.: Spectroscopic Probes of the Quasi-Liquid Layer on Ice, J. Phys. Chem. A., 111, 11 006-11 012, doi:10.1021/jp074551o, 2007.

Kappen, L.: Plant activity under snow and ice, with particular reference to lichens, Arctic, 46, 297-302, 1993.

Kerbrat, M., Pinzer, B., Huthwelker, T., Gäggeler, H. W., Ammann, M., and Schneebeli M.: Measuring the specific surface area of snow with X-ray tomography and gas adsorption: comparison and implications for surface smoothness, Atmos. Chem. Phys. Disc., 7, 10 287-10322, 2007.

Keyser, L. F., Moore, S. B., and Leu, M. T.: Surface-Reaction and Pore Diffusion in Flow-Tube Reactors, J. Phys. Chem., 95, 54965502, 1991.

Keyser, L. F., Leu, M. T., and Moore, S. B.: Comment on Porosities of Ice Films Used to Simulate Stratospheric Cloud Surfaces, J. Phys. Chem., 97, 2800-2801, 1993.

Kimball, J. S., McDonald, K. C., Frolking, S., and Running, S. W.: Radar remote sensing of the spring thaw transition across a boreal landscape, Rem. Sens. Env., 89, 163-175, 2004.

King, M. D. and Simpson, W. R.: Extinction of UV radiation in Arctic snow at Alert, Canada ( $\left.82^{\circ} \mathrm{N}\right)$, J. Geophys. Res., 106 (D12), 12 499-12 508, 2001.

Knight, C. A.: Surface layers on ice, J. Geophys. Res.-Atmos., 101(D8), 12 921-12 928, 1996a.

Knight, C. A.: Surface layers on ice - Reply, J. Geophys. Res.Atmos., 101(D8), 12 933-12 936, 1996 b.

Kojima, K.: A field experiment on the rate of densification, Proceedings of the Grindelwald Symposium, IAHS Publication, 114, 298-308, 1975.

Kokhanovsky, A. A. and Zege E. P.: Scattering optics of snow, Appl. Optics, 43, 1589-1602, 2004.

Kokhanovsky, A. A.: Scaling constant and its determination from simultaneous measurements of light reflection and methane adsorption by snow samples, Opt. Lett., 31, 3282-3284, 2006.

Kokhanovsky, A. A.: Cloud Optics, Dordrecht, Springer, 2006.

Kokhanovsky, A. A.: Physical interpretation and accuracy of the Kubelka-Munk theory, J. Appl. Phys., D40, 2210-2216, 2007.

Koop, H. and Sterck, F. J.: Light penetration through structurally complex forest canopies - an example of a lowland tropical rainforest, Forest Ecol. Manag., 69, 111-122, 1994.

Kou, L., Labrie, D., and Chylek, P.: Refractive indices of water and ice in the 0.65- to 2.5- $\mu \mathrm{m}$ spectral range, Appl. Optics, 32, 3531-3540, 1993. 
Kubelka, P. and Munk, F.: Ein Beitrag zur Optik der Farbanstriche, Z. Tech. Phys. (Leipzig) 12, 593-601, 1931.

Kubelka, P.: New contribution to the optics of intensely lightscattering materials. Part I, J. Opt. Soc. Am. 38, 448-457, 1948.

Kuhn, M. and Siogas, L.: Spectroscopic studies at McMurdo, South Pole and Siple stations during the austral summer 197778, Antarct J. US, 13, 178-179, 1978.

Laird, S. K. and Sommerfeld, R. A.: Nitric acid adsorption on ice: A preliminary study, Geophys. Res. Lett. 22, 921-924, 1995.

Lange, M.: Measurement of thermal parameters in Antarctic snow and firn, Ann. Glaciol., 6, 100-104, 1985.

Lee-Taylor, J. and Madronich, S.: Application of TUV Tropospheric Radiative Transfer Model to Snowpack Photochemistry, J. Geophys. Res., 107, 4796, 2002.

Legagneux, L., Cabanes, A., and Domine, F.: Measurement of the specific surface area of 176 snow samples using methane adsorption at $77 \mathrm{~K}$, J. Geophys. Res., 107(D17), 4335, doi:10.1029/2001JD001016, 2002.

Legagneux, L., Lauzier, T., Dominé, F., Kuhs, W. F., Heinrichs, T., and Techmer, K.: Rate of decay of the specific surface area of snow during isothermal experiments and morphological changes studied by scanning electron microscopy, Can. J. Phys., 81, 459468, 2003.

Legagneux, L., Taillandier, A.-S., and Domine, F.: Grain growth theories and the isothermal evolution of the specific surface area of snow, J. Appl. Phys., 95, 6175-6184, 2004.

Legrand, M., Léopold, A., and Dominé, F.: Acidic gases (HCl, HF, $\mathrm{HNO}_{3}, \mathrm{HCOOH}$ and $\mathrm{CH}_{3} \mathrm{COOH}$ ): a review of ice core data and some preliminary discussions on their air-snow relationships, in: NATO ASI Series, vol I 43, Chemical exchange between the atmosphere and polar snow, edited by: Wolff, E. and Bales, R. C., Springer, Berlin, 19-44, 1996.

Lehning, M., Bartelt, P., Brown, R. L., Russi, T., Stöckli, U., and Zimmerli, M.: Snowpack Model Calculations for Avalanche Warning based upon a new Network of Weather and Snow Stations, Cold Reg. Sci. Technol., 30, 145-157, 1999.

Lehning, M., Bartelt, P., Brown, B., Fierz, C., and Satyawali, P.: A physical SNOWPACK model for the Swiss avalanche warning Part II: Snow microstructure, Cold Reg. Sci. Technol., 35, 147167, 2002a.

Lehning, M, Bartelt, P. B., Brown, R. L., Fierz, C., and Satyawali, P.: A physical SNOWPACK model for the Swiss Avalanche Warning Services. Part III: Meteorological Boundary Conditions, Thin Layer Formation and Evaluation, Cold Reg. Sci. Technol., 35, 169-184, 2002b.

Lehning, M., Völksch, I., Gustafsson, D., Nguyen, T. A., Stähli, M., and Zappa, M.: ALPINE3D: A detailed model of mountain surface processes and its application to snow hydrology, Hydrol. Process, 20, 2111-2128, 2006.

Leu, M. T., Keyser, L. F., and Timonen, R. S.: Morphology and surface areas of thin ice films, J. Phys. Chem. B, 101, 62596262, 1997.

Libbrecht, K. G.: The physics of snow crystals., Rep. Prog. Phys., 68, 855-895, 2005.

Li, W., Stamnes, K., Chen, B., and Xiong, X.: Snow grain size retrieved from near-infrared radiances at multiple wavelengths, Geophys. Res. Lett., 28, 1699-1702, doi:10.1029/2000GL011641, 2001.

Lied, A., Dosch, H., and Bilgram, J. H.: Surface Melting Of Ice I(H)
Single-Crystals Revealed By Glancing Angle X-Ray-Scattering, Phys. Rev. Lett., 72(22), 3554-3557, 1994.

Liljequist, G. H.: Energy exchange of an Antarctic snow-field, in Norwegian-British-Swedish Antarctic Expedition 1949-1952, Scientific results vol. 2, 93-103, Norsk Polarinstitutt, Oslo, 1956.

Liu, H, Wang, L, and Jezek, K. C.: Spatiotemporal variations of snowmelt in Antarctica derived from satellite scanning multichannel microwave radiometer and Special Sensor Microwave Imager data (1978-2004), J. Geophys. Res., 111, F01003, doi:10.1029/2005JF000318, 2006.

Luciano, G. L. and Albert, M. R.: Bi-directional Permeability Measurements of Polar Firn, Annals Glaciol., 35, 63-66, 2002.

Macelloni, G., Paloscia, S., Pampaloni, P., and Tedesco, M.: Microwave emission from dry snow: a comparison of experimental and model results, IEEE T. Geosci. Remote., 39, 12, 2649-2656, 2001.

Mader, H. M.: Observations of the Water-Vein System in Polycrystalline Ice, J. Glaciol., 38, 333-347, 1992a.

Mader, H. M.: The Thermal-Behavior of the Water-Vein System in Polycrystalline Ice, J. Glaciol., 38, 359-374, 1992b.

Madronich, S.: Photodissociation in the atmosphere 1. Actinic flux and the effects of ground reflections and clouds, J. Geophys. Res., 92, 9740-9752, 1987.

Marbouty, D.: An experimental study of temperature gradient metamorphism, J. Glaciol., 26, 303-312, 1980.

Marsh, P. and Woo, M.-K.: Wetting Front Advance and Freezing of Meltwater Within a Snow Cover, 1. Observations in the Canadian Arctic, Water Resour. Res., 20, 1853-1864, 1984.

Mason, E. A. and Malinauskas, A. P.: Gas transport in porous media: the dusty gas model, Elsevier, pp. 194, 1983.

Massman, W. J.: A review of the molecular diffusivities of $\mathrm{H}_{2} \mathrm{O}$, $\mathrm{CO}_{2}, \mathrm{CH}_{4}, \mathrm{CO}, \mathrm{O}_{3}, \mathrm{SO}_{2}, \mathrm{NH}_{3}, \mathrm{~N}_{2} \mathrm{O}, \mathrm{NO}$, and $\mathrm{NO}_{2}$ in air, $\mathrm{O}_{2}$ and $\mathrm{N}_{2}$ near STP, Atmos. Environ., 32, 1111-1127, 1998.

Matzl, M. and Schneebeli, M.: Measuring specific surface area of snow by near-infrared photography, J. Glaciol., 52, 558-564, 2006.

Mätzler, C.: Passive microwave signatures of landscapes in winter, Meterology and Atmospheric Physics, 54, 241-260, 1994.

Mauldin, R. L., Eisele, F., Tanner, D. J., Kosciuch, E., Shetter, R., Lefer, B., Hall, S. R., Nowak, J. B., Buhr, M., Chen, G., Wang, P., and Davis, D: Measurements of $\mathrm{OH}, \mathrm{H}_{2} \mathrm{SO}_{4}$, and MSA at the South Pole during ISCAT, Geophys. Res. Lett., 28, 3629-3632, 2001.

McConnell, J. R., Bales, R. C., Stewart, R. W., Thompson, A. M., Albert, M. R., and Ramos R.: Physical based modeling of atmosphere-to-snow-to-firn transfer of $\mathrm{H}_{2} \mathrm{O}_{2}$ at South Pole, J. Geophys. Res., 103(D9), 10 561-10 570, 1998.

McNeill, V. F., Loerting, T., Geiger, F. M., Trout, B. L., and Molina, M. J.: Hydrogen chloride-induced surface disordering on ice, P. Natl. Acad. Sci. USA, 103(25), 9422-9427, 2006.

Meier, R. R., Anderson, G. P., Cantrell, C. A., Hall, L. A., Lean, J., Minschwaner, K., Shetter, R. E., Shettle, E. P., and Stamnes K. Actinic radiation in the terrestrial atmosphere, J. Atmos. Sol.Terr. Phy., 59, 2111-2157, 1997.

Meirold, I. and Lehning, M.: Measurements and model calculations of the solar shortwave fluxes in snow on Summit, Greenland, Ann. Glaciol., 38, 279-284, 2004.

Mellor, M.: Engineering properties of snow, J. Glaciol. 19, 15-66, 1977. 
Mialon, A., Fily, M., and Royer, A.: Seasonal snow cover extent from microwave remote sensing data: Comparison with existing ground and satellite based measurements, EARSeL eProceedings, 4(2), 215-225, 2005.

Mie, G.: Beiträge zur Optik trüber Medien speziell kolloidaler Metallösungen, Annalen der Physik, 25, 377-445, 1908.

Mishchenko, M. I., Dlugach, J. M., Yanovitskij, E. G., and Zakharova N. T.: Bidirectional reflectance of flat, optically thick particulate layers : an efficient radiative transfer solution and applications to snow and soil surfaces, J. Quant. Spectrosc. Ra., 63, 409-432, 1999.

Mizuno, Y. and Hanafusa, N.: Studies of Surface-Properties of Ice Using Nuclear-Magnetic-Resonance, J. Phys., 48(C-1), 511517, 1987.

Mulvaney, R., Wolff, E., and Oates, K.: Sulphuric acid at grain boundaries in Antarctic ice, Nature, 331, 247-249, 1988.

Nakaya, U.: Snow Crystals: Natural and Artificial. Harvard, Harvard University Press, 1954.

Narita, H.: Specific surface of deposited snow II, Low Temp. Sci. A29, 69-81, 1971.

Navarre, J. P.: Modèle unidimensionnel d'évolution de la neige deposée, Modèle perce-neige, Météorologie, 4, 103-120, 1975.

Neshyba, S., Grenfell, T. C., and Warren, S. G.: Representation of a nonspherical ice particle by a collection of independent spheres for scattering and absorption of radiation: II. Hexagonal columns and plates, J. Geophys. Res., 108, 4448, 2003.

Neumann, T. A. and Waddington, E. D.: Effects of firn ventilation on isotopic exchange, J. Glaciol, 50, 183-194, 2004.

Nolin, A. W. and Dozier, J.: Estimating snow grain size using AVIRIS data, Remote Sens. Environ., 44, 231-238, 1993.

Nolin, A. W. and Dozier, J.: A hyperspectral method for remotely sensing the grain size of snow, Remote Sens. Environ., 74, 207216, 2000.

Nye, J. F.: Thermal-Behavior of Glacier and Laboratory Ice, J. Glaciol., 37, 401-413, 2003, 1991.

Painter, T. H., Dozier, J., Roberts, D. A., Davis, R. E., and Greene, R. O.: Retrieval of subpixel snow-covered area and grain size from imaging spectrometer data, Remote Sens. Environ., 85, 6477, 2003.

Painter T. H., Barrett, A. P., Landry, C. C., Neff, J. C., Cassidy, M. P., Lawrence, C. R., McBride, K. E., and Farmer, G. L.: Impact of disturbed desert soils on duration of mountain snow cover, Geophys. Res. Lett., 34, L12502, doi:10.1029/2007GL030284, 2007.

Papa, F., Legresy, B., Mognard, N. M., Josberger, E. G., and Remy, F.: Estimating terrestrial snow depth with the TOPEX-Poseidon altimeter and radiometer, IEEE T. Geosci. Remote, 40, 10, p. 2162-2169, 2002.

Perla, R., Dozier, J., and Davis, R. E.: Preparation of serial sections in dry snow specimens, J. Microsc. 141, 111-114, 1986.

Perovich, D. K. and Govoni, J. W.: Absorption coefficients of ice from 250 to $400 \mathrm{~nm}$, Geophys. Res. Lett., 18, 1233-1235, 1991.

Perovich, D. K.: Light reflection and transmission by a temperate snow cover, J. Glaciol., 53, 201-210, 2007.

Petersen, L. W., Moldrup, P., Jacobsen, O. H., Rolston, D. E.: Relations between specific surface area and soil physical and chemical properties, Soil Sci., 161, 9-21, 1996.

Petrenko, V. F. and Whitworth, R. W.: Physics of ice, Oxford University Press, Oxford, U.K., 1999.
Picard, G. and Fily, M.: Surface melting observations in Antarctica by microwave radiometers: correcting 26-year long time series from changes in acquisition hours, Remote Sens. Environ., 104, 325-336, 2007.

Pielke, R. A., Liston, G. E., Chapman, W. L., and Robinson, D. A.: Actual and insolation-weighted northern hemisphere snow cover and sea ice between 1973-2002, Clim. Dynam. 22, 591595, 2004.

Phillips, G. J. and Simpson, W. R.: Verification of snowpack radiation transfer models using actinometry, J. Geophys. Res., 110, D08306, 2005.

Pomeroy, J. W., Davies, T. D., Jones, H. G., Marsh, P., Peters, N. E., and Tranter, M.: Transformations of snow chemistry in the boreal forest: accumulation and volatilization, Hydrol. Process., 13, 2257-2273, 1999.

Proposito, M., Becagli, S., Castellano, E., Flora, O., Genoni, L., Gragnani, R., Stenni, B., Traversi, R., Udisti, R., and Frezzotti, M.: Chemical and isotopic snow variability along the 1998 ITASE traverse from Terra Nova Bay to Dome C, Antarctica, Ann. Glaciol, 35, 187-194, 2002.

Pulliainen, J. T.: Mapping of snow water equivalent and snow depth in boreal and sub-arctic zones by assimilating space-borne microwave radiometer data and ground-based observations, Remote Sense Environ., 101, 257-269, 2006.

Pulliainen, J. T. Grandell, J., and Hallikainen, M. T.: HUT snow emission model and its applicability to snow water equivalent retrieval, IEEE T. Geosci. Remote., 37, 3, 1378-1390, 1999.

Qiu, R., Green, S. A., Honrath, R. E., Peterson, M., Lu, C.Y., and Dziobak, M.: Measurements of $\mathrm{J}\left(\mathrm{NO}_{3}^{-}\right)$in snow by nitrate-based chemical actinometry, Atmos. Environ., 36, 2751, 2002.

Raymond, C. F. and Tusima, K.: Grain coarsening of watersaturated snow, J. Glaciol., 86, 83-105, 1979.

Rick, U. and Albert, M. R.: Microstructure and Permeability in the Near-Surface Firn Near a Potential U.S. Deep Drilling Site in West Antarctica, Ann. Glaciol., 39, 62-66, 2004.

Romanov, P., Gutman, G., and Csiszar, I.: Automated Monitoring of Snow Cover over North America with Multispectral Satellite Data, J. Appl. Meteorol., 39, 1866-1880, 2000.

Rosenberg, R.: Why is ice slippery?, Phys. Today, 58, 50-55, 2005.

Rosenfeld, S. and Grody, N.: Anomalous microwave spectra of snow cover observed from Special Sensor Microwave/Imager measurements, J. Geophys. Res., 105, 14 913-14 926, 2000.

Roth, C. M., Goss, K.-U., and Schwarzenbach, R. P.: Sorption of diverse organic vapors to snow, Environ. Sci. Technol., 38, 40784084, 2004.

Roy, V., Goïta, K., Royer, A., Walker, A. E., and Goodison, B. E.: Snow Water Equivalent Retrieval in a Canadian Boreal Environment From Microwave Measurements Using the HUT Snow Emission Model, IEEE T. Geosci. Remote., 42, (9), 1850-1859, 2004.

Schneebeli, M. and Sokratov, S. A.: Tomography of temperature gradient metamorphism of snow and associated changes in heat conductivity, Hydrol. Process., 18, 3655-3655, doi:10.1002:hyp.5800, 2004.

Schwander, J., Stauffer, B., and Sigg, A.: Air mixing in firn and the age of the air at pore close-off, Ann. Glaciol., 10, 141-145, 1988.

Segelstein, D.: The refractive index of water, Master thesis, University of Missouri-Kansas City, 1981.

Sherjal I. and Fily, M.: Temporal variations of microwave bright- 
ness temperatures over Antarctica, Ann. Glaciol., 20, 19-25, 1994.

Shimizu, H.: Air permeability of deposited snow. Institute of low temperature science: Sapporo, Japan. Contribution $N^{\circ} 1053$, English translation, 1970.

Shuman, C. A., Bromwich, D. H., Kipfstuhl, J., and Schwager, M.: Multiyear accumulation and temperature history near the North Greenland Ice Core Project site, north central Greenland, J. Geophys. Res., 106D, 33 935-33 950, 2001.

Simpson, W. R., King, M. D., Beine, H. J., Honrath, R. E., and Zhou, X.: Radiation-transfer modeling of snow pack photochemical processes during ALERT2000., Atmos. Environ., 36, 26632670, 2002a.

Simpson, W. R., King, M. D., Beine, H. J., Honrath, R. E., and Peterson, M. C.: Corrigendum to "Atmospheric photolysis rates during the Polar Sunrise Experiment ALERT2000" (Atmos. Environ., 36, 2471-2480, 2002), Atmos. Environ., 36, 5749, 2002 b.

Simpson, W. R., von Glasow, R., Riedel, K., Anderson, P., Ariya, P., Bottenheim, J., Burrows, J., Carpenter, L. J., Frieß, U., Goodsite, M. E., Heard, D., Hutterli, M., Jacobi, H.-W., Kaleschke, L., Neff, B., Plane, J., Platt, U., Richter, A., Roscoe, H., Sander, R., Shepson, P., Sodeau, J., Steffen, A., Wagner, T., and Wolff, E.: Halogens and their role in polar boundary-layer ozone depletion, Atmos. Chem. Phys., 7, 4375-4418, 2007, http://www.atmos-chem-phys.net/7/4375/2007/.

Sokolov, O. and Abbatt, J. P. D.: Adsorption to ice of n-alcohols (ethanol to 1-hexanol), acetic acid, and hexanal, J. Phys. Chem. A, 106, 775-782, 2002.

Sommerfeld, R. A. and LaChapelle, E.: The classification of snow metamorphism, J. Glaciol., 9, 3-17, 1970.

Sommerfeld, R. A. and Rocchio J. E.: Permeability measurements on new and equitemperature snow, Water Resour. Res., 29, 2485 2490, 1993.

Spicer, C. W., Plastridge, R. A., Foster, K. L., Finlayson-Pitts, B. J., Bottenheim, J. W., Grannas, A. M., and Shepson P. B.: Molecular halogens before and during ozone depletion events in theArctic at polar sunrise: concentrations and sources, Atmos. Environ, 36, 2721-2731, 2002.

Stamnes, K., Tsay, S. C., Wiscombe, W., and Jayaweera K.: Numerically stable algorithm for discrete-ordinate method radiative transfer in multiple scattering and emitting layered media, Appl. Optics, 27, 2502-2510, 1988.

Steffen, A., Schroeder, W., Bottenheim, J., Narayan, J., and Fuentes, J. D.: Atmospheric mercury concentrations: measurements and profiles near snow and ice surfaces in the Canadian Arctic during Alert 2000, Atmos. Environ., 36, 2653-2661, 2002.

Stogryn, A.: A study of the microwave brightness temperature of snow from the point of view of strong fluctuation theory, IEEE T. Geosci. Remote., GE-24, 220-231, 1986.

Sturm, M. and Johnson J.: Natural convection in the subarctic snow cover, J. Geophys. Res., 96, 11 657-11 671, 1991.

Sturm, M.: The role of thermal convection in heat and mass transport in the subarctic snow cover U.S. Army Cold Regions Research and Engineering Laboratory, Hanover, New Hampshire, CRREL Report 91-19, 1991.

Sturm, M. and Johnson J.: Thermal conductivity measurements of depth hoar, J. Geophys. Res., 97, 2129-2139, 1992.

Sturm, M., Holmgren, J., König, M., and Morris, K.: The thermal conductivity of snow, J. Glaciol., 43(143), 26-41, 1997.

Sturm, M. and Benson, C. S.: Vapor transport, grain growth and depth hoar development in the subarctic snow, J. Glaciol. 43, 4259, 1997.

Sturm, M. and Benson, C. S.: Scales of spatial heterogeneity for perennial and seasonal snow layers, Ann. Glaciol., 38, 253-260, 2004.

Sumner, A. L. and Shepson, P. B.: Snowpack production of formaldehyde and its effect on the Arctic troposphere, Nature, 398, 230-233, 1999.

Surdyk, S. and Fily, M.: Results of a stratified snow emissivity model based on the wave approach: application to the Antarctic Ice Sheet, J. Geophys. Res., 100C, 8837-8848, 1994.

Surdyk, S. and Fily, M.: Comparison of microwave spectral signature of the Antarctic Ice Sheet with traverse ground data, Ann. Glaciol., 17, 161-166, 1993.

Surdyk, S.: Using microwave brightness temperature to detect short-term surface air temperature changes in Antarctica: An analytical approach, Remote Sense Environ., 80, 256-271, 2002.

Swanson, A. L., Blake, N. J., Blake, D. R., Rowland, F. S., and Dibb, J. E.: Photochemically induced production of $\mathrm{CH}_{3} \mathrm{Br}$, $\mathrm{CH}_{3} \mathrm{I}, \mathrm{C}_{2} \mathrm{H}_{5} \mathrm{I}$, ethene and propene within surface snow, Atmos. Environ., 36, 2671-2682, 2002.

Taillandier, A.-S., Domine, F., Simpson, W. R., Sturm, M., Douglas, T. A., and Severin, K.: Evolution of the Snow Area Index (SAI) of the subarctic snowpack in Central Alaska over a whole season. Consequences for the air to snow transfer of pollutants, Environ Sci. Technol., 40, 7521-7527, doi:10.1021/es060842j, 2006.

Taillandier, A.-S., Domine, F., Simpson, W.R., Sturm, M., and Douglas, T.A.: The rate of decrease of the specific surface area of dry snow: isothermal versus temperature gradient conditions, J. Geophys. Res., 112, F03003, doi:10.1029/2006JF000514, 2007.

Tanikawa, T., Aoki, T., and Nishio, F.: Remote sensing of snow grain-size and impurities from Airborne Multispectral Scanner data using a snow bidirectional reflectance distribution function model, Ann. Glaciol., 34, 74-80, 2002.

Tedesco, M. Pampaloni, P. Pulliainen, J., and Hallikainen, M.: Classification and retrieval of dry snow parameters by means of SSM/I data and artificial neural networks, Proc. Geoscience and Remote Sensing Symposium, 1, 330-332, 2003.

Tedesco, M. and Kokhanovsky A. A.: The semi-analytical snow retrieval algorithm and its application to MODIS data, Rem. Sens. Environ., 111, 228-241, 2007.

Tedesco, M.: Special issue Remote Sensing of the Cryosphere, Remote Sens. Environ., 111, 135, 2007.

Thibert, E. and Dominé, F.: Thermodynamics and kinetics of the solid solution of $\mathrm{HCl}$ in ice, J. Phys. Chem. B 101, 3554-3565, 1997.

Thibert, E. and Dominé, F.: Thermodynamics and kinetics of the solid solution of HNO3 in ice, J. Phys. Chem. B 102, 4432-4439, 1998.

Thomas, G. E. and Stamnes, K.: Shortwave Radiative Transfer, in Radiative Transfer in the Atmosphere and Ocean, 335-383, Cambridge University Press, Cambridge, 2002.

Torinesi O., Fily, M., and Genthon, C.: Interannual variability and trend of the Antarctic summer melting period from 20 years of spaceborne microwave data, J. Climate, 16, 1047-1060, 2003.

Tsang, L., Chen, Z., Oh, S., Marks, R. J., and Chang, A. T. C.: Inversion of Snow Parameters from Passive Microwave Remote 
Sensing Measurements by a Neural Network Trained with a Multiple Scattering Model, IEEE T. Geosci. Remote, 30, 1015-1024, 1992.

Tsang, L., Chen, C., Chang, A. T. C., Guo, J., and Ding, K.: Dense media radiative transfer theory based on quasicrystalline approximation with applications to passive microwave remote sensing of snow, Radio Sci., 35, 731-749, 2000.

Ulaby, F. T., Moore, R. K., and Fung, A. K.: Microwave remote sensing: active and passive. Volume 1. Microwave remote sensing fundamentals and radiometry, Norwood, M. A. Artech House, 1981.

Underwood, E. E.: Quantitative stereology, Addison-Wesley, Reading, MA, 1970.

Vermote, E. and Vermeulen, A.: Atmospheric correction algorithm: Spectral reflectances (MOD09), ATBD version 4.0 available at http://eospso.gsfc.nasa.gov/ftp_ATBD/REVIEW/ MODIS/ATBD-MOD-08/atbd-mod-08.pdf, 1999.

Verseghy, D. L.: CALSS- A Canadian land surface scheme for GCMs. I. Soil model, Int. J. Climatol., 11, 111-133, 1991

Waddington, E. D., Cunningham, J., and Harder, S.: The effects of snow ventilation on chemical concentrations, in: Chemical Exchange Between the Atmosphere and Polar Snow, edited by: Wolff, E. W. and Bales, R. C., Springer, pp. 403-451, 1996.

Warren, S. G.: Optical properties of snow, Rev. Geophys., 20, 6789, 1982.

Warren, S. G. : Optical constants of ice from the ultraviolet to the microwave, Appl. Opt., 23, 1206-1225, 1984.

Warren, S. G. and Wiscombe, W. J.: A model for the spectral albedo of snow. II: Snow containing atmospheric aerosols, J. Atmos. Sci. 37, 2734-2733, 1980.

Warren, S. G. and Wiscombe, W. J.: Dirty snow after nuclear war, Nature, 313, 467-470, 1985.

Warren, S. G., Brandt, R. E., and Grenfell, T. C.: Visible and nearultraviolet absorption spectrum of ice from transmission of solar radiation into snow. Appl. Optics, 45, 5320-5334, 2006.

Wei, X., Miranda, P. B., Zhang, C., and Shen, Y. R.: Sum-frequency spectroscopic studies of ice interfaces, Phys. Rev. B, 66, 085401, 2002.

Wergin, W. P., Rango, A., and Erbe, E. F.: Observations of Snow Crystals Using Low-Temperature Scanning Electron Microscopy, Scanning, 17, 41-49, 1995.

Wergin, W. P., Rango A., Erbe, E. F., and Murphy, C. A.: Low Temperature S. E. M. of Precipitated and Metamorphosed Snow Crystals Collected and Transported from Remote Sites, J. Microsc. Soc. Amer., 2, 99-112, 1996.
Wettlaufer, J. S.: Impurity effects in the premelting of ice, Phys. Rev. Lett., 82, 2516-2519, 1999.

Wiesmann, A. and Mätzler C.: Microwave emission model of layered snowpacks, Remote Sens. Environ., 70, 307-316, 1999.

Wiesmann, A., Fierz, C., and Matzler, C.: Simulation of microwave emission from physically modeled snowpacks, Ann. Glaciol., 31, 397-405, 2000.

Wilson, L., Tsang, L., Hwang, J.-N., and Chen, C.-T.: Mapping snow water equivalent in mountainous areas by combining a spatially distributed snow hydrology model with passive microwave remote sensing data, IEEE T. Geosci. Remote, 37, 690-704, 1999.

Wilson, L. L, Tsang, L., and Hwang, J.-N.: Mapping SWE by combining a spatially distributed snow hydrology model with passive microwave remote-sensing data, IEEE TGARS, 37, 690704, 1999.

Winebrenner, D. P., Arthern, R. J., and Shuman, C. A.: Mapping Greenland accumulation rates using observations of thermal emission at 4.5-cm wavelength, J. Geophys. Res., 106D, 33919 $33934,2001$.

Wiscombe, W. J.: The delta-Eddington approximation for a vertically inhomogeneous atmosphere, NCAR Technical Note, NCAR/TN-121+STR, 1-66, 1977.

Wiscombe, W. and Warren, S.: A model for the spectral albedo of snow. 1: pure snow, J. Atmos. Sci., 37, 2712-2733, 1980.

Wismann, V.: Monitoring of seasonal snowmelt on Greenland with ERS scatterometer data, IEEE T. Geosci. Remote, 38, 18211826, 2000.

Xie, Y., Yang, P., Gao, B.-C., Kattawar, G. W., and Mishchenko M. I.: Effect of ice crystal shape and effective size on snow bidirectional reflectance, J. Quant. Spectrosc. Ra., 100, 457-469, 2006.

Zappa, M., Pos, F., Strasser, U., Warmerdam, P., and Gurtz, J.: Seasonal water balance of an Alpine catchment as evaluated by different methods for spatially distributed snowmelt modelling, Nordic Hydrol., 34, 179-202, 2003.

Zege, E. P., Ivanov A. P., and Katsev I. L.: Image transfer through a scattering medium, Berlin: Springer, 1991.

Zhou, X., Beine, H. J., Honrath, R. E., Fuentes, J. D., Simpson, W., and Shepson, P. B.: Snowpack photochemical production of HONO: a major source of $\mathrm{OH}$ in the Arctic boundary layer in spring time, Geophys. Res. Lett., 28, 4087-4090, 2001.

Zhou, X., Li, S., and Stamnes, K.: Effects of vertical inhomogeneity on snow spectral albedo and its implications for remote sensing of snow, J. Geophys. Res., 108, 4738, doi:10.1029/2003JD003859, 2003. 